\title{
PATHWAYS TO WELL BEING: THE INFLUENCE OF MINDFULNESS ON STRESS, APPRAISALS, AND COPING
}

\author{
by \\ Valerie Repta \\ A thesis submitted to \\ the Faculty of Graduate and Postdoctoral Affairs \\ in partial fulfillment of the requirements for the degree of
}

Master of Arts

in

Psychology

Carleton University

Ottawa, Canada

(C)2011 Valerie Repta 
Library and Archives Canada

Published Heritage Branch

395 Wellington Street Ottawa ON K1A ON4 Canada
Bibliotheque et

Archives Canada

Direction du

Patrimoine de l'édition

395 , rue Wellington

Ottawa ON K1A ON4

Canada
Your file Votre référence

ISBN: 978-0-494-83116-8

Our file Notre référence

ISBN: 978-0-494-83116-8
NOTICE:

The author has granted a nonexclusive license allowing Library and Archives Canada to reproduce, publish, archive, preserve, conserve, communicate to the public by telecommunication or on the Internet, loan, distribute and sell theses worldwide, for commercial or noncommercial purposes, in microform, paper, electronic and/or any other formats.

The author retains copyright ownership and moral rights in this thesis. Neither the thesis nor substantial extracts from it may be printed or otherwise reproduced without the author's permission.
AVIS:

L'auteur a accordé une licence non exclusive permettant à la Bibliothèque et Archives Canada de reproduire, publier, archiver, sauvegarder, conserver, transmettre au public par télécommunication ou par l'Internet, prêter, distribuer et vendre des thèses partout dans le monde, à des fins commerciales ou autres, sur support microforme, papier, électronique et/ou autres formats.

L'auteur conserve la propriété du droit d'auteur et des droits moraux qui protège cette thèse. Ni la thèse ni des extraits substantiels de celle-ci ne doivent être imprimés ou autrement reproduits sans son autorisation.
In compliance with the Canadian Privacy Act some supporting forms may have been removed from this thesis.

While these forms may be included in the document page count, their removal does not represent any loss of content from the thesis.
Conformément à la loi canadienne sur la protection de la vie privée, quelques formulaires secondaires ont été enlevés de cette thèse.

Bien que ces formulaires aient inclus dans la pagination, il n'y aura aucun contenu manquant.

\section{Canadä}




\section{THE INFLUENCE OF MINDFULNESS ON STRESS}

Abstract

Mindfulness has been associated with a number of well being indices, but the processes through which it improves health have not been determined. The current research assessed how trait (Study 1;N=369) and state (Study 2; $N=329$ ) mindfulness, the latter primed through a writing exercise, were related to appraisals and coping of stressful situations. Trait mindfulness was negatively related to depression and was mediated by appraisals of threat, distress, and pessimistic outcome expectations, as well as problemfocused, emotion-focused, and avoidant coping use. Trait mindfulness also moderated bidirectional relationships between distress appraisals and levels of problem-focused and avoidant coping. Priming mindfulness had only marginal effects on individuals' threat appraisals and outcome expectations, and varied by gender, as males were more negatively influenced by priming mindlessness. Although priming mindfulness was ineffective, results corroborated the benefits of trait mindfulness and identified pathways through which it enhances well being. 


\section{THE INFLUENCE OF MINDFULNESS ON STRESS}

\section{Acknowledgements}

I owe a debt of gratitude to my advisor, Hymie Anisman, for his continual guidance, insight, and patience. Hymie helped me to realize my own potential and his unwavering support kept me going throughout this process. I could not have asked for a better advisor and am so grateful that I had the opportunity to work with him.

I was also very fortunate to work with Kelly Christie, who has been an excellent research partner, consultant, and friend. Kelly was not only always willing to offer her valuable feedback, but did so amicably and without reservation. Working with her has made my Master's that much more enjoyable. My other lab mates were another great source of knowledge and conversation over tea breaks. Finally, I would like to thank my family for their support and understanding.

This research was supported by the Canadian Institutes of Health Research. 
THE INFLUENCE OF MINDFULNESS ON STRESS

Table of Contents

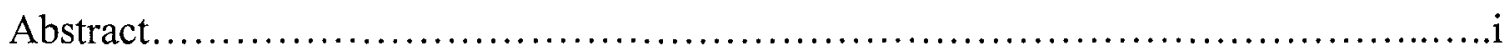

Acknowledgements................................................................

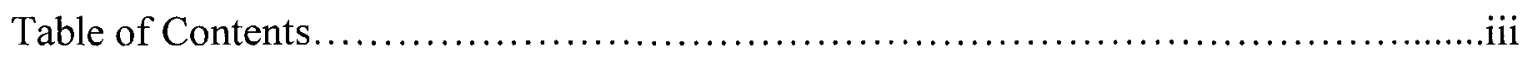

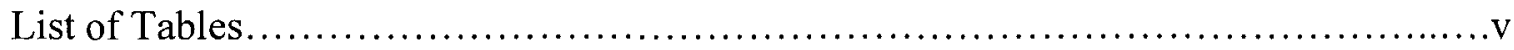

List of Figures.....................................................................

List of Appendices. ...............................................................

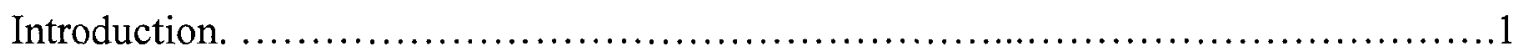

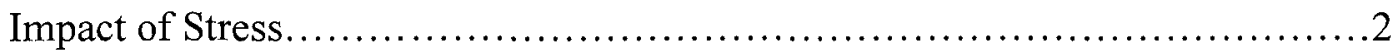

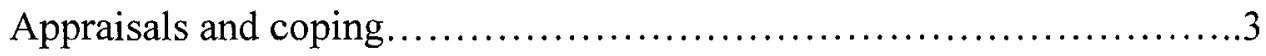

Problem-focused coping .....................................4

Emotion-focused coping.......................................5

Avoidant coping............................................ 6

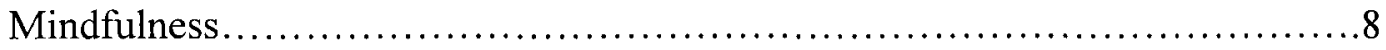

The effects of mindfulness on appraisals and coping.....................9

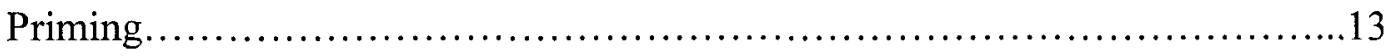

Purpose of the Proposed Research..........................................15

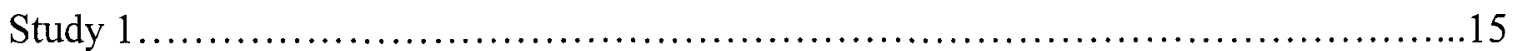

Method..........................................................................

Participants........................................................... 16

Procedure.............................................................

Measures......................................................... 18

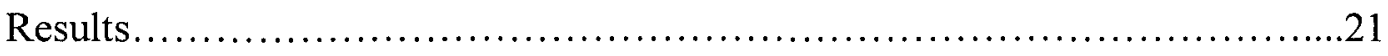




\section{THE INFLUENCE OF MINDFULNESS ON STRESS}

Discussion.............................................................

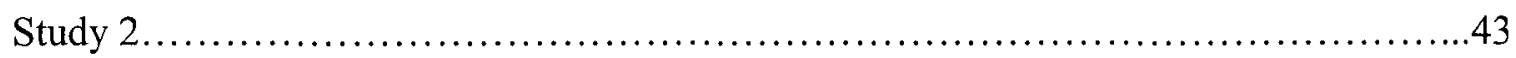

Method...............................................................43

Participants...................................................43

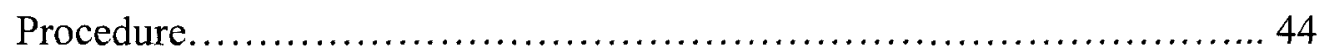

Measures....................................................... 45

Results............................................................ 45

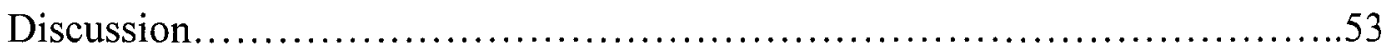

General Discussion....................................................... 54

Limitations and Conclusion.................................................59

References.............................................................63 
THE INFLUENCE OF MINDFULNESS ON STRESS

\section{List of Tables}

Table 1. Descriptive statistics (means, standard deviations, and ranges)

Table 2. Bivariate correlations between trait mindfulness, appraisals, coping, and indices of well being.....

Table 3. Nonsignificant moderations of mindfulness on the effects of appraisals predicting coping styles

Table 4. Nonsignificant moderations of mindfulness on the effects of coping styles predicting appraisals.

Table 5. Hierarchical regression assessing the influence of trait mindfulness on the effectiveness of priming mindfulness as a function of threat appraisals.

Table 6. Hierarchical regression assessing the influence of trait mindfulness on the effectiveness of priming mindfulness as a function of outcome expectations .50 
THE INFLUENCE OF MINDFULNESS ON STRESS

List of Figures

Figure 1. Appraisals (threat, distress, outcome expectations and control) as multiple mediators of the relationship between trait mindfulness and depressive symptomatology

Figure 2. Coping styles (problem-focused, emotion-focused, and avoidant coping) as multiple mediators of the relationship between trait mindfulness and Depressive symptomatology

Figure 3. Slopes indicating the moderating effect of trait mindfulness on the relationship between distress appraisals and problem-focused coping. 30

Figure 4. Slopes indicating the moderating effect of trait mindfulness on the relationship between distress appraisals and avoidant coping.

Figure 5. Slopes indicating the moderating effect of trait mindfulness on the relationship between problem-focused coping and distress appraisals....

Figure 6. Slopes indicating the moderating effect of trait mindfulness on the relationship between avoidant coping and distress appraisals. 34

Figure 7. Slopes indicating the moderating effect of trait mindfulness on the relationship between avoidant coping and pessimistic outcome expectations.....35

Figure 8. Mean threat appraisals as a function of priming condition .48

Figure 9. Mean outcome expectations as a function of priming condition. 48

Figure 10. Effect of priming condition on threat appraisals, by gender................52

Figure 11. Effect of priming condition on distress appraisals, by gender. 
THE INFLUENCE OF MINDFULNESS ON STRESS

List of Appendices

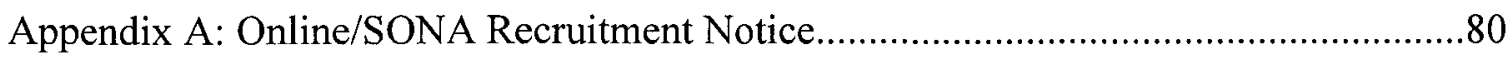

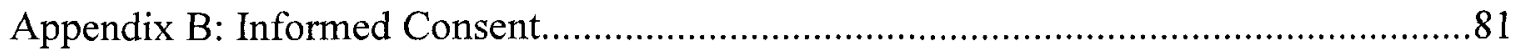

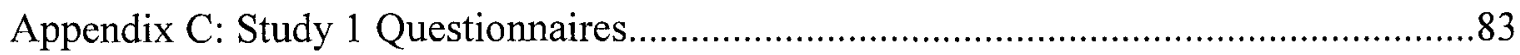

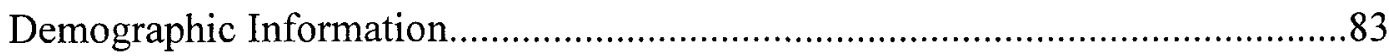

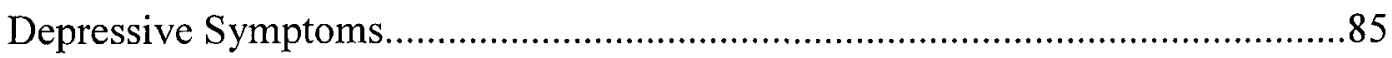

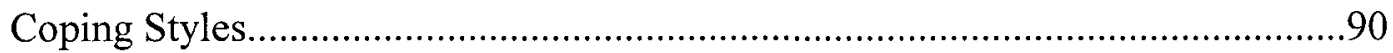

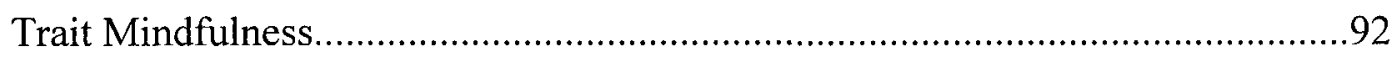

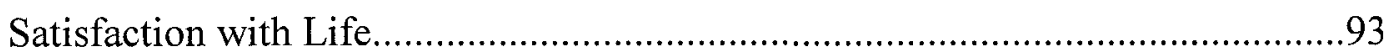

Appraisals of Ambiguous Situations...............................................................94

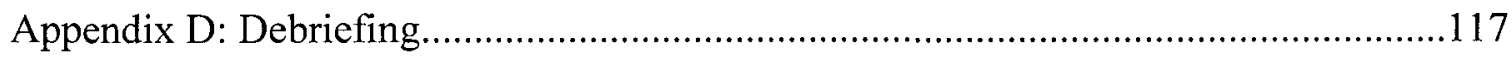

Appendix E: Study 2 Written Priming Exercise.........................................................119 
The impact of stressors on health and well being is largely influenced by the ways in which individuals appraise and cope with stressful events. Individuals who appraise stressors in adaptive ways are more likely to cope with the stressors effectively, reducing the negative impacts of the stressor. This, in turn, might promote a sense of competency or personal development (e.g., self-efficacy, mastery, autonomy) which may further serve to reduce the stressors' harmful effects. In contrast, strong associations have been reported between maladaptive appraisals, poor coping, and the development of pathologies such as depression and anxiety (Brosschot, Pieper, \& Thayer, 2005; Lazarus, 1991; Matheson \& Anisman, 2009; Newth \& DeLongis, 2004; Park \& Adler, 2003; Paykel, 1994).

Although well being may be enhanced by appraising stressors appropriately, appraisals represent, in part, an automatic and immediate process. One variable that may enable individuals to improve both their appraisals and coping of stressful events is mindfulness, generally defined as focusing attention on the current moment in an accepting and nonjudgmental manner (Segal, Teasdale, \& Williams, 2002). Mindfulness has shown to be as effective as cognitive behavioural therapy in treating severely depressed patients (Kenny \& Williams, 2007) and as effective as antidepressants in preventing depressive relapse (Segal et al., 2010). Despite research indicating that mindfulness improves a number of health and well being indices (e.g., Brown \& Ryan, 2003; Greeson, 2009; Hofmann, Sawyer, Witt, \& Oh, 2010), the processes through which mindfulness elicits these broad-reaching effects have not been determined.

One possibility is that mindfulness could lead individuals to appraise situations differently. That is, it may help individuals perceive situations, especially stressful 
situations, more clearly and adaptively by enabling individuals to better recognize and address stressors rather than denying or resisting them. In addition to enhancing appraisals, mindfulness may improve coping by identifying and reducing use of dysfunctional coping styles, and increasing use of effective coping methods.

Individuals vary in levels of both dispositional mindfulness (Brown \& Ryan, 2003) and state mindfulness (Segal et al., 2002) that may be applied to certain situations, including stressful events. Thus, the proposed research sought to determine whether trait mindfulness, as well as state mindfulness, primed through a writing exercise, was related to the way in which stressors were appraised. Moreover, it was of interest to determine whether mindfulness, besides affecting appraisals per se, could serve to moderate the influence of other coping styles on appraisals, thereby helping individuals handle stressful situations instead of reacting reflexively.

\section{Impact of Stress}

Strong associations have been found between stress and the development of mental and physical health pathologies (McEwen, 2003; Paykel \& Cooper, 1992). These have included depression (Anisman \& Zacharko, 1982; Gutman \& Nemeroff, 2011; Hammen, 2005; Paykel, 2003), mood disorders (McEwen, 2003), infections (Cohen \& Williamson, 1991), viruses (Pereira et al., 2003), hypertension (Galosy \& Gaebelein, 1977), coronary artery disease (Rozanski, Blumenthal, \& Kaplan, 1999) and cancer (Solomon \& Amkraut, 1981). These pathological outcomes may be instigated by a broad range of hormone, neurochemical and immunological processes that may be determined, at least to some extent, by the appraisal and coping methods that individuals adopt (Anisman, Merali, \& Stead, 2008). 
Appraisals and coping. Appraisals vary among individuals and situations, in that individuals interpret and cope with the same stressful situation in unique ways (Carver \& Scheier, 1994). Appraisals generally involve two distinct stages: During primary appraisal, individuals evaluate whether there is anything at risk in the situation and assess the event's extent of threat or challenge. During secondary appraisal, individuals evaluate whether anything can be done to overcome barriers, and assess their coping resources to deal with the event (Folkman, Lazarus, Dunkel-Schetter, DeLongis, $\&$ Gruen, 1986). These appraisals inform subsequent coping efforts which can generally be distinguished as emotion-focused, avoidant, or problem-focused coping. Emotionfocused coping (e.g., emotional expression, emotional containment, self blame, other blame, rumination, humour, passive resignation, wishful thinking) addresses distress or other unpleasant emotions associated with the stressful event; avoidant coping (e.g., cognitive distraction, active distraction), comprises denial or ways to avoid directly dealing with the stressor; problem-focused coping (e.g., problem solving, cognitive restructuring, social support) seeks to mitigate the stressor itself (Lazarus \& Folkman, 1984; Matheson \& Anisman, 2003).

Although many studies have suggested that problem-focused coping tends to lead to better outcomes than emotion-focused and avoidant coping, all forms of coping can be helpful. No single type of coping strategy can be uniformly applied to all stressful situations successfully because the most effective coping strategies depend on the nature of the situation encountered. Furthermore, many situations require more than a single type of coping strategy (Smith, 1991). Generally, emotion-focused strategies are considered beneficial when stressors are uncontrollable, or in order to help individuals 
emotionally adjust to stressors, whereas problem-focused coping strategies are best applied to controllable stressors, to improve the situation (Folkman \& Lazarus, 1988; Folkman et al., 1986). Avoidant coping has been frequently regarded as dysfunctional (e.g., Felton, Revenson, \& Hinrichsen, 1984; Kashdan \& Kane, 2010), but it may be used adaptively when dealing with unremitting stressful events or when positive outcomes are implausible (e.g., facing a terminal illness, death of a loved one).

It is important to note that these coping styles reflect the general tendencies of individuals, rather than the specific strategies that may be applied to stressful events. Examining specific coping strategies may certainly be useful, but since strategies are often used concurrently, it may be more helpful to group them into general styles, to encompass a broad perspective of coping that may better pertain to how individuals actually handle stressful events (Carver, Scheier, \& Weintraub, 1989; Matheson \& Anisman, 2003). Regardless of the utility of coping strategies and styles, however, appraisals are fundamental to shaping coping efforts.

Problem-focused coping. When individuals are able to appraise a stressful event as one that can be dealt with, then effective coping is more likely to ensue, whereas negative appraisals increase the use of less effective coping strategies and may be more likely to compound the harmful ramifications of stressful events (Carver \& Scheier, 1994; Folkman et al., 1986). For example, appraising a stressful situation as a manageable challenge is more likely to lead to effective coping that alleviates distress. When individuals were asked to negotiate schedule and budgeting projects, those who perceived the task to be a challenge used active, confrontation-based strategies, whereas those who perceived the task as a threat acted more passively and were less successful in 
achieving project goals (O'Connor, Arnold, \& Maurizio, 2010). Similarly, students who appraised exam stress as a challenge used coping strategies that directly tackled problems related to the exam (e.g., studying) and improved their prospects of exam success. Those who appraised it as a threat used coping strategies that diverted attention away from the event and were therefore less likely to perform well on the exam (Bargiel-Matusiewicz, Trzcieniecka-Green, \& Kielan, 2005).

Emotion-focused coping. Although emotion-focused coping has frequently been regarded as dysfunctional, emotional reactions can alert individuals to stressors and orient them toward their goals. For instance, women with a cancer diagnosis who used emotional expression as a means of coping were found to report better health three months following treatment completion, including increased energy, decreased distress, and fewer medical appointments for cancer-related issues (Stanton et al., 2005). For students with exam anxiety, addressing exam stress with traditional problem-focused coping strategies may not suffice; students need to keep the stressful event in perspective, and actively reappraise it as it unfolds in order to manage their anxiety without becoming overwhelmed (Davis, DiStano \& Schutz, 2008).

Certain types of emotion-focused coping, however, may be less helpful than others. For instance, rumination, or continually focusing on the negative aspects of events with a passive, sorrowed attitude, tends to represent a dysfunctional emotionfocused coping method. Rumination has been associated with binge drinking, anxiety, self-harm (Nolen-Hoeksema, Wisco, \& Lyubomirsky, 2008), and, perhaps most notably, depression (Matheson \& Anisman, 2003; Nolen-Hoeksema \& Morrow, 1993). Although rumination may be used adaptively when accompanied by a constellation of other coping 
strategies (i.e., problem-focused coping methods), when used on its own or in conjunction with certain emotion-focused coping strategies, it may exacerbate depression and anxiety (Kelly, Matheson, Ravindran, Merali, \& Anisman, 2007).

Avoidant coping. Avoidant coping tends to be preceded by appraisals that suggest individuals are poorly equipped to deal with the encountered stressful event. For example, students who anticipate that they will perform inadequately on tests have been found to resort to avoidant coping strategies, indicative of their attempts to avoid failure, rather than work towards potential success (Hagtvet \& Zuo, 2000; Schutz, Benson, \& Decuir-Gunby, 2008). Avoidant coping tends to be regarded as a poor coping method because it does not reduce long term distress or contribute to the resolution of stressful events (Folkman et al., 1986), but its effectiveness largely depends on the nature of the situation encountered. It has been associated with adverse outcomes including distress, low self-esteem, and poor adjustment to physical illness (Felton et al., 1984; Nowack, 1989), but it has also been found to reduce distress, pain, and anxiety (Suls \& Fletcher, 1985). In fact, Suls and Fletcher (1985) found that problem-focused strategies were not superior to avoidant coping strategies across a range of different stressful situations. Thus, while avoidance may be controversial, in some situations it could also be quite beneficial.

In addition to a general association with poor outcomes, negative appraisals have been associated with depression. Beck's cognitive theory of depression suggests that pessimistic appraisals propel and sustain depressive symptoms; depressed individuals tend to adopt pervasive, negative views of themselves and the world (Beck, Rush, Shaw, \& Emery, 1979). Furthermore, although appraisals are thought to be fundamental in 
shaping coping efforts, coping also influences appraisals. Essentially, individuals who develop habitually poor coping styles tend to appraise events negatively, creating a cycle of negative appraisals and weak coping that perpetuates depressive symptoms (Beck et al., 1979). In this regard, it has been shown that depressed individuals appraise events more negatively and use poorer coping methods than non-depressed controls (Krackow \& Rudolph, 2008; Troy, Wilhelm, Shallcross, \& Mauss, 2010). Treatments that target both appraisals and coping may hence be a particularly effective way to protect against the development of pathologies such as depression.

Given the importance of appraisals and coping, factors that help individuals to appraise and cope with stressful events could be indispensable to moderating the impact of stressors and improving well being. Cognitive Behaviour Therapy (CBT; Beck et al., 1979) can help to curb negative appraisals and improve coping by terminating dysfunctional thinking patterns, but other treatment approaches are clearly warranted. As many as $50 \%$ of depressed patients do not completely recover in CBT and may be vulnerable to relapse (Elkin et al., 1989). CBT may be less helpful for clients who attempt to suppress their negative thoughts, which has been associated with poor moods and increased anxiety (Corcoran \& Woody, 2009). In addition, programs that focus on individuals' dysfunctional perceptions may be counterproductive if clients perceive the therapy as targeting their personal faults and weaknesses. This could be a particularly sensitive topic for individuals with depressive symptoms who already tend to feel guilty and disappointed in themselves. Interventions that instead target the cause of dysfunctional thought patterns by addressing the automaticity of appraisals may be more beneficial in protecting against the development and maintenance of pathologies. 


\section{Mindfulness}

Mindfulness may be a unique way for individuals to recognize negative thought patterns without prohibiting their thoughts, blaming themselves or feeling guilty. Mindfulness was first introduced to the medical and psychological community by Jon Kabat-Zinn, who defined it as "paying attention in a particular way: on purpose, in the present moment, and nonjudgmentally" (Kabat-Zinn, 1994, p. 4). Although it originated as a Buddhist meditative practice, mindfulness is considered to be a cognitive processing model rather than a religious doctrine. Thus, mindfulness can be applied to all experiences by bringing awareness to thoughts, emotions, and physical sensations as they arise in a non-judgemental manner. In this way, experiences are recognized and accepted, rather than trying to control or change them. Mindfulness can be applied to experiencing internal processes (e.g., breathing, thoughts, emotions, etc.) as well as external events, including both everyday tasks and stressful situations.

Mindfulness has been associated with positive measures of health and incorporated into treatment programs such as mindfulness-based stress reduction (MBSR; Kabat-Zinn, 1990) and mindfulness-based cognitive therapy (MBCT; Segal, Williams, \& Teasdale, 2002). It has become popular as a treatment approach for a growing number of disorders and has diminished depression (Hargus, Crane, Barnhofer, \& Williams, 2010; Kenny \& Williams, 2007), substance abuse (Witkiewitz \& Bowen, 2010), chronic pain (Kabat-Zinn, Lipworth, \& Burney, 1985), binge eating (Kristeller \& Hallett, 1999), and anxiety and mood disorders (Hofmann et al., 2010). It has also shown to be beneficial for healthy populations, improving romantic relationships (Carson, Carson, Gil, \& Baucom, 2007), tolerance to pain (Zeidan, Gordon, Merchant, \& Goolkasian, 2010) and 
cardiovascular health (Ditto, Eclache, \& Goldman, 2006). These broad-reaching effects have led to much speculation about the processes through which mindfulness improves health (e.g., Anderson, Lau, Segal, \& Bishop, 2007; Shapiro, Carlson, Astin, \& Freedman, 2006), but the specific ways in which it improves health have not been determined. Mindfulness has been found to reduce distress (Brown \& Ryan, 2003; Speca, Carlson, Goodey, \& Angen, 2000) and increase well being (Anderson et al., 2007; Greeson, 2009), but its benefits could additionally be due to its influence on appraisals and coping. Its focus on non-judgemental awareness and present moment receptivity might help individuals to appraise stressful situations with clarity and insight, and thereby improve their coping of stressful events.

The effects of mindfulness on appraisals and coping. When encountering stressful situations, current moment awareness may help individuals to focus on the pertinent situation, rather than becoming overwhelmed with past or future concerns. Mindfulness increases attention control (Jha, Krompinger, \& Baime, 2007; Wenk-Sormaz, 2005) and self-regulation (Jimenez, Niles \& Park, 2010), which may help individuals to appraise stressors in a focused and more objective manner. Likewise, by increasing awareness of thoughts, it may help individuals to identify and terminate dysfunctional thinking patterns that lead to maladaptive appraisals. For instance, individuals may discover that distressing thoughts (e.g., thoughts regarding the stressfulness of situations or their inabilities to deal with stressors) can lead to dramatic, adverse emotional and physical reactions, even though these thoughts may be poorly founded or irrational. As individuals recognize that thoughts are fleeting and may be unreasonable, they can dismiss them and refocus their attention usefully. As Kabat-Zinn explained, "When you 
look at thoughts as just thoughts, purposefully not reacting to their content and to their emotional charge, you become at least a little freer from their attraction or repulsion...It becomes easier to remind yourself that you don't have to get caught up in their content." (Kabat-Zinn, 1990, p. 343). Thus, mindfulness may promote astute, adaptive appraisals of situations, rather than becoming carried away with thoughts that could potentially exacerbate a difficult situation.

Mindfulness might also allow individuals to notice positive moments that occur during stressful events, even if they are minor, which may alleviate negative affect. Selectively focusing on only negative aspects of a situation tends to magnify the distress of an event and perpetuate negative thinking (Beck et al., 1979). Conversely, mindfulness involves bringing greater attention to all aspects of a situation, which may lead individuals to experience pleasant moments that might be overlooked in habituated modes of thinking. Indeed, pausing to stand back and take a breather when faced with a stressful event has been correlated, albeit weakly, with the experience of positive emotions (Carver \& Scheier, 1994). In this way, mindfulness could help to remedy the binary thinking that is common in depression and other disorders (i.e., the tendency to categorize events as either positive or negative without recognizing the positive and negative aspects of each situation) to bolster mental health.

Appraising stressful events mindfully may be dramatically different than typical reactions to stressful events, including overreacting, which may cause unnecessary distress, or denying the reality of stressful events, which may lead to maladaptive avoidance. Suppressing thoughts tends to increase the frequency of the avoided thoughts, which can lead to anxiety and negative moods (Corcoran \& Woody, 2009), and resisting 
stressful events increases distress and complicates coping (Eifert \& Forsyth, 2005).

Similarly, although inferences and automatic behaviours can be efficient, relying on these mechanisms during stressful events may preclude individuals from even recognizing that a situation requires attention and inhibit coping. Instead, mindfulness may enable individuals to conscientiously experience thoughts, emotions, and events, by accepting them as they arise and directing their attention wisely.

Accordingly, in addition to its effects on appraisals, mindfulness may reduce reliance on dysfunctional coping and instead promote effective coping use. Dysfunctional coping styles, such as rumination, are often reflexive (Papageorgiou \& Wells, 2000); since mindfulness challenges automaticity, it may help to replace these habituated reactions with more thoughtful coping efforts. Attempting to reduce rumination has thought to be disadvantageous because it may be helpful when used in conjunction with other coping strategies (i.e., distraction) and efforts to cease rumination may be futile (Kelly et al., 2007). However, mindfulness does not seek to change or reduce any coping method. Rather, it focuses on bringing attention to reflexive responses, and may therefore help to decrease dysfunctional coping mechanisms when warranted.

In line with this rationale, mindfulness has been negatively associated with rumination and its association with depression (Sanders \& Lam, 2010). Furthermore, emotion-focused coping has been found to mediate the relationship between automatic negative thoughts and depression (Clarke \& Goosen, 2009). Since mindfulness helps to reduce automatic negative thoughts (Segal et al., 2002), it may help to replace 
dysfunctional emotion-focused coping with more effective coping methods, which could then attenuate depressive symptoms.

Mindfulness may also help to equip individuals for handling stressful events by increasing their threshold for uncomfortable thoughts and emotions. This may enable individuals to deal with stressors directly, supporting the use of problem-focused coping. The acceptance and non-judgemental facets of mindfulness could additionally help individuals acknowledge the reality of distress and discomfort to enhance effective emotion-focused coping. Indeed, acceptance is considered a critical component of appraisals and coping efforts, and theorized to predict lower levels of distress (Carver \& Scheier, 1994). By promoting acceptance, mindfulness may help to decrease feelings of guilt and self-criticism, and address emotional ramifications of stressors.

Awareness of thoughts and emotions may furthermore give individuals insight into their own appraisal processes to foster personal responsibility and self-efficacy. By noticing their reactions to stressors, in concert with the unfolding of stressful events, individuals may be more likely to tailor their coping strategies to suit them, increasing the effectiveness of their coping methods. Finally, mindfulness has been found to decrease worry (Sugiura, 2004) and increase creative problem solving (Langer, 1989) persistence when encountering difficult tasks (Evans, Baer, \& Segerstrom, 2009), and use of flexible coping strategies (Langer, 1989), all of which further contribute to successful coping.

Although mindfulness is thought to alter appraisal and coping processes (Segal et al., 2002; Sugiura, 2004; Teasdale, Segal, \& Williams, 1995), a limited number of studies have reliably investigated the scope of its effects on appraisals and coping. For instance, mindfulness is theorized to reduce rumination (Teasdale et al., 1995) but much of the 
research in this area has been conducted by uncontrolled, non-randomized studies using small samples of participants in mindfulness training programs (for a review, see Chiesa \& Serretti, 2009). Similarly, mindfulness has been found to promote experiential acceptance instead of experiential avoidance (i.e., accepting uncomfortable experiences as they occur rather than pulling away from or resisting them) among individuals with social phobia (Bogels \& Mansell, 2004), but results have rarely been generalized to broader populations.

One of the few projects that applied mindfulness to appraisals and coping found that mindful individuals appraised stressful tasks more adaptively and coped with stressors using approach-based strategies (i.e., problem-focused coping) rather than avoidance (Weinstein, Brown, \& Ryan, 2009). The relationship between mindfulness and well being was found to be mediated by mindful individuals' more benign stress appraisals, including more positive appraisals of threat and distress, rather than other characteristics common to these individuals.

\section{Priming}

In addition to general dispositional mindfulness, state mindfulness can be elicited and actively practiced. Increasing state mindfulness is the focus of many mindfulnessbased treatments (e.g, MBCT; Segal et al., 2002), but it may be possible to encourage state mindfulness in a format simpler than most mindfulness treatment programs. Mindfulness treatments are typically time consuming, as MBSR (which facilitates mindfulness practice for better physical and mental health) consists of 26 in-class hours (Kabat-Zinn, 1990), and MBCT (comprising mindfulness practice plus cognitive therapy) consists of 22 in-class hours (Segal et al., 2002). These requirements clearly limit 
treatment compliance and utility. Moreover, it seems that time spent practicing mindfulness is not necessarily correlated with improvements in symptomatology (Astin, 1997). Carmody \& Baer (2009) compared effect sizes and number of in-session hours in MBSR programs and found that shorter versions of MBSR were equally effective in alleviating distress. Examining briefer mindfulness programs has been recommended (e.g., Carmody \& Baer, 2009), but encouraging mindfulness in other formats may also be worthwhile.

One simple method to activate state mindfulness may be through priming. Although mindfulness has been used to reduce the effects of priming and stereotypes (e.g., Djikic, Langer, \& Stapleton, 2008; Radel, Sarrazin, Legrain, \& Gobance, 2009), to our knowledge, no research has attempted to prime mindfulness itself. However, other dispositions, motivations, and attitudes have been primed (e.g., Bargh, Chen, \& Burrows, 1996; Wheeler, Morrison, DeMarree, \& Petty, 2008), and mindfulness has been briefly induced. A 15 minute focused breathing induction led to more adaptive responses to negative stimuli and more positive affect (Arch \& Craske, 2006). Similarly, a ten minute focused breathing induction improved cognitive selectivity among seniors, by reducing reliance on inferences and promoting adaptation to task demands (McHugh, Simpson, \& Reed, 2010).

Because priming is itself an automatic response, it was of interest to examine whether mindfulness, the antithesis of automaticity, could be primed and what effects, if any, it would have on appraisals of stressful situations. Furthermore, since language, especially written language, is critical in activating a mindful state (Collins et al., 2009; 
Moore \& Brody, 2009), it was of interest to examine whether mindfulness could be primed through a writing exercise using key mindfulness words.

It is also of interest to investigate whether levels of trait mindfulness influence the efficacy of priming mindfulness. In one sense, mindful individuals may be more inclined to apply mindfulness to everyday stressful events; conversely, individuals with low levels of trait mindfulness may be more receptive to priming, and may show greater gains from a mindfulness induction. Thus, it was of exploratory interest to examine whether individuals with high or low levels of trait mindfulness would be more receptive to the priming of mindfulness.

\section{Purpose of the proposed research}

The effects of mindfulness on general well being have been well established. The proposed research seeks to explore whether mindfulness influences well being via its impact on appraisals and coping with stressful events. Research in mindfulness has focused on levels of trait mindfulness, that vary among individuals, as well as the state mindfulness that is taught and practiced in treatment programs. The proposed research, comprising two experiments, sought to examine trait and state mindfulness (the latter elicited by priming), to measure dispositional process variables of mindfulness (Study 1), as well as to assess the efficacy of priming mindfulness and its potential effects on appraisals of stressful events (Study 2).

\section{Study 1}

The goals of Study 1 were to assess the relationship between trait mindfulness, appraisals, coping styles, and depressive symptomatology. The relationship among appraisals, coping, and depression is clearly established, as is the relationship between 
mindfulness and depression. However, the role of mindfulness in relation to appraisals and coping efforts has not been determined, nor has this relationship's impact on depression been established. Moreover, the specific ways through which mindfulness improves appraisals and/or coping are largely unknown. Accordingly, the initial study was conducted to determine whether trait mindfulness was associated with individuals' appraisals of potentially stressful events, and the coping styles that individuals use to deal with stressors. In this regard, primary appraisal strategies were evaluated, including threat appraisals, distress appraisals, control appraisals, and outcome expectations (i.e., anticipating a pessimistic outcome from an ambiguous situation), which are thought to be fundamental to the theoretical footings of mindfulness (Kabat-Zinn, 1990; Weinstein et al., 2009).

It was hypothesized that:

1. trait mindfulness would be positively correlated with satisfaction with life and negatively correlated with depressive symptoms.

2. individuals who report high levels of trait mindfulness would have more adaptive appraisals of stressful events, including lower appraisals of threat, distress, and pessimistic outcome expectations, and higher appraisals of control.

3. the relationship between mindfulness and depressive symptoms would be mediated by appraisals (i.e., lower appraisals of threat, distress, and pessimistic outcome expectations, and higher appraisals of control) and coping style (i.e., higher reported levels of problemfocused, emotion-focused, and lower levels of avoidant coping).

4. trait mindfulness would serve to moderate the relationship between appraisals and coping styles. Specifically, mindfulness was expected to increase coping levels, even 
among individuals with poor appraisals (i.e., higher appraisals of threat, distress, and pessimistic outcome expectations, and lower appraisals of control).

\section{Method}

\section{Participants}

Participants were voluntarily recruited from the pool of undergraduate Psychology students at Carleton University, and invited to participate in an on-campus study on appraisals, coping, and well being. A total of $369(n=102$ male, $n=267$ female) students participated, whose ages ranged from 17 to 49 years ( $M_{\text {age }}=20.88$ years, $S D=5.02$ years $).$ Most participants were Caucasian $(57.7 \%, n=213)$, followed by Middle Eastern (10.8\%, $n=40)$, East Asian (9.5\%, $n=35)$, African American/Canadian $(5.7 \%, n=21)$, South Asian $(5.7 \%, n=21)$, Hispanic/South American $(2.2 \%, n=8)$, Native American/Canadian $(1.6 \%, n=6)$, and other/multi-ethnic $(6.5 \%, n=24)$ and not declared $(0.3 \%, n=1)$. The majority of participants were registered as full-time students $(90.5 \%, n=334)$, with a small subset registered as part-time $(4.1 \%, n=15)$ or special (i.e., non-degree) students $(5.4 \%, n=20)$.

\section{Procedure}

A description of the study was posted on Carleton University's online Psychology experimental system (SONA) to recruit students (see Appendix A for online recruitment notice). Students registered to participate in the study via the online system, and were invited to an in-laboratory study session of 1.5 hours. When students arrived for their session, they were reminded of the nature and duration of the study, and received informed consent (see Appendix B). Participants then completed a series of questionnaires, measuring demographic information, depressive symptoms (BDI; Beck, 
1961), coping styles endorsed (SCOPE; Matheson \& Anisman, 2003), trait mindfulness (MAAS; Brown \& Ryan, 2003), satisfaction with life (Diener, Emmons, Larsen, \& Griffin, 1985) and appraisals of ambiguous, stressful situations (Appraisals of Ambiguous Situations Questionnaire; Kelly, Matheson \& Anisman, 2003) (see Appendix C for the questionnaire package).

When participants completed the study, they were provided with debriefing information and a list of support services if they experienced distress during the study (see Appendix D). Students were compensated 1.5 credits in an introductory psychology course for their participation in the study.

\section{Measures}

Demographics. The demographic questionnaire assessed basic descriptive and classification information, including age, gender, marital status, ethnicity, student status, educational background, and prior history of depressive symptoms.

Depressive symptoms. The Beck Depression Inventory (BDI; Beck, 1961) measured the presence and severity of depressive symptoms among participants. This scale has been used extensively with clinical and non-clinical samples (e.g., Steer, Ball, Ranieri, \& Beck, 1999). Participants were asked to read 21 groups of statements describing varying degrees of depressive symptomatology and to select the statement that best reflected how they felt. Each statement corresponded to a value, ranging from 0 (no feelings of depression) to 3 (severe feelings of depression). Responses were summed, and higher scores denoted greater depressive symptomatology. Internal consistency was high in the present sample (Cronbach's $\alpha=.90$ ).

Coping styles. The Survey of Coping Profiles Endorsed (SCOPE; Matheson \& 
Anisman, 2003) assessed participants' perceptions of the coping strategies they regularly use. Participants were asked to reflect upon stressful situations they had recently encountered, and to indicate the degree to which they used various strategies to cope with the stressors. The scale was comprised of 27 individual items, representing 13 coping dimensions (problem solving, social support seeking, avoidance, rumination, emotional expression, emotional containment, active distraction, passive resignation, humour, selfblame, other-blame, cognitive restructuring and religion). Items were rated on a 5-point Likert scale, ranging from 0 ('Never') to 4 ('Almost Always'). Mean scores were calculated for each of the 13 subscales, with higher scores representing greater endorsement of the given coping strategy.

A factor analysis (CFA) was performed using a varimax rotation to confirm the factor structure of the SCOPE. A preliminary analysis of factor loadings suggested that religion did not load on any dimensions and this item was thus excluded from further analyses. Three factors emerged that accounted for $51.52 \%$ of variance: problem-focused coping (comprising problem solving, cognitive restructuring, and social support seeking), emotion-focused coping (comprising rumination, humour, emotional expression, emotional containment, self-blame, other blame, wishful thinking, and passive resignation), and avoidant coping (comprising active distraction and cognitive distraction). Internal consistency reliability was adequate to good for all factors (problem-focused $\alpha=.75$; emotion-focused $\alpha=.68$; avoidant $\alpha=.81$ ).

Trait Mindfulness. The Mindful Attention Awareness Scale (MAAS; Brown \& Ryan, 2003) assessed dispositional differences in mindfulness. This scale has been widely validated and used in a number of previous studies, especially when assessing 
mindfulness in healthy populations (Brown, Ryan, \& Creswell, 2007). Eleven items (e.g., "I do jobs or tasks automatically, without being aware of what I'm doing", "I find it difficult to stay focused on what's happening in the present") were rated on a 6-point Likert scale, with 1 representing 'almost always' and 6 representing 'almost never'. Responses were summed, with higher scores indicating greater trait mindfulness. The present study had good internal consistency reliability (Cronbach's $\alpha=.82$ ).

Satisfaction With Life. The Satisfaction With Life Scale (SWLS; Diener et al., 1985) was used to assess contentment with life as a measure of well being. Participants were asked to rate 5 items pertaining to life satisfaction (e.g., "If I could live my life over, I would change almost nothing") on a 7-point Likert scale, with -3 representing 'strongly disagree' and 3 representing 'strongly agree.' Responses were summed, with higher scores representing greater life satisfaction. Internal consistency was good in the present study (Cronbach's $\alpha=.87$ ).

Appraisals of Ambiguous Stressful Situations. The Appraisal of Ambiguous Situations Questionnaire (AASQ; Kelly et al., 2003) assessed participants' appraisals of 29 vague, potentially stressful situations. For each item, participants were asked to read a statement describing a hypothetical, potentially stressful scenario and to rate the situation along 4 appraisal dimensions: Threat (e.g., "How threatening would this situation be to you?"), distress (e.g., "How distressing would this situation be for you?"), control (e.g., "How much control do you think you would have over the outcome of this event?"), and outcome expectations (e.g., "What would you be most likely to think will happen?"). The threat and distress dimensions were rated on a 5-point Likert scale, ranging from 1 (not at all) to 5 (extremely), with higher scores representing greater (i.e., pessimistic) perceptions 
of threat and distress, respectively. The control dimension was similarly assessed on a 5point Likert scale, ranging from 1 (no control) to 5 (complete control), with higher scores representing greater (i.e., beneficial) perceptions of control. Finally, outcome expectations were rated on a 5-point Likert scale, in which 1 represents the expectation of a positive or benign outcome (e.g., "This is probably just another rumour") and 5 represents the expectation of a negative outcome (e.g., "I' $m$ definitely in serious danger"). Responses were summed and a mean score was calculated to represent perceived threat, distress, control and outcome expectations. Cronbach's reliability coefficients were high for all subscales in this sample (threat appraisals $\alpha=.91$; distress appraisals $\alpha=.91$; control appraisals $\alpha=.91$; Outcome expectations $\alpha=.88$ ).

\section{Results}

\section{Preliminary Analyses}

Descriptives. Participants' reports of trait mindfulness as measured by the Mindful Attention Awareness Scale (Brown \& Ryan, 2003) ranged from 18 to 64, from a possible range of 11 to 66 . Reported depressive symptoms from the Beck Depression Inventory (Beck, 1961) ranged from 0 to 36 , out of a possible 0 to 63 range. Most participants were not depressed $(67.5 \% ; n=249)$, with 82 participants in the mildmoderate depression range $(22.2 \%), 32$ in the moderate-severe depression range $(8.7 \%)$ and 5 in the severe depression range (1.4\%). Scores on the Satisfaction with Life Scale (Diener et al., 1985) varied from -14 to 15 , from a possible range of -15 to 15 .

Table 1.

Descriptive statistics (means, standard deviations, and ranges) 


\begin{tabular}{llll}
\hline & $M$ & $S D$ & Range \\
\cline { 2 - 4 } Trait mindfulness & 42.93 & 9.44 & 46.00 \\
Depressive symptomatology & 8.08 & 7.38 & 36.00 \\
Satisfaction with life & 4.98 & 6.89 & 29.00 \\
\hline
\end{tabular}

Gender differences. A one-way ANOVA was conducted to identify any potential gender differences in levels of trait mindfulness. Consistent with previous research (e.g., Brown, Kasser, Ryan, Linley, \& Orzech, 2009; MacKillop \& Anderson, 2007), males (M $=43.89, S D=8.40)$ and females $(M=42.01, S D=9.78)$ did not differ significantly in trait mindfulness levels $(p=.09, n s)$.

Ethnicity differences. A one-way ANOVA was also conducted to identify potential ethnic differences in trait mindfulness, since individuals from Asian cultures may be more mindful than those from other ethnic backgrounds, as some research has postulated (Christopher, Charoensuk, Gilbert, Neary, \& Pearce, 2009). Mindfulness did not differ significantly between Caucasian $(M=41.62)$ and East Asian $(M=41.91)$ individuals, $p=1.00, n s$, or between Asians and any other ethnic group.

\section{Trait Mindfulness and Well Being}

Table 2 provides a summary of bivariate correlations between trait mindfulness, satisfaction with life, depressive symptoms, coping styles, and appraisals. As hypothesized, correlation analyses showed that trait mindfulness was positively associated with satisfaction with life and negatively associated with depressive symptoms. Consistent with previous research (Weinstein et al., 2009), trait mindfulness was also associated with more adaptive appraisals of stressful events, including lower appraisals of threat, distress, and pessimistic outcome expectations, and higher appraisals 
of control. Trait mindfulness was positively related to problem-focused and avoidant coping, and negatively related to emotion-focused coping. 
Table 2. Bivariate correlations between trait mindfulness, appraisals, coping, and indices of well being.

\begin{tabular}{|c|c|c|c|c|c|c|c|c|c|c|}
\hline & 1 & 2 & 3 & 4 & 5 & 6 & 7 & 8 & 9 & 10 \\
\hline 1. Trait mindfulness & - & $.33 * * *$ & $-.43 * * *$ & $.12^{*}$ & $-.32 * * *$ & $.12^{*}$ & $-.20 * * *$ & $-.18 * * *$ & $.22 * * *$ & $-.28 * * *$ \\
\hline 2. Satisfaction with life & & - & $-.63 * * *$ & $.22 * * *$ & $-.30 * * *$ & $.27 * * *$ & -.10 & $-.17 * * *$ & $.16^{* * *}$ & $-.33 * * *$ \\
\hline 3. Depressive symptoms & & & - & $-.16^{* *}$ & $.46^{* * *}$ & $-.22 * * *$ & $.18 * * *$ & $.26 * * *$ & $-.23 * * *$ & $.41^{* * *}$ \\
\hline 4. Problem-focused coping & & & & - & $.29 * * *$ & $.35 * * *$ & -.01 & -.01 & .07 & -.09 \\
\hline 5. Emotion-focused coping & & & & & - & $.11^{*}$ & $.32 * * *$ & $.28 * * *$ & -.10 & $.33 * * *$ \\
\hline 6. Avoidant coping & & & & & & - & .03 & -.02 & .08 & $-.11 *$ \\
\hline 7. Threat appraisals & & & & & & & - & $.79 * * *$ & $-.22 * * *$ & $.66^{* * *}$ \\
\hline 8. Distress appraisals & & & & & & & & - & $-.22 * * *$ & $.64^{* * *}$ \\
\hline 9. Control appraisals & & & & & & & & & - & $-.38 * * *$ \\
\hline 10. Outcome expectations & & & & & & & & & & - \\
\hline
\end{tabular}

${ }^{*} p<.05,{ }^{* *} p<.01, * * * p<.001$ 
Mediation analyses. Based on previous research (Weinstein et al., 2009), it was hypothesized that the relationship between mindfulness and depressive symptoms would be mediated by appraisals and coping styles. Appraisals and coping were examined separately in 2 multiple mediation models to investigate the indirect effects of 4 appraisal measures (threat, distress, pessimistic outcome expectations, and control) and 3 coping measures (problem-focused, emotion-focused coping, and avoidant coping). As recommended by Preacher and Hayes (2004), this hypothesis was analyzed using bootstrapping to determine the significance of indirect effects using 5000 iterations.

In the appraisal model, mindfulness was significantly related to all 4 appraisal measures, including negatively related to threat, $B=-.03, t=-3.97, p<.001$, distress, $B=$ $-.02, t=-3.44, p<.001$, and outcome expectations, $B=-.03, t=-5.65, p<.001$, and positively related to control, $B=.03, t=4.30, p<.001$. In turn, appraisals of threat, $B=$ $1.66, t=-3.65, p<.001$, distress, $B=1.05, t=2.35, p=.019$, and pessimistic outcome expectations, $B=2.72, t=5.77, p<.001$, impacted depressive symptoms ${ }^{1}$. The effect of control appraisals on depression was not significant, $B=-.19, t=-.69$, ns. The model's total indirect effect, including all 4 mediators, was significant, $F(5,363)=31.56, p<$ .001 , and threat appraisals, distress appraisals, and outcome expectations were found to be significant mediators of the relationship between mindfulness and depressive symptoms (Figure 1). This was evident as the $95 \%$ confidence intervals $(\mathrm{CI})$ for threat (.01 to .09$)$, distress (-.05 to -.01$)$, and outcome expectations ( -.13 to -.05$)$ did not contain

\footnotetext{
${ }^{1}$ Although the model indicates that the relationship between threat appraisals and depressive symptoms is negative, this unexpected direction appears to be caused by suppression due to including multiple mediators. The relationship between threat appraisals and depressive symptoms was shown to be positive in a simple mediation between these variables (i.e., the indirect effect of threat appraisals on the relationship between mindfulness and depression), $B=.60, t=2.10, p=.037$, in line with the positive direction of bivariate correlations (Table 1).
} 
zero. The CI for control appraisals contained zero (-.02 to .01) and control appraisals were thus not considered to mediate the relationship between mindfulness and depression above and beyond the impact of other mediators. 


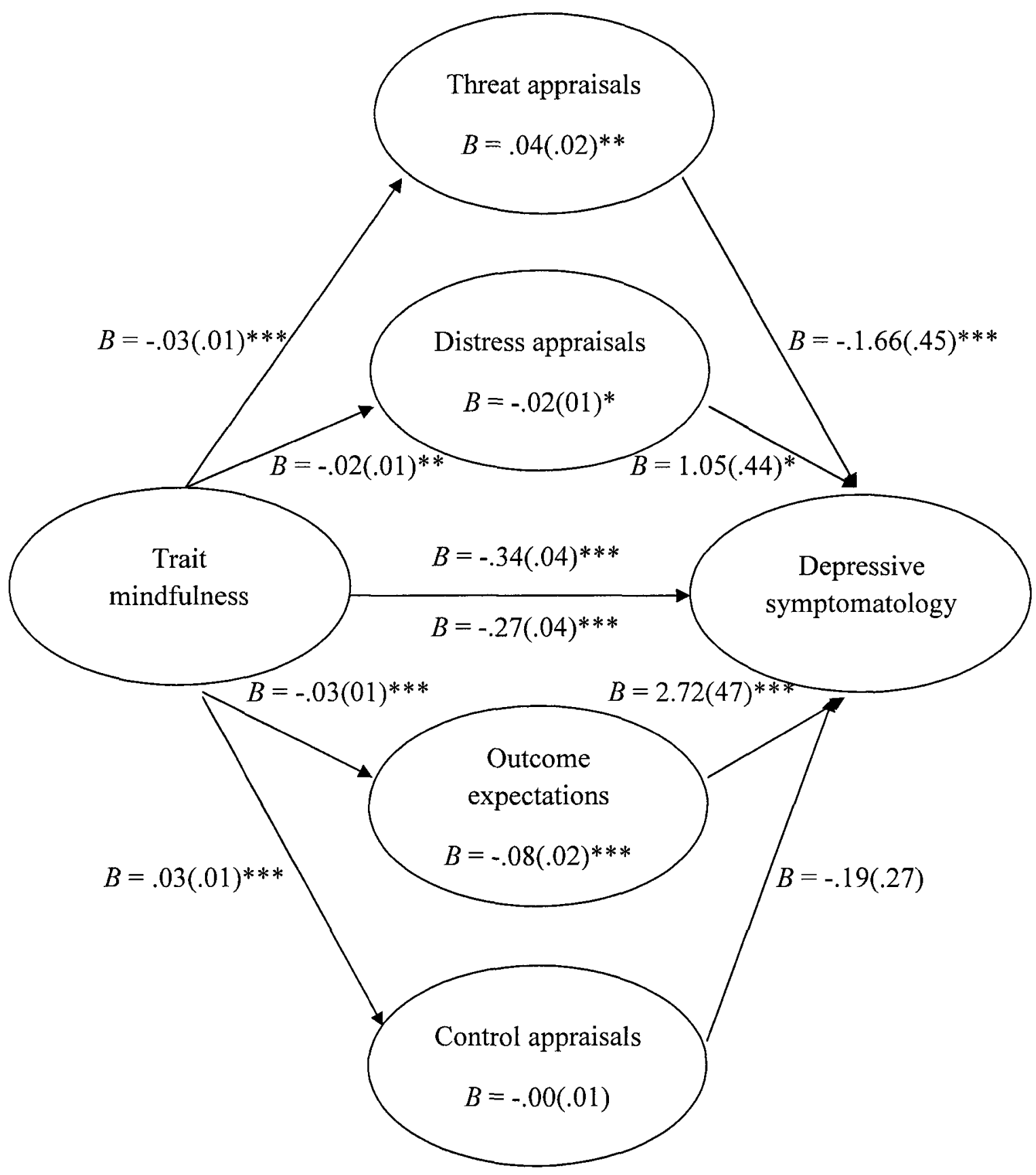

Figure 1. Appraisals (threat, distress, outcome expectations and control) as multiple mediators of the relationship between trait mindfulness and depressive symptomatology $\left({ }^{*} p<.05,{ }^{* *} p<.01, * * * p<.001\right)$. 
A mediation analysis was also conducted to examine the effects of coping styles (problem-focused, emotion-focused, and avoidant coping) in mediating the relationship between trait mindfulness and depression. Trait mindfulness was positively related to problem-focused coping, $B=-.03, t=2.36, p=.019$, and avoidant coping, $B=.02, t=$ $2.36, p=.019$, and negatively related to emotion-focused coping, $B=-.17, t=-6.44, p<$ .001 . Next, problem-focused, $B=-.62, t=-4.47, p<.001$, emotion-focused, $B=.68, t=$ $10.00, p<.001$, and avoidant coping, $B=-.82, t=-3.75, p<.001$, were all shown to predict depressive symptoms, such that problem-focused and avoidant coping were negatively associated with depression, and emotion-focused coping was positively associated with depression. The model's indirect effects indicated that all 3 coping styles mediated the relationship between mindfulness and depression, $F(5,363)=56.89, p<$ .001 . The $\mathrm{CI}$ of problem-focused coping (-.04 to -.00$)$, emotion-focused coping (-.17 to $.07)$ and avoidant coping (-.04 to -.00$)$ indicated that the indirect effects were significant (Figure 2). 


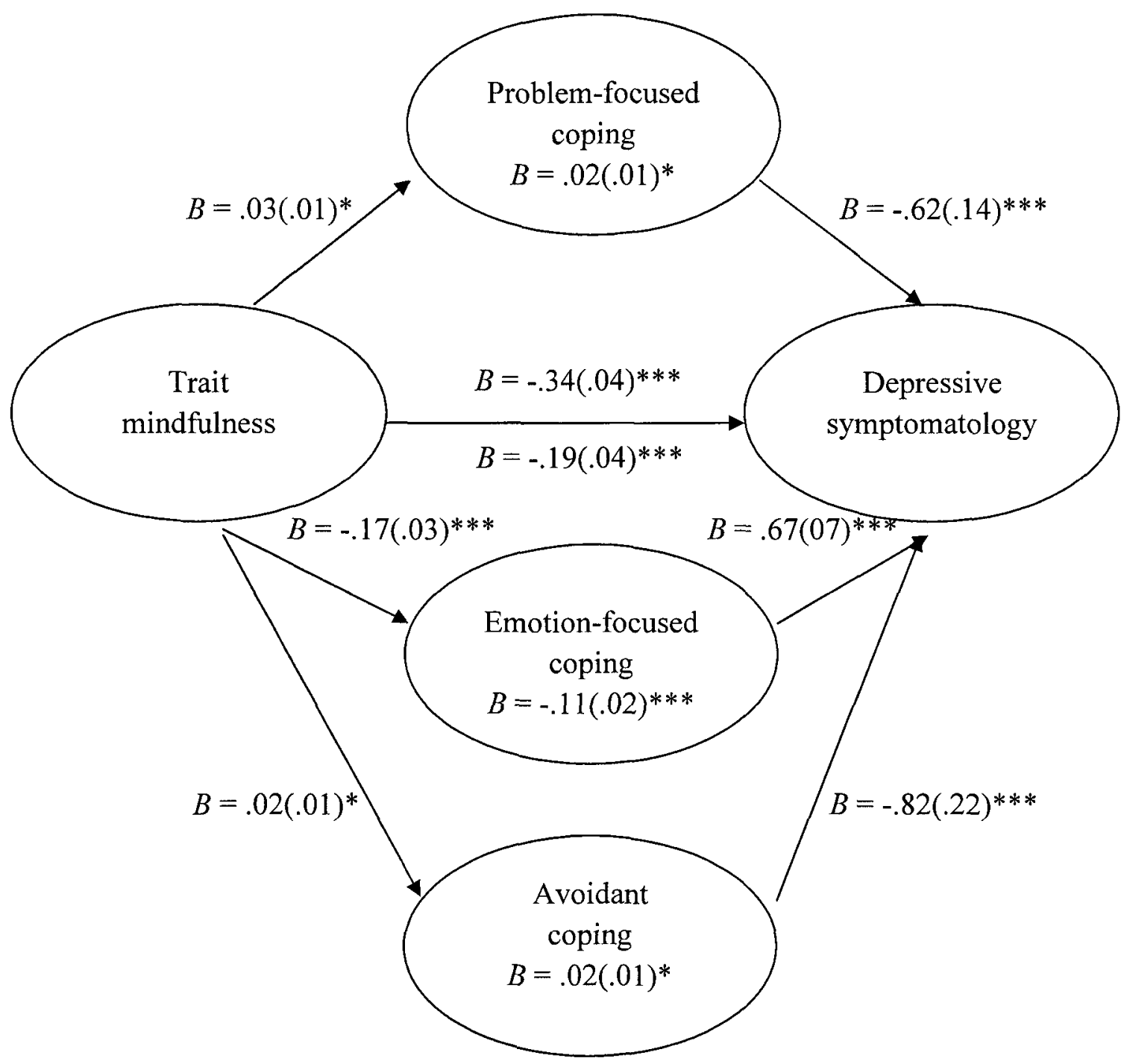

Figure 2. Coping styles (problem-focused, emotion-focused, and avoidant coping) as multiple mediators of the relationship between trait mindfulness and depressive symptomatology $(* p<.05, * * * p<.001)$. 
To account for the multicollinearity between appraisals and coping, all appraisal and coping measures were also entered into the same model. Consistent with the results of the former separate models, appraisals of threat (CI: .01 to .10) distress (CI: -.05 to .01 ) and outcome expectations (CI: - .09 to -.03 ) were significant mediators, along with problem-focused (CI: -.04 to -.00), emotion-focused (CI: -.16 to -.07) and avoidant coping styles (CI: -.03 to -.00$), F(8,360)=36.54, p<.001$. Thus, the relationship between mindfulness and depression may be partially explained by the ways in which individuals appraise and cope with stressful events.

Moderation analyses. It was also hypothesized that trait mindfulness would moderate the effect of appraisals in predicting adaptive coping styles. Although positive appraisals tend to generally predict beneficial coping, mindfulness was predicted to moderate this relationship by leading to higher levels of coping even if appraisals were pessimistic.

Individual moderation models were examined for each type of appraisal (threat, distress, outcome expectations, and control) and coping style (problem-focused, emotionfocused, and avoidant coping). To examine the variance of each coping style, hierarchical regressions were conducted with the centered appraisal and mindfulness variables entered on the first step, and the interaction terms between appraisals and mindfulness entered on the second step.

As predicted, mindfulness was found to moderate the impact of distress appraisals on problem-focused coping, $R_{c h a}^{2}=.011, F_{c h a}(3,365)=4.17, p=.04$. This moderation was further examined by conducting a simple slopes analysis to measure the relationship between distress appraisals and problem-focused coping at one standard deviation above 
and below the mean of trait mindfulness. When individuals appraised situations as highly distressing, trait mindfulness did not substantially impact coping, but when individuals appraised events as low in distress, levels of problem-focused coping were higher for mindful individuals than those low in mindfulness, $\beta=.106, t=2.04, p=.04$ (Figure 3). In effect, mindful individuals were more likely to report higher use of problem-focused coping if their distress appraisals were low.

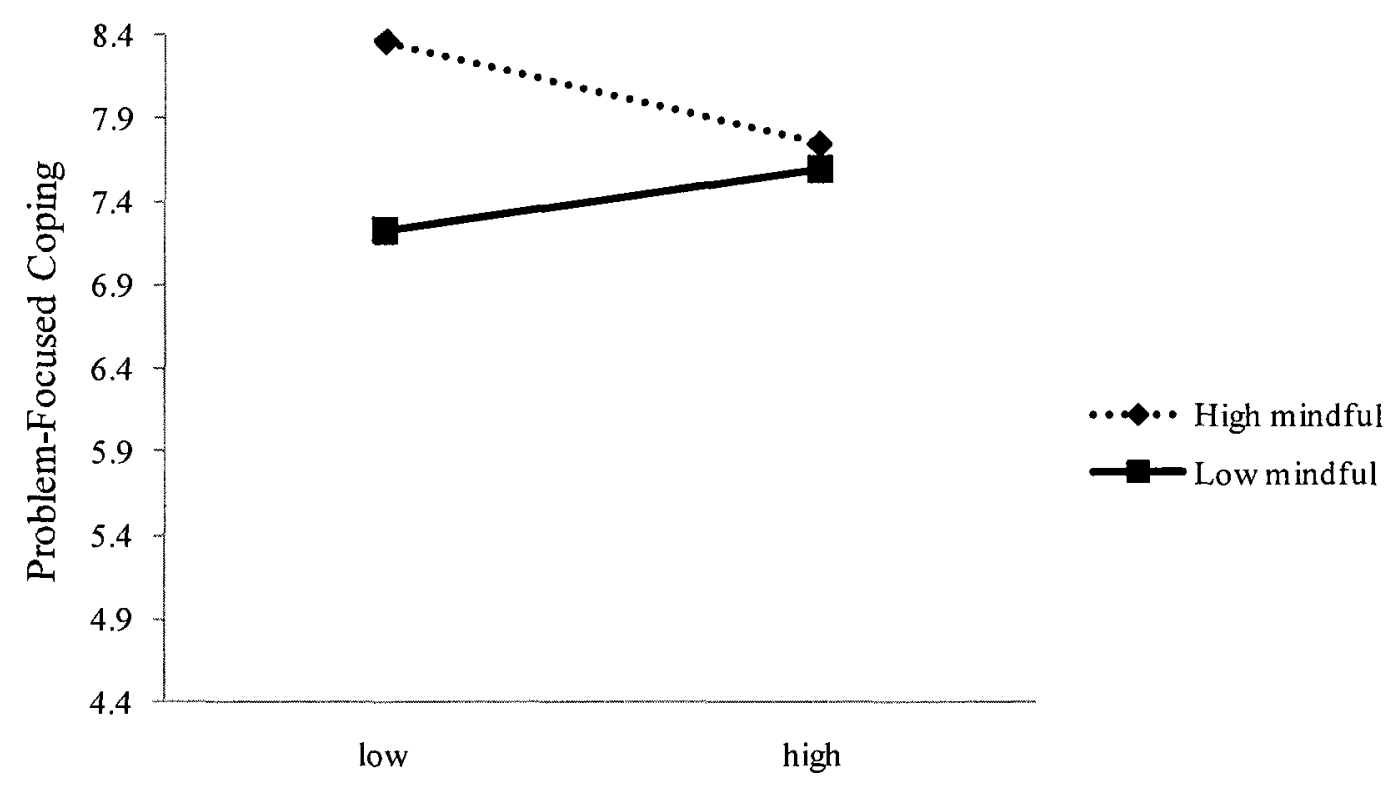

Distress Appraisals

Figure 3. Slopes indicating the moderating effect of trait mindfulness on the relationship between distress appraisals and problem-focused coping (at 1 standard deviation below and above the mean of mindfulness).

As in the problem-focused coping model, trait mindfulness moderated the effect of distress appraisals on avoidant coping, $R_{c h a}^{2}=.011, F_{c h a}(3,365)=3.99, p=.05$. A simple slopes analysis showed that when distress appraisals were high, mindfulness did 
not impact coping, but when distress appraisals were low, avoidant coping was higher among mindful individuals compared to those low in mindfulness, $\beta=.104, t=1.20, p=$ .05 (Figure 4). Essentially, among individuals low in mindfulness, increasing distress appraisals was associated with higher coping levels, but among mindful individuals, increasing distress appraisals was tied to lower coping levels.

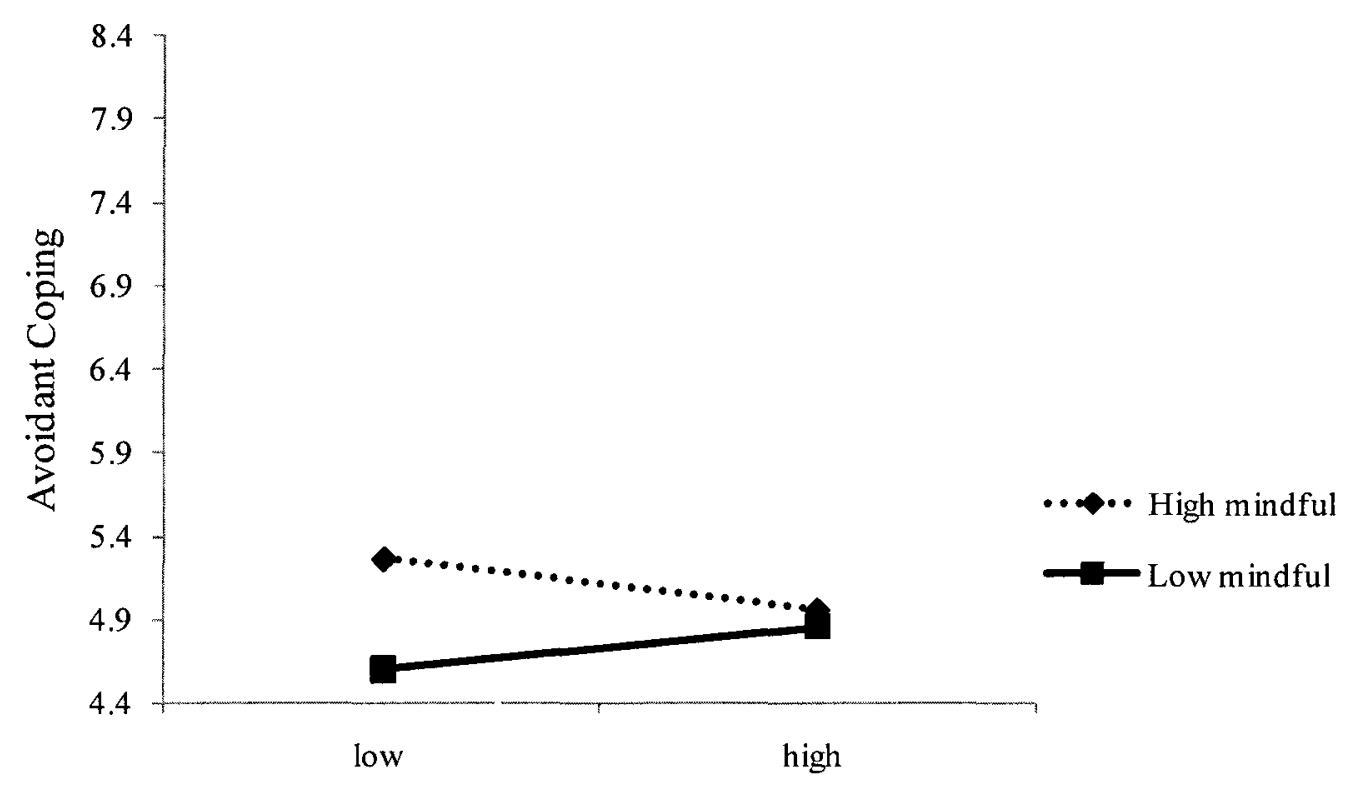

Distress Appraisals

Figure 4. Slopes indicating the moderating effect of trait mindfulness on the relationship between distress appraisals and avoidant coping (at 1 standard deviation below and above the mean of mindfulness).

As shown in Table 3, the effects of other appraisal measures on both problemfocused and avoidant coping, including appraisals of threat, control, and outcome expectations, were not moderated by trait mindfulness. Mindfulness did not moderate any appraisal measures on emotion-focused coping. 
Table 3.

Nonsignificant moderations of mindfulness on the effects of appraisals predicting coping styles.

\begin{tabular}{lccccccccccc} 
& \multicolumn{3}{c}{ Problem-focused coping } & \multicolumn{3}{c}{ Avoidant coping } & \multicolumn{3}{c}{ Emotion-focused coping } \\
\cline { 2 - 11 } & \multicolumn{1}{c}{} & $T$ & $p$ & 6 & $t$ & $p$ & 6 & $t$ & $p$ \\
\cline { 2 - 10 } & .01 & 1.14 & .26 & .01 & 1.28 & .20 & .01 & .58 & .56 \\
Threat appraisals & & & & & & & .01 & .48 & .63 \\
Distress appraisals & & & & & & & .01 & .30 & .76 \\
Outcome expectations & .02 & 1.34 & .18 & .01 & 1.24 & .22 & .01 & .30 \\
Control appraisals & -.01 & -.57 & .56 & -.00 & -.36 & .72 & .00 & .09 & .93 \\
\hline
\end{tabular}

Since the relationship between appraisals and coping is regarded as bidirectional, in addition to investigating the moderating effects of appraisals on coping, we assessed whether mindfulness also moderated the effects of coping styles on appraisals.

Hierarchical regression analyses were conducted to examine the relationship between coping styles (as predictors) and appraisals (as outcome variables), using mindfulness as a moderator. As in the former moderation models, 3 coping styles (i.e., problem-focused, emotion-focused, and avoidant coping) and 4 appraisal variables (i.e., appraisals of threat, distress, outcome expectations, and control) were measured.

Analogous to the previously reported models, trait mindfulness was found to moderate the impact of problem-focused coping on distress appraisals, $R_{c h a}^{2}=.013$, $F_{c h a}(3,365)=4.87, p=.028$. A simple slopes analysis indicated that among individuals low in problem-focused coping, mindfulness did not influence the relation between coping and appraisals, but among individuals high in problem-focused coping, mindfulness was associated with reduced distress appraisals, $\beta=.113, t=2.208, p=.028$. As Figure 5 displays, mindful individuals reported lower distress appraisals, especially if they were high in problem-focused coping. Individuals low in mindfulness not only had 
higher distress appraisals, but their higher levels of problem-focused coping were associated with further increased distress. Conversely, among mindful individuals, higher coping levels were associated with reduced appraisals of distress.

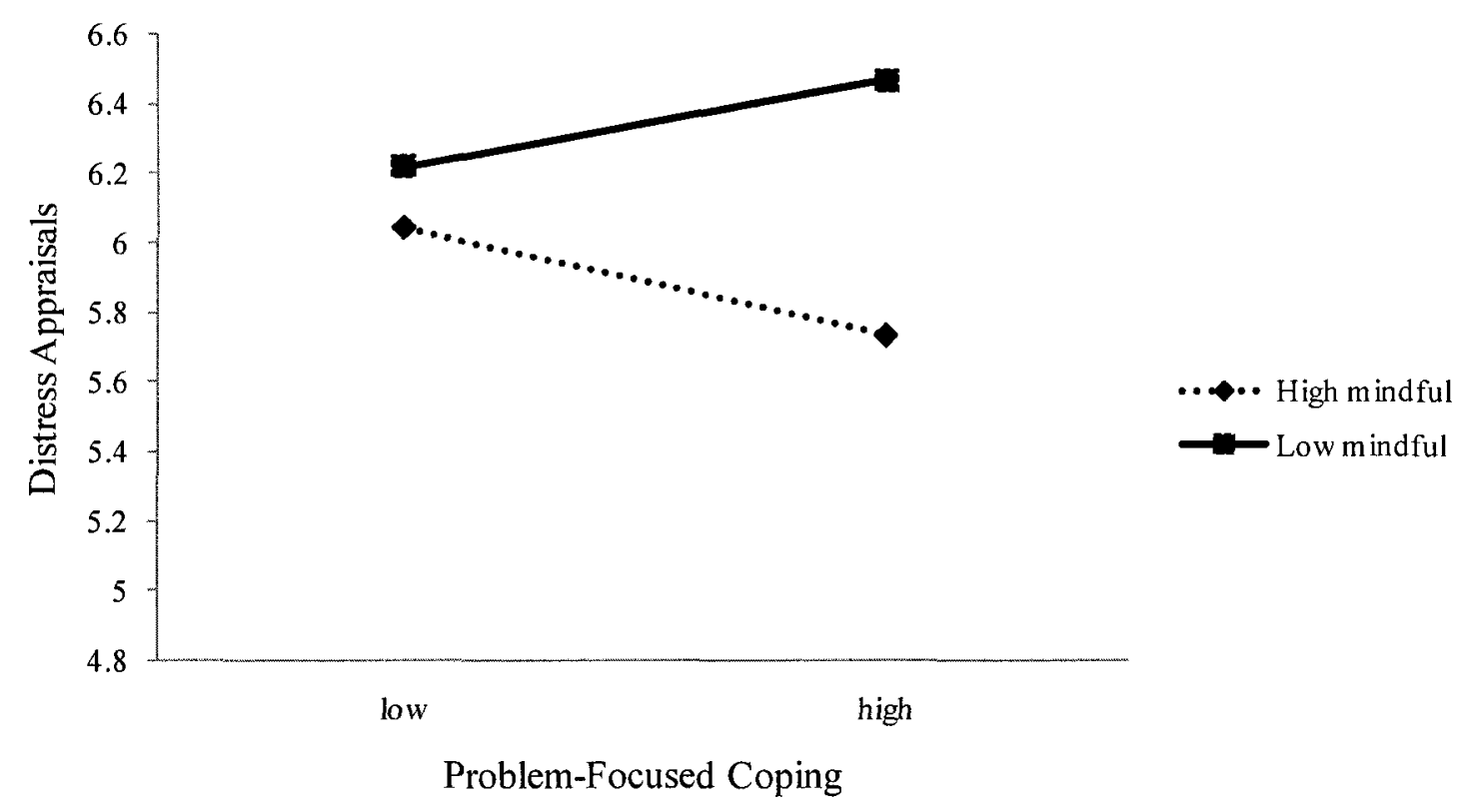

Figure 5. Slopes indicating the moderating effect of trait mindfulness on the relationship between problem-focused coping and distress appraisals (at 1 standard deviation below and above the mean of mindfulness).

Trait mindfulness was also found to moderate the impact of avoidant coping on distress appraisals, $R_{c h a}^{2}=.047, F_{c h a}(3,365)=5.97, p=.015$. Mindfulness did not affect distress appraisals among individuals low in avoidant coping, but was associated with lower distress among individuals high in avoidant coping, $\beta=.126, t=2.443, p=.015$ (Figure 6). Again, individuals low in mindfulness displayed increased distress appraisals, especially among those reporting high levels of avoidant coping. High levels of 
mindfulness were accompanied by a reversal of this relationship, as mindful individuals had lower distress appraisals, especially among individuals who also reported high levels of avoidant coping.

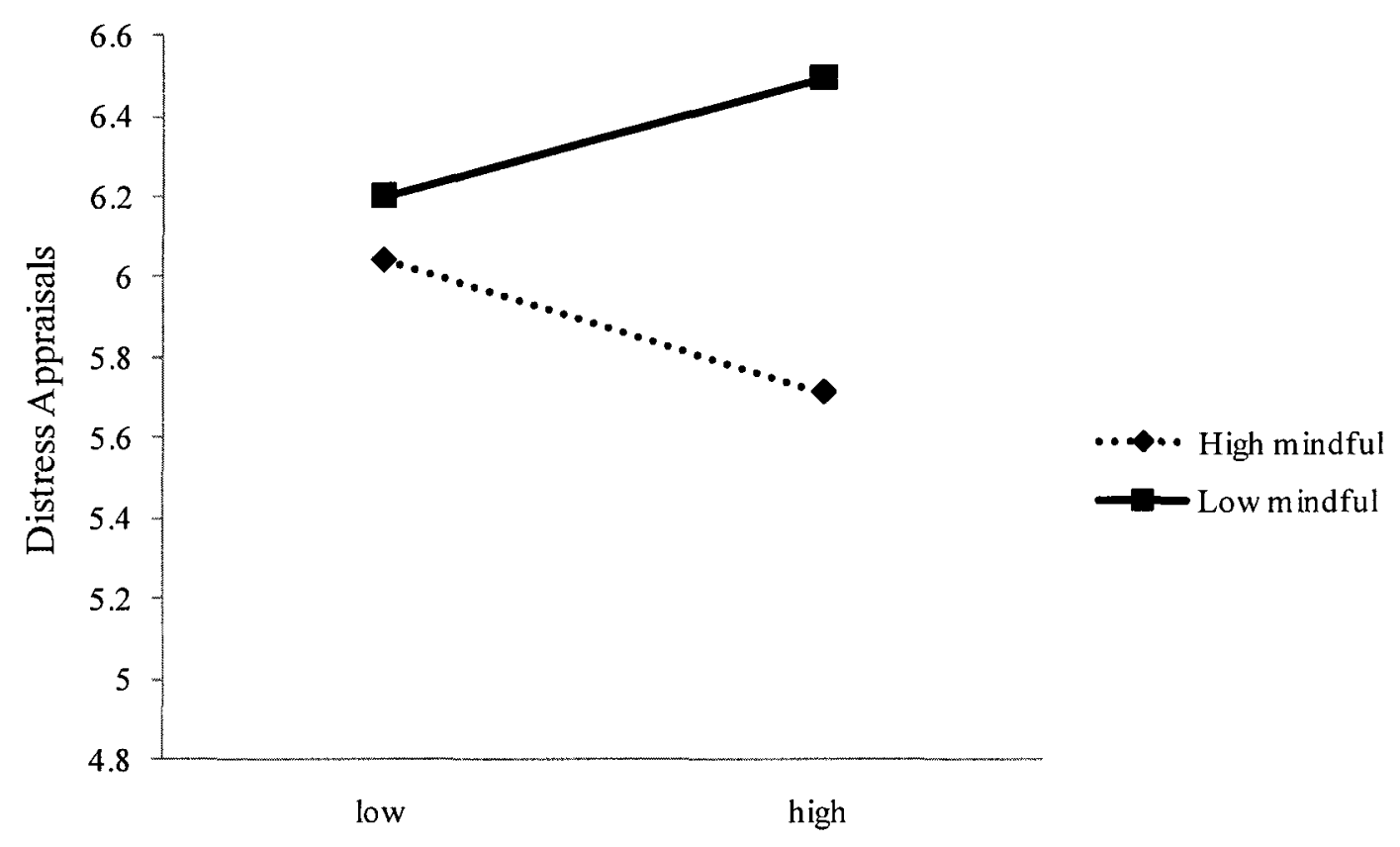

Avoidant Coping

Figure 6. Slopes indicating the moderating effect of trait mindfulness on the relationship between avoidant coping and distress appraisals (at 1 standard deviation below and above the mean of mindfulness).

Finally, mindfulness moderated the effect of avoidant coping on pessimistic outcome expectations, $R_{\text {cha }}^{2}=.01, F_{\text {cha }}(3,365)=3.96, p=.047$. Individuals with low levels of trait mindfulness had more pessimistic expectations, especially those with high levels of avoidant coping, whereas mindful individuals with both low and high levels of 
avoidant coping reported more optimistic expectations, $\beta=1.00, t(365)=1.99, p=.047$ (Figure 7).

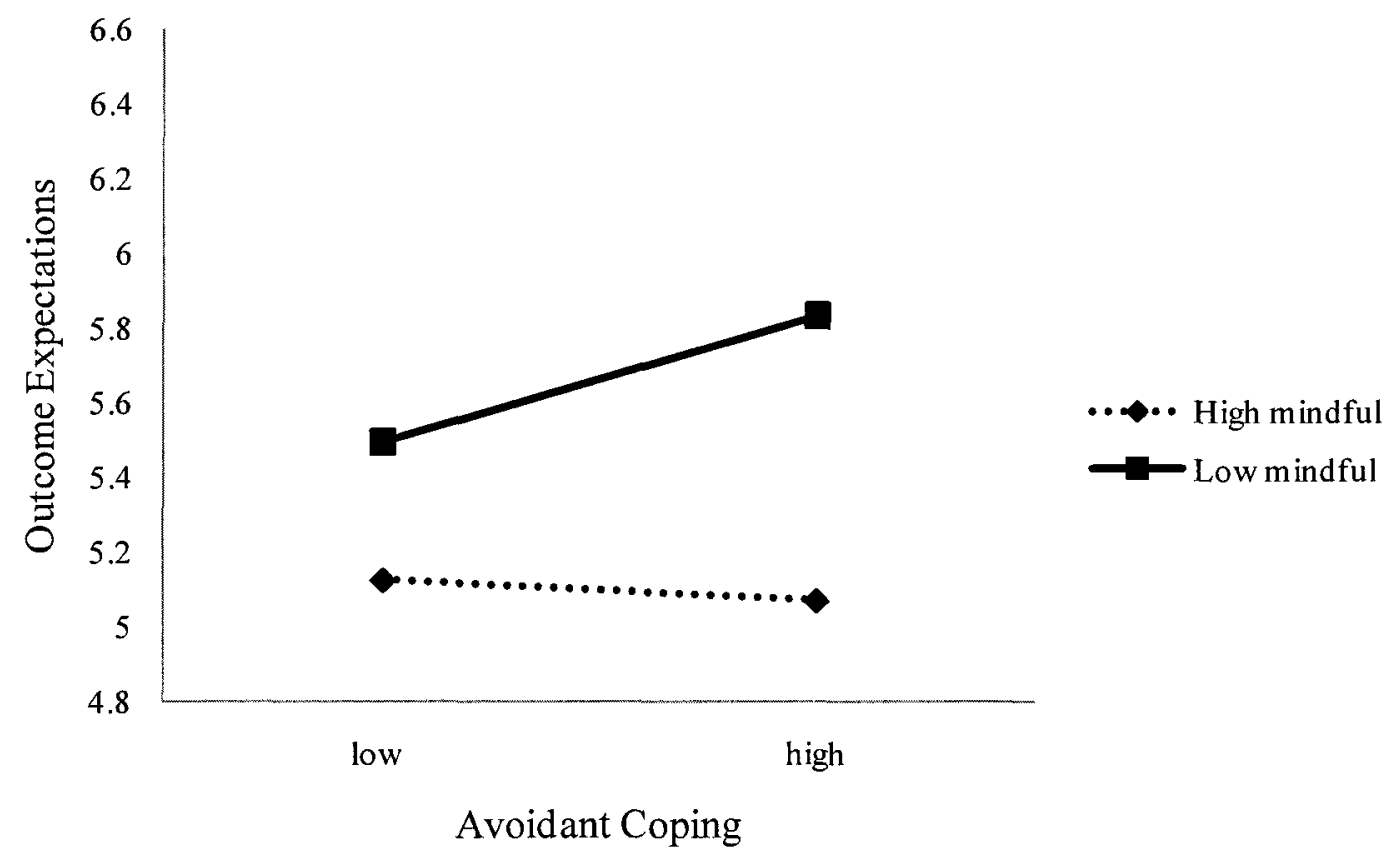

Figure 7. Slopes indicating the moderating effect of trait mindfulness on the relationship between avoidant coping and pessimistic outcome expectations (at 1 standard deviation below and above the mean of mindfulness).

Mindfulness did not moderate the effect of any other appraisal measure for either problem-focused or avoidant coping. Mindfulness did not moderate the effect of emotion-focused coping on any appraisal measure (see Table 4). 
Table 4.

Nonsignificant moderations of mindfulness on the effects of coping styles predicting appraisals.

\begin{tabular}{|c|c|c|c|c|c|c|c|c|c|c|c|c|}
\hline & \multirow{2}{*}{\multicolumn{3}{|c|}{$\begin{array}{c}\text { Threat } \\
\text { appraisals }\end{array}$}} & \multirow{2}{*}{\multicolumn{3}{|c|}{$\begin{array}{c}\text { Distress } \\
\text { appraisals }\end{array}$}} & \multirow{2}{*}{\multicolumn{3}{|c|}{$\begin{array}{c}\text { Outcome } \\
\text { expectations }\end{array}$}} & \multirow{2}{*}{\multicolumn{3}{|c|}{$\begin{array}{c}\text { Control } \\
\text { appraisals }\end{array}$}} \\
\hline & & & & & & & & & & & & \\
\hline & $B$ & $t$ & $p$ & 8 & $t$ & $p$ & 8 & $t$ & $p$ & 8 & $T$ & $p$ \\
\hline Problem-focused coping & .00 & 1.29 & .20 & & & & .00 & 1.83 & .07 & -.00 & -.54 & .59 \\
\hline Avoidant coping & .01 & 1.72 & .09 & & & & & & & -.00 & -.42 & .67 \\
\hline Emotion-focused coping & .00 & .03 & .10 & .00 & -.24 & .81 & -.00 & -1.04 & .30 & .00 & -.35 & .73 \\
\hline
\end{tabular}

\section{Discussion}

Although it has often been surmised that the benefits of mindfulness are accrued through its stress reducing capacity, few studies have actually assessed the impact of mindfulness on stressor appraisal and coping processes. Mindfulness has been shown to attenuate perceptions of threat and negative affect in specific situations (Arch \& Craske, 2006; Weinstein et al., 2009), but further clarification is needed to understand how mindfulness broadly influences cognitive responses to stressors, as well as coping strategies, which have been found to vary in relation to mindfulness among different situations (Weinstein et al., 2009).

As expected, trait mindfulness was related to greater life satisfaction, fewer depressive symptoms, and more benign appraisals of stressful events, including lower appraisals of threat, distress, and pessimistic outcome expectations, and higher appraisals of control. Interestingly, the negative association between mindfulness and emotionfocused coping was stronger than the positive associations between both mindfulness and 
problem-focused coping, and mindfulness and avoidant coping. Although mindful individuals are not necessarily high in either problem- or emotion-focused coping, the present results indicated that trait mindfulness may limit the use of emotion-focused forms of coping, perhaps by enabling individuals to assess situations at arms-length, instead of becoming caught up in emotions and overreacting (Carmody et al., 2009; Teasdale et al., 2002). Consequently, while it may not encourage adaptive coping, such as problem-focused efforts, it was found to be negatively related to emotion-focused types of coping, which, although dependent on the situation encountered and individual dealing with the stressor, have been considered generally less preferable (Folkman \& Lazarus, 1988). These results are consistent with previous research that found negative health outcomes (e.g., depression) are associated with reduced use of dysfunctional coping methods (e.g., emotion-focused coping) but not necessarily related to increased use of adaptive coping methods (e.g., problem-focused coping; Clarke \& Goosen, 2009; Matheson \& Anisman, 2003).

In addition, relatively weak correlations between mindfulness and avoidant coping and mindfulness and problem-focused coping were apparent. This implies that while mindfulness was negatively associated with emotion-focused coping, it is not necessarily related to active coping efforts. In fact, mindfulness even appeared to be weakly related to avoidance. Its focus on observing situations, instead of trying to change them (Kabat-Zinn, 1990; Segal et al., 2002), may explain the small correlation between mindfulness and avoidant coping, although previous research showed that the relationship between mindfulness and avoidance was negative (Weinstein et al., 2009). Theoretically, mindfulness certainly promotes experiencing thoughts, emotions, and 
situations, rather than trying to circumvent them (Kabat-Zinn, 1990; Segal et al., 2002) and we thus expected mindfulness to be negatively related to avoidant coping by increasing tolerance to adversity (Carmody et al., 2009). However, avoidant coping has been shown to be adaptive in many circumstances (Newth \& DeLongis, 2004; Suls \& Fletcher, 1985) and mindful individuals may recognize situations in which avoidance would be beneficial. Alternatively, despite the theoretical underpinnings of mindfulness, the association between mindfulness and avoidant coping may change when actually dealing with certain types of stressful events, especially among individuals who, although high in trait mindfulness, have likely not had any formal mindfulness training.

The relationships between mindfulness, appraisals, coping, and depression were further elucidated by multiple mediation analyses that showed the negative association between mindfulness and depression was partially driven by the indirect effects of appraisals and coping styles. In the appraisal model, outcome expectations were the primary mediator of the relationship between trait mindfulness and depression, followed by threat appraisals and distress appraisals.

Outcome expectations likely had the greatest mediating effect in this model because mindfulness by definition involves monitoring thoughts and the reactions they incite, and thereby may prevent individuals from exacerbating a negative situation (Brown \& Ryan, 2003; Segal et al., 2002). Indeed, mindfulness helps to protect against depression by encouraging an open receptivity to experience, characterized by curiosity and focused attention (Carmody et al., 2009) rather than fixating on negative thoughts or adopting a hopeless perspective, which increases depressive susceptibility (Abramson, Metalsky, \& Alloy, 1989; Nolen-Hoeksema \& Morrow, 1993; Peterson \& Seligman, 
1984). By learning to gain an ongoing awareness of their thinking patterns, coupled with an attitude of acceptance, individuals are thought to develop the ability to view their thoughts and reactions as mental events instead of factual truths, and thereby reduce their depressive vulnerability (Segal et al., 2002; Teasdale et al., 2002; Williams, Duggan, Crane, \& Fennell, 2006). Perceiving situations realistically may also reduce depressive symptoms by decreasing the need for any coping methods, since situations that are appraised as benign do not warrant coping efforts.

Interestingly, although lower threat appraisals were shown to mediate the relationship between mindfulness and depression in a simple mediation, both in the present study and in previous research (Weinstein et al., 2009), when other appraisal facets (i.e., distress appraisals, control appraisals, and outcome expectations) were accounted for, higher threat mediated this relationship. Even though negative appraisals are typically indicative of greater depressive susceptibility (Brosschot, Gerin, \& Thayer, 2006; Folkman, Lazarus, Gruen, \& DeLongis, 1986), the present results suggested this relationship may change when accounting for trait mindfulness. Mindful individuals may use threat appraisals as a method of alerting them to stressors, to facilitate subsequent coping, but further investigation of this outcome is necessary.

Control appraisals did not mediate associations between mindfulness and depression, perhaps because mindful individuals are more likely to acknowledge their lack of control when dealing with a stressful event. Letting go of trying to control thoughts and emotions is a focus of mindfulness programs (e.g., MBSR, Kabat-Zinn, 1990; MBCT, Segal et al., 2002) and individuals in these treatment programs learn to recognize the futility of attempting to change an uncontrollable situation (Teasdale et al., 
2002). Similarly, although mindfulness and control appraisals shared a positive, significant relationship on their own, it is possible that well being was not contingent on perceptions of control among mindful individuals, and control therefore did not mediate the relationship between mindfulness and depression. Highly mindful individuals may be able to contend with feelings of a lack of control quite adaptively, even if their mindfulness is associated with greater control in general. Thus, rather than trying to control stressful events, mindful individuals may place greater emphasis on personal responses they can directly manage (e.g., thoughts, feelings of harm, future expectations, etc.), which would account for the mediating effects of the other appraisal measures.

The second multiple mediation showed that the association between mindfulness and depression was also partially driven by the negative relationship between mindfulness and emotion-focused coping, followed by the positive relationships between mindfulness and both problem-focused and avoidant coping. This finding corroborates both theories (Segal et al., 2002) and evidence (Sanders \& Lam, 2010; Weinstein et al., 2009) that mindfulness is associated with less emotion-focused coping and greater problem-focused coping, as it encourages individuals to process events conscientiously, using a self-regulatory process that aligns itself with a problem-focused approach (Carmody et al., 2009; Carver \& Scheier, 1994; Kabat-Zinn, 1990). Avoidant coping has been previously been associated with negative outcomes (Felton et al., 1984; Holahan \& Moos, 1985), but when mediating the negative relationship between mindfulness and depressive symptoms, it was negatively related to depression and therefore appears to represent effective coping. 
Although both the appraisal and coping models were significant, the associations between mindfulness and depression were still significant after controlling for the indirect effects of appraisals and coping. Thus, many other factors may contribute to the relationship between trait mindfulness and depression. Mindfulness was significantly related to almost all appraisal, coping, and well being measures, and relationships between these variables were clearly complex. Consequently, a number of alternative models and pathways may be viable.

The field of research on mindfulness, appraisals and coping is still in an emergent stage, and further studies, including causal research, are required to determine the specific pathways through which mindfulness and well being are related. In particular, identifying whether mindfulness leads to improved appraisals and coping or whether appraisals and coping support higher levels of mindfulness could help to define how mindfulness improves well being to inform treatment programs. Although the present research did not eliminate the possibility of other potential pathways, its findings may draw attention to gaps in mindfulness literature that may be further examined by future research.

Finally, when mindfulness was used as a moderating variable on the bidirectional relationships between appraisals and coping style, it was found to moderate the effects of distress appraisals on problem-focused and avoidant coping, and the effects of problemfocused and avoidant coping styles on distress appraisals. Mindfulness also moderated the effects of avoidant coping on outcome expectations. The weak correlations between mindfulness and problem-focused and avoidant coping may have been due to these moderating effects. Although emotion-focused coping had a stronger association with 
mindfulness, in general, the relationships between mindfulness and problem-focused and avoidant coping may be more indicative of the ways that mindfulness shapes coping, and thus more meaningful.

Models for both problem-focused and avoidant coping indicated that when distress appraisals were low, trait mindfulness was associated with greater coping efforts, but when distress was high, coping did not differ among individuals who were high and low in mindfulness. Although mindfulness is certainly advantageous for individuals with low distress appraisals, its benefits appear to be lost among individuals who rate situations as highly distressing. A similar pattern was evident when coping styles were used as predictors and distress appraisals were used as outcome variables: Distress varied according to mindfulness levels among individuals high in problem-focused and avoidant coping, but mindfulness levels were irrelevant among individuals low in each type of coping style. In other words, the benefits of mindfulness appear to be salient primarily among individuals with low distress appraisals, and high levels of coping styles. When distress levels are high or coping levels are low, mindfulness does little to improve one's prospects.

Since mindfulness enables individuals to experience thoughts and emotions without becoming wrapped up in their content (Segal et al., 2002), it may increase the use of coping strategies. This effect may be more pronounced for individuals with low distress appraisals because the benefits of mindfulness may be more apparent when combined with other factors of good mental health. Research in other appraisals and coping areas has found this effect; for example, the effects of cognitive strategies on emotional outcomes have been found to be moderated by neuroticism in virtually 
analogous research: Individuals who were low in neuroticism benefitted from greater cognitive strategy use, but high neuroticism individuals were unaffected by increased strategy use (Ng \& Diener, 2009). Thus, trait mindfulness may not only be associated with beneficial appraisals and coping in general, but it may increase the effectiveness of appraisals and coping as well.

\section{Study 2}

As indicated earlier, it might be possible to influence appraisals by priming mindfulness. Thus, Study 2 assessed the efficacy of priming mindfulness via writing about a stressful event, and determined its potential influence on appraisals of stressful situations. If priming mindfulness is effective, it may be a simple, time-efficient method of inducing mindfulness. Study 2 was embedded in Study 1, since the same outcome measures (appraisals of ambiguous stressful situations, including appraisals of threat, distress, control, and outcome expectations) were assessed. Study 2 thus used a subset of participants from Study 1, and followed the general format of Study 1 procedures.

It was hypothesized that:

1. individuals who are primed with mindfulness would have more adaptive appraisals of stressful events, including lower appraisals of threat, distress, and pessimistic outcome expectations, and higher appraisals of control, compared to individuals primed with nonmindfulness and those who received no priming.

2. It was also of exploratory interest to examine whether individuals with high or low levels of trait mindfulness would be more receptive to the priming of mindfulness, as measured by their appraisals of stressful events (i.e., appraisals of threat, distress, control and pessimistic outcome expectations). 


\section{Method}

\section{Participants}

A subset of the same participants who were voluntarily recruited for Study 1 participated in a writing exercise designed to prime mindfulness, during the same study session. A total of 329 students ( $n=89$ male, $n=240$ female) from Carleton University's Psychology pool of undergraduate students participated. As in Study 1, participants ranged in age from 17 to 55 years $\left(M_{\text {age }}=20.98\right.$ years, $S D=5.22$ years $)$. Most participants were Caucasian $(59.3 \%, n=195)$, followed by Middle Eastern (11.2\%, $n=37)$, East Asian (8.5\%, $n=28)$, South Asian (6.1\%, $n=20)$, African American/Canadian (4.6\%, $n=15)$, Hispanic/South American $(1.8 \%, n=6)$, Native American/Canadian $(1.8 \%, n=6)$, and other/multi-ethnic $(6.4 \%, n=21)$. One participant's ethnicity was undeclared $(0.3 \%, n=1)$. Most participants were registered as full-time students $(90.6 \%, n=298)$, with a small subset registered as part-time $(4.0 \%, n=$ 13) or special (i.e., non-degree) students $(5.5 \%, n=18)$.

\section{Procedure}

Participants received informed consent and were randomly assigned to one of three experimental priming conditions: mindfulness $(n=103)$, non-mindfulness (which represented mindlessness; $n=108)$, or a control condition $(n=118)$. After completing a battery of questionnaires, participants were asked to write about a recent stressful experience. To prime either mindfulness or non-mindfulness (i.e., mindlessness), participants were asked to include either key mindfulness words (aware, noticed, accepted, observed, attention), non-mindfulness words, (distracted, concerned, rushed, unaware, overwhelmed) or no specific words (representing a control condition) in their 
descriptions. Instructions for the writing exercise were minimal, and the type and severity of the stressful experience described was entirely the participant's choice. (See Appendix E for instructions for writing exercise). Following the writing exercise, students completed the Appraisals of Ambiguous Situations Questionnaire (AASQ; Kelly et al., 2003), as described in Study 1.

\section{Measures}

After completing all Study 1 measures except for the AASQ (Kelly et al., 2003), participants were asked to write a 1 page description of a recent stressful event.

Writing Exercise. To prime mindfulness and non-mindfulness, participants were asked to write a 1 page description of a recent stressful event they had experienced. To engage participants in the activity, they were asked to describe their thoughts and feelings, and were invited to select any type of stressful event. Participants in the mindful condition were asked to include the words aware, noticed, accepted, observed, and attention in their descriptions; participants in the non-mindfulness condition were asked to include the words distracted, concerned, rushed, unaware, and overwhelmed; participants in the control condition were not asked to include any specific words. Instructions for the exercise were otherwise identical.

Participants' descriptions of stressful events were read to ensure that participants understood and followed instructions. Participants who did not comply with instructions (e.g., left exercise blank, showed evidence of language barriers, etc.) or who failed to include 2 or more of the requested priming words were removed from the original sample (reducing the sample to $N=329$ ). 
Appraisals of Ambiguous Stressful Situations. Participants completed the AASQ (Kelly et al., 2003) after the writing exercise. Cronbach's reliability coefficients were again high (Threat $\alpha=.90 ;$ Distress $\alpha=.91$; Control $\alpha=.91$; Outcome expectation $\alpha=$ $.87)$.

\section{Results}

Priming condition differences in trait mindfulness. A one-way ANOVA was conducted to ensure that the random assignment of individuals into priming conditions did not result in systematic differences in trait mindfulness. Baseline mindfulness levels were not different among the mindfulness $(M=42.56, S D=8.68)$, non-mindfulness ( $M=$ 41.29, $S D=9.21)$, and control conditions $(M=43.43, S D=9.43), F(2,326)=1.56, n s$.

\section{Effect of Priming Mindfulness on Appraisals}

Priming mindfulness through a writing exercise was predicted to improve appraisals of stressful events (i.e., reduce appraisals of threat, distress, and pessimistic outcome expectations, and increase appraisals of control) compared to priming nonmindfulness and receiving no prime. To analyze this hypothesis, a MANOVA was conducted using the priming condition as the predictor variable and the 4 appraisal measures as outcome variables. Priming mindfulness was found to have only a marginal impact on appraisals of stressful situations, $F(8,648)=1.91, p=.056$, Pillai's Trace $=$ $.05, \eta_{\mathrm{p}}{ }^{2}=.02$. Examining appraisals individually using univariate ANOVAs with Bonferroni adjusted alpha levels of .013 showed that priming had only a marginal effect on appraisals of threat, $F(2,326)=3.54, p=.030, \eta_{\mathrm{p}}{ }^{2}=.02$, and outcome expectations, $F(2,326)=3.67, p=.026, \eta_{\mathrm{p}}{ }^{2}=.02$, and effect sizes for both measures were very small. 
The effects of priming mindfulness on distress appraisals, $F(2,326)=2.84$, $n s$, and control appraisals, $F(2,326)=2.44$, $n s$ were not significant.

Tukey post hoc tests were conducted to determine between-group differences. Individuals in the mindfulness condition $(M=5.99, S D=1.07)$ had lower threat appraisals than individuals in the non-mindfulness condition $(M=6.42, S D=1.26), p=$ .025 , but the control condition $(M=6.24, S D=1.24)$ did not differ from either experimental group (Figure 8). Likewise, the mindfulness condition $(M=5.29, S D=.93$ ) had lower pessimistic outcome expectations than the non-mindfulness condition $(M=$ $5.63, S D=.95), p=.038$, but neither group differed from the control group $(M=5.35$, $S D=1.02)($ Figure 9). Thus, while there was a trend toward more negative appraisals in the non-mindfulness priming group compared to the mindfulness priming and control conditions, priming effects were marginal and small at best; suggesting that the priming manipulations altered appraisals may be premature. 


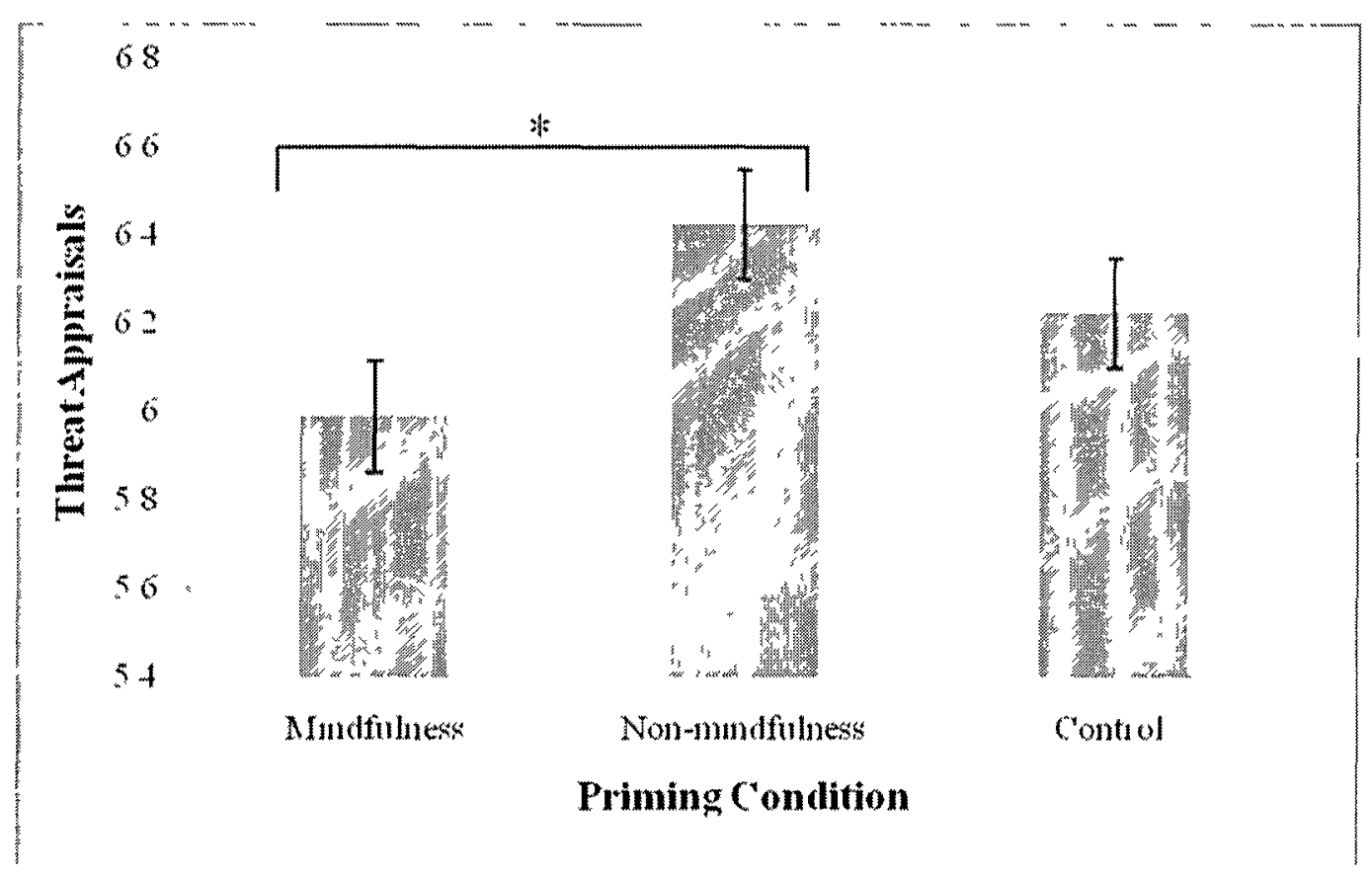

Figure 8. Mean ( $\pm \mathrm{SE})$ threat appraisals as a function of priming condition. ${ }^{*} p<.05$ 


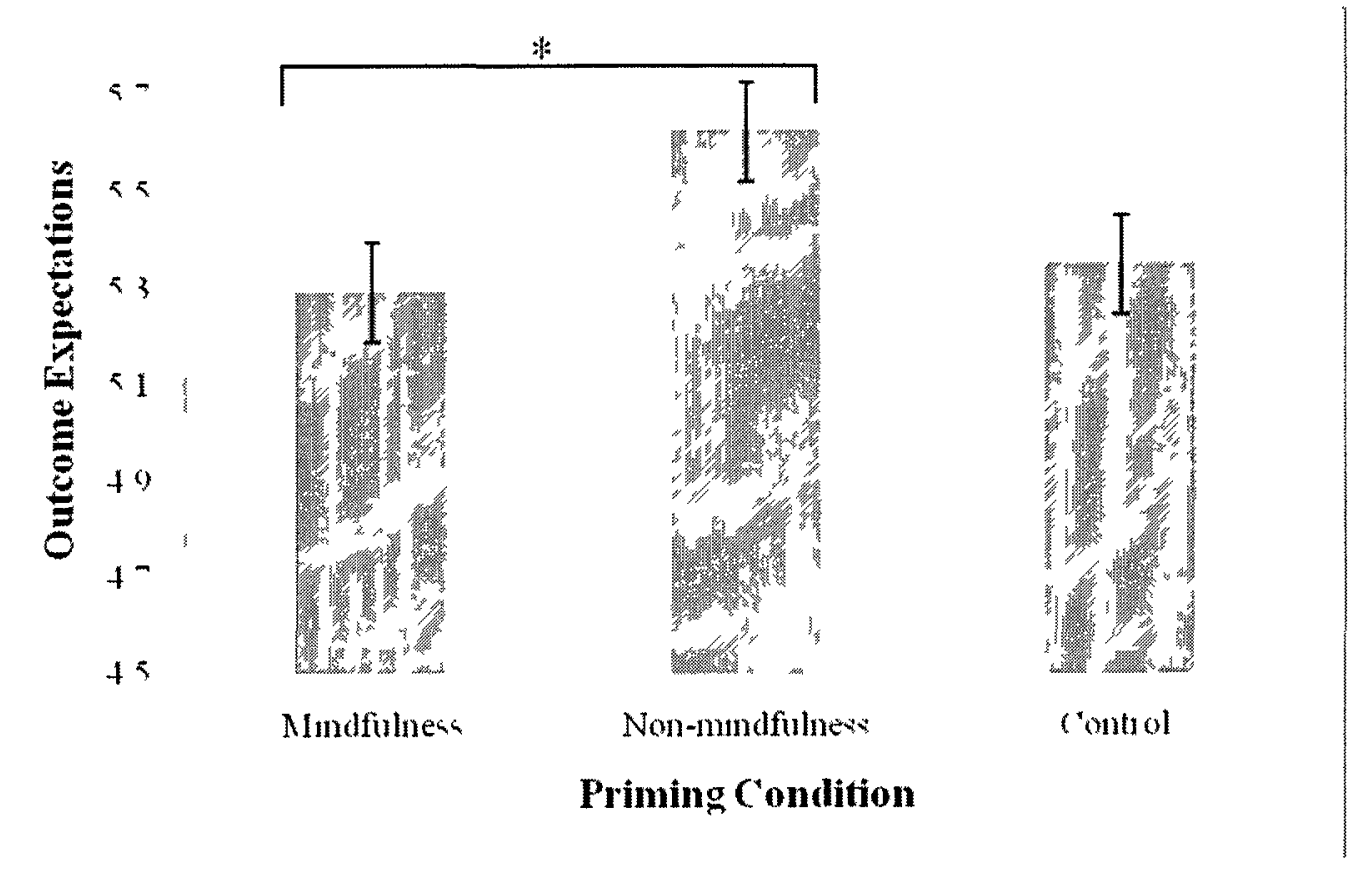

Figure 9 Mean $( \pm \mathrm{SE})$ outcome expectations as a function of priming condition. $* p<.05$

Moderation analysis It was also of interest to investigate whether trait mindfulness was related to the effectiveness of the priming manipulation, as measured by individuals' appraisals of stressful events. This exploratory hypothesis was analyzed with moderated regressions, in which priming condition and standardized trait mindfulness variables were entered in the first step of the analysis, and the interaction terms between trait mindfulness and priming condition was entered on the second step. Given that priming mindfulness only marginally influenced threat appraisals and outcome expectations as discussed earlier, only these appraisal measures were examined.

Main effects were evident for the impact of trait mindfulness, $\beta=-.30, t=-4.51, p$ $<.001$, and priming mindfulness, $\beta=-.11, t=-2.45, p=.015$, on threat appraisals, but trait mindfulness did not influence priming mindfulness, $t=.94, n s$ (Table 5 ). Trait mindfulness was related to outcome expectations, $\beta=-.32, t=-6.00, p<.001$, but both 
the main effect of priming mindfulness, $t=-1.67, n s$, and the interaction between trait and primed mindfulness, $t=1.14, n s$, were nonsignificant (Table 6).

Table 5. Hierarchical regression assessing the influence of trait mindfulness on the effectiveness of priming mindfulness as a function of threat appraisals.

\begin{tabular}{lccc}
\cline { 2 - 4 } & \multicolumn{3}{c}{ Threat appraisals } \\
& $\beta$ & $S E$ & $R_{\text {cha }}^{2}$ \\
\hline Trait mindfulness & $-.30^{* * *}$ & .07 & $.08^{* * *}$ \\
Priming mindfulness & $-.11^{*}$ & .05 & .00 \\
Trait mindfulness x priming mindfulness & .05 & .05 & .00 \\
\hline
\end{tabular}

${ }^{*} p<.05,{ }^{* * *} p<.001$

Table 6. Hierarchical regression assessing the influence of trait mindfulness on the effectiveness of priming mindfulness as a function of outcome expectations.

\begin{tabular}{lccc}
\cline { 2 - 4 } & \multicolumn{3}{c}{ Outcome expectations } \\
& $\beta$ & $S E$ & $R_{\text {cha }}^{2}$ \\
\hline Trait mindfulness & $-.32^{* * *}$ & .05 & $.11^{* * *}$ \\
Priming mindfulness & -.06 & .04 & .00 \\
Trait mindfulness $x$ priming mindfulness & .05 & .04 & .00 \\
\hline$* * * p<.001$ & &
\end{tabular}

Gender effects. To further explore factors that might affect the efficacy of the priming manipulation, a 3 (priming condition: mindfulness prime, non-mindfulness prime, or control) by 2 (gender: male or female) ANOVA was conducted using a Bonferroni adjusted alpha level of .013. In contrast to previous research that reported no 
priming differences between males and females (e.g., Herlitz, Nilsson, \& Backman, 1997), gender was found to influence mindfulness priming, $F(2,323)=5.77, p=.003$, $\eta_{\mathrm{p}}{ }^{2}=.04^{2}$. In an interaction comprising of effects for gender, $F(1,323)=4.72, p=.031$, $\eta_{\mathrm{p}}{ }^{2}=.01$, and priming condition, $F(2,323)=6.50, p=.002, \eta_{\mathrm{p}}{ }^{2}=.04$, females had higher threat appraisals in general, but males were more susceptible to the non-mindfulness priming, as measured by their increased threat appraisals in the non-mindfulness condition, relative to their appraisals in the mindfulness and control conditions. Specifically, males $(M=5.60, S D=1.04)$ had lower threat appraisals than females $(M=$ 6.13, $S D=1.06)$ in the mindfulness priming condition, $p=.039$. Males $(M=5.69, S D=$ .98) also had lower threat appraisals than females $(M=6.49, S D=1.24)$ in the control condition, $p<.001$. Although females $(M=6.34, S D=1.24)$ had slightly lower threat appraisals than males $(M=6.71, S D=1.33)$ in the non-mindfulness condition, the difference was negligible. Thus, threat appraisals for females were relatively consistent across conditions, whereas males appeared to be more negatively influenced by nonmindfulness priming (Figure 10).

The impact of priming mindfulness on distress appraisals was also marginally influenced by gender, $F(2,323)=3.68, p=.026, \eta_{\mathrm{p}}{ }^{2}=.02^{3}$, as the main effects of priming, $F(2,323)=5.24, p=.006, \eta_{\mathrm{p}}{ }^{2}=.03$, and gender, $F(1,323)=16.16, p<.001, \eta_{\mathrm{p}}{ }^{2}$ $=.05$, varied to some extent across males, females, and priming condition. However, the interaction effect was not statistically significant after using the Bonferroni adjusted

\footnotetext{
${ }^{2}$ Results, including an interaction effect between priming condition and gender, $F(2,197)=4.99, p=.008$, $\eta_{\mathrm{p}}{ }^{2}=.05$, were replicated with equal samples of males and female participants.

${ }^{3}$ An interaction effect between priming condition and gender, $F(2,197)=3.93, p=.021, \eta_{\mathrm{p}}{ }^{2}=.04$, was again replicated with equal samples of males and females.
} 
alpha level. Nevertheless, male distress appraisals $(M=5.45, S D=.80)$ were lower than female distress appraisals $(M=6.25, S D=1.07)$ in the mindfulness condition, $p=.002$. Similarly, male appraisals $(M=5.42, S D=1.15)$ were lower than female appraisals $(M=$ 6.34, $S D=1.26$ ) in the control condition, $p<.001$. Although the non-mindfulness priming did not increase female appraisals $(M=6.38, S D=1.18)$ relative to their appraisals in the other conditions, male distress appraisals $(M=6.36, S D=1.27)$ were higher after non-mindfulness priming (Figure 11). Essentially, males appeared to assess situations less threatening and distressing, except when primed with non-mindfulness. Conversely, females tended to have higher appraisals of both threat and distress, regardless of priming condition.

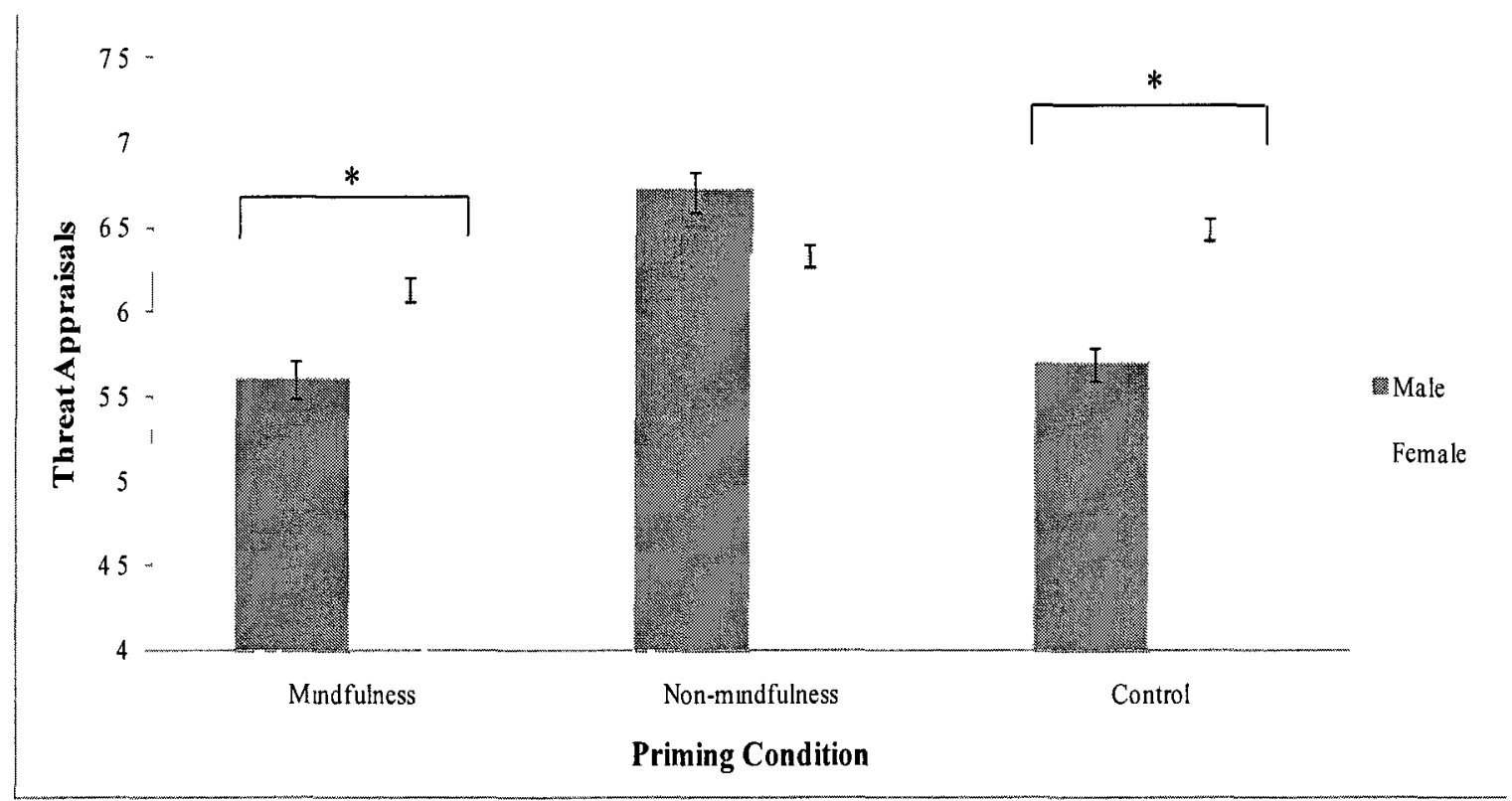

Figure 10. Effect of priming condition on threat appraisals, by gender. $p<.05$ 


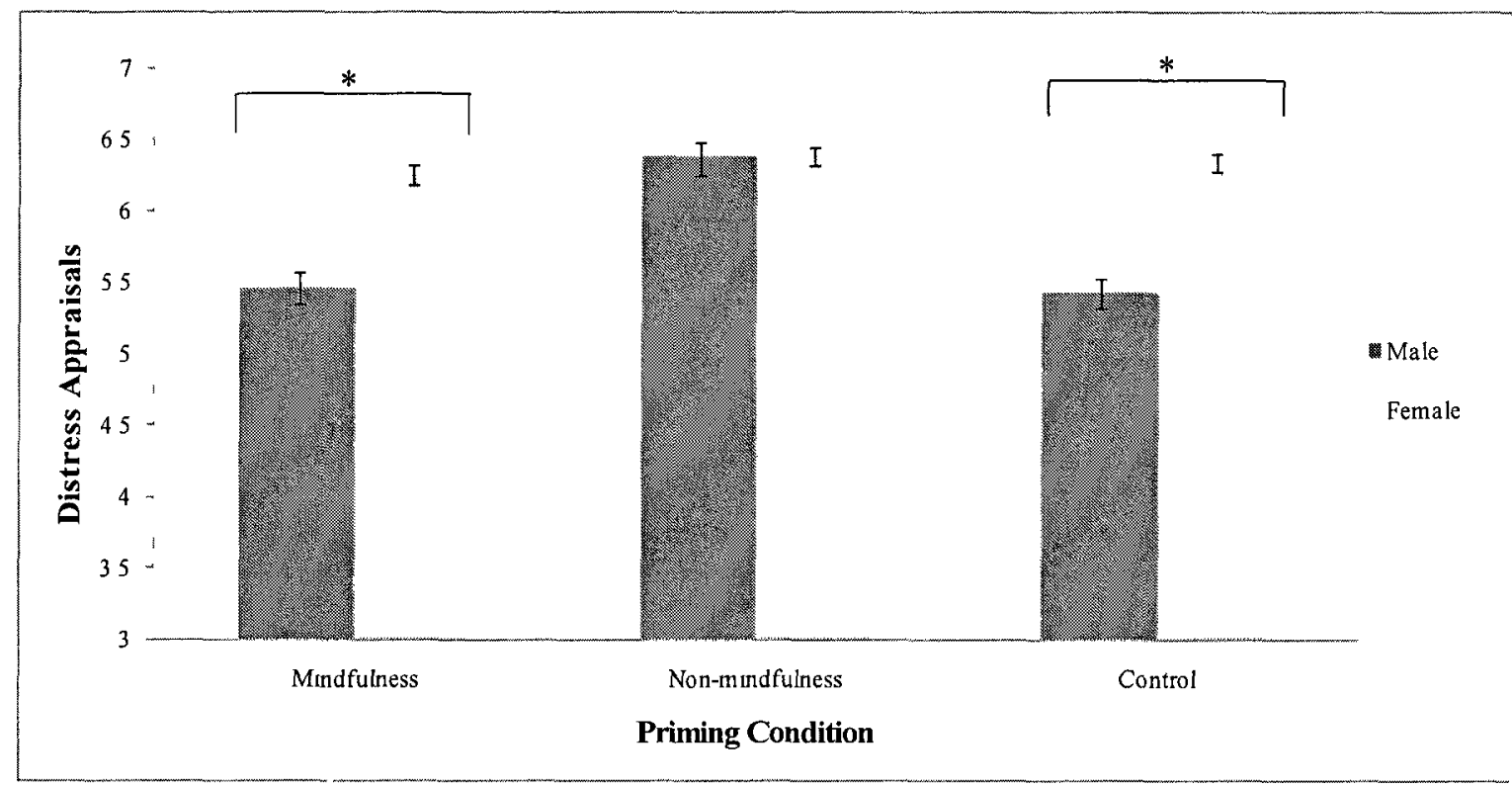

Figure 11. Effect of priming condition on distress appraisals, by gender.

$p<.05$

\section{Discussion}

The priming manipulations only marginally influenced some of the appraisal measures sampled, and even those effects were very small. Before gender was accounted for, only threat appraisals and outcome expectations were influenced by the priming manipulations, and these effects were statistically marginal. The effect sizes observed were, in fact, comparable to those reported using other brief mindfulness induction procedures (e.g., Zeidan et al., 2010). In contrast to the effect of priming mindfulness, priming mindlessness impacted appraisals. It seems that although exacerbating a situation can easily be provoked through priming mindlessness, improving appraisals may require more thorough mindfulness practice. Clearly, the present findings did not 
support the efficacy of priming mindfulness, although it is premature to dismiss the possibility that alternative brief procedures that include priming would be ineffective.

Priming non-mindfulness not only was found to affect appraisals more than priming mindfulness, but this effect varied by gender. Males were more negatively influenced by the non-mindfulness priming than females, and rated situations in the mindfulness and control situations similarly. It appears that while stimulating mindlessness worsens appraisals for men, priming mindfulness does little to improve their appraisals. Women's responses to the priming manipulations differed from men's reactions in that women not only appraised situations more negatively in general, but were also less negatively influenced by non-mindfulness priming. Essentially, in the control condition, in which neither mindfulness nor non-mindfulness words were presented, males rated situations as benignly as they did in the mindfulness condition. Conversely, females appraised situations as negatively as they did in the non-mindfulness condition. This may not only reflect a more negative appraisal style among women in general, but also a male receptivity to pessimism through a priming method.

To our knowledge, little previous research has focused on gender differences with respect to mindfulness; when gender has been controlled for, differences between males and females are often not found (e.g., Brown et al., 2009; Kabat-Zinn, Lipworth, \& Burney, 1985; MacKillop \& Anderson, 2007), especially in psychosocial research that excludes physiological measures. Priming differences between men and women have often concerned different reactions to priming feminine or masculine concepts (e.g., Masaki \& Kunihiro, 2009; Ortner \& Sieverding, 2008; Robers \& Gettman, 2004); when primes are gender-neutral, gender differences are frequently not reported (e.g., Collins et 
al., 2009; Radel et al., 2009), or men and women respond similarly (Ray, Bates, \& Bly, 2004). However, men and women process semantic information differently (Keillor, 1999; van Dyke, 2007), and women have been found to report higher depressive symptoms and levels of distress compared to men (Carlson, Ursuliak, Goodey, Angen, \& Speca, 2001; Pearson, Watkins, Mullan, \& Moberly, 2010). These differences may help to explain the observed differences between males and females in the priming conditions, though further research is required to clarify gender differences in mindfulness inductions. Gender differences may be necessary to examine in future research on the applications of trait mindfulness, even if males and females report similar levels of trait mindfulness.

\section{General Discussion}

Dispositional mindfulness has been associated with reduced feelings of distress and increased well being (Baer, Smith, Hopkins, Krietemeyer, \& Toney, 2006; Brown \& Ryan, 2003), and mindfulness training has been shown to elicit similar effects (Anderson et al., 2007; Ditto, Eclache, \& Goldman, 2006; Greeson, 2009; Speca et al., 2000; Williams, 2006). However, evidence of the specific processes through which mindfulness leads to well being has been limited. For instance, attempts to discover variables that mediate the relationship between mindfulness and positive changes have often been inconclusive or revealed only minor effects (Carmody, Baer, Lykins, \& Olendzki, 2009). Furthermore, few studies have examined how mindfulness comes to attenuate perceptions of threat and negative affect, and more research is needed to clarify the relation between mindfulness and appraisals, especially across different stressful situations (Arch \& Craske, 2006; Weinstein et al., 2009). Similarly, although it has been 
speculated that mindfulness improves coping (Baer et al., 2006; Shapiro, Brown, \& Biegel, 2007; Sugiura, 2004), the influence of mindfulness on coping methods has not been systematically investigated. The present research was designed to address these gaps and elucidate upon how trait and state mindfulness lead to well being by examining relationships between mindfulness, appraisals, and coping methods across a range of common stressful situations.

Appraisals of stressors are critical in leading to effective coping responses and improved health outcomes (Anisman et al., 2008; Carver \& Scheier, 1994; Lazarus \& Folkman, 1984). Since mindfulness improves perceptions of stressors by encouraging benign appraisals and receptivity to uncomfortable situations (Baer et al., 2006; Segal et al., 2002), mindfulness was predicted to be negatively associated with depressive symptoms, and this relationship was expected to be mediated through indirect effects of appraisal and coping processes.

Several controlled experiments revealed that mindfulness reduced depression (e.g., Hargus et al., 2010; Teasdale et al., 2000; Teasdale et al., 2002; Williams, Duggan, Crane, \& Fennell, 2006), and the present findings raise the possibility that the negative relationship between mindfulness and depression was mediated by appraisals of threat, distress, and pessimistic outcome expectations, as well as coping methods endorsed. By incorporating the role of mindfulness in traditional appraisal and coping models (e.g., Lazarus \& Folkman, 1984), these findings help to bridge mindfulness and cognitive appraisal research, and demonstrate the central role of appraisals in mindfulness processes. 
The results of the present study differed from previous research (i.e., Weinstein et al., 2009) as higher levels of avoidant coping, rather than lower levels of avoidant coping, were found to mediate the relationship between mindfulness and depression. The reason for this discrepancy may be related to the types of stressful situations presented in these studies. Whereas Weinstein et al. (2009) presented a controllable stressor (i.e., exam stress) that favoured problem-focused coping, the present study investigated the recent coping styles that individuals reported employing. Although often considered dysfunctional, avoidant coping can be used adaptively in situations (Newth \& DeLongis, 2004; Suls \& Fletcher, 1985) as participants may have been using avoidance to alleviate distress from unrelenting stressors or to deal with the implausibility of positive outcomes. In the present study, higher levels of problem-focused coping and lower levels of emotion-focused also mediated this relationship. These findings were, indeed, in line with earlier research suggesting that, in general, problem-focused coping may by associated with fewer depressive symptoms and more preferable outcomes than emotionfocused coping (Matheson \& Anisman, 2003).

It has been reported that mindfulness is associated with more approach-based coping (Weinstein et al., 2009), creative problem solving (Langer, 1989), and increased persistence during challenging tasks (Evans et al., 2009), all of which are were expected to relate to increased problem-focused coping. The present study indicated that although mindful individuals did not use higher levels of traditionally preferable coping methods (i.e., problem-focused coping), these individuals used fewer emotion-focused methods. This finding corresponds with frequent reports that while depressed individuals predominantly use emotion-focused coping, they do not necessarily exhibit lower levels 
of problem focused coping (Matheson \& Anisman, 2003). In effect, depressed individuals might not be less amenable to using problem focused methods, but proportionately, their use of emotion-focused is greater than that evident in those who are not depressed.

As expected, the relations between distress appraisals and both problem-focused and avoidant coping styles were moderated by mindfulness. When individuals with low distress appraisals were also high in trait mindfulness, they reported higher levels of problem-focused and avoidant coping, yet when individuals had high distress appraisals, mindfulness did not differentiate coping levels. Thus, although trait mindfulness does not generally relate to greater use of problem-focused or avoidant coping, it was associated with greater use of these coping styles among individuals with low distress appraisals. Together with earlier research (Weinstein et al., 2009), these results suggest that mindful individuals may very well be more likely to appraise events benignly compared to nonmindful individuals. This dispositional association between appraisals and mindfulness may help to account for the interaction of these factors in predicting coping levels.

In addition to the interaction between trait mindfulness and appraisals in relation to coping styles, it was considered that the effects of both problem-focused and avoidant coping in shaping distress appraisals (i.e., the tendency for one's general coping styles to predict their appraisals of stressful events) were moderated by trait mindfulness. In fact, it was observed that individuals who were high in trait mindfulness as well as problemfocused or avoidant coping appraised situations as relatively non-distressing, whereas mindfulness did not moderate distress appraisals among individuals low in each coping style. In effect, mindfulness is more closely tied to reduced perceptions of distress when 
individuals are already high in problem-focused and avoidant coping. Thus, the salience of mindfulness is more apparent when individuals are already low in distress appraisals, and high in problem-focused and avoidant coping. These findings correspond with previous literature showing that mindfulness predicts lower stress responses as measured by psychosocial (Baer et al., 2006; Weinstein et al., 2009) and physiological (Brown, Ryan, Creswell, \& Niemiec, 2008; Ditto, Eclache, \& Goldman, 2006) responses. They also supplement previous coping research by adding another factor (i.e., mindfulness) that moderates the effectiveness of coping methods.

Unlike the strong relations between trait mindfulness and appraisals, a single priming session was found to have less noticeable effects in this regard. Despite evidence that shorter treatment programs are equally effective in teaching individuals mindfulness and reducing symptomatology (Astin, 1997; Carmody \& Baer, 2009), priming mindfulness was not efficacious in the present study. This may be due to the non-traditional method of inducing mindfulness through a priming exercise, since priming represents an involuntary phenomenon, in direct contrast to the concepts of mindfulness that emphasize the importance of consciously directed attention. Thus, although it may still be advantageous to explore the potential effectiveness of encouraging mindfulness in formats other than traditional, mediation-based practices, it may be useful to induce mindfulness using methods that are consistent with its awareness-based approach.

While priming mindfulness did not have a significant effect on appraisals of stressful events, priming non-mindfulness impacted appraisals among males. It appeared that men were more negatively affected by the non-mindfulness priming than women, 
and women were found to have more threatening and distressing appraisals across conditions. Gender differences have been systematically researched in regard to stress and coping measures (e.g., Carver et al., 1989; Matheson \& Anisman, 2003), but very little research has focused on gender differences concerning mindfulness. In fact, many mindfulness studies have not even controlled for potential gender effects. The results of the present study underscores the need for research examining differences in how men and women apply mindfulness to appraisals, even if their levels of trait mindfulness are similar, since it is possible that the pathways through which mindfulness improves health differ by gender.

\section{Limitations and Conclusion}

Several limitations were present in the current research. First, Study 1 exclusively involved correlational data, and causal relationships can therefore not be drawn between trait mindfulness, appraisals, coping, and depressive measures. Next, as alluded to earlier, the priming manipulations in Study 2 were cursory and do not conform to traditional awareness-based methods of encouraging mindfulness. Priming is an automatic process, since individuals are often not aware that they are experiencing priming, as was the case in the presented study. This directly contrasts with traditional mindfulness training in which individuals develop skills through slow, deliberate practice. We acknowledge that the present research does not in any way represent a mindfulness treatment program, and that priming mindfulness is, at best, a short-term method of inducing a mindful state, rather than teaching individuals enduring mindfulness skills. 
The words used in the mindfulness and non-mindfulness conditions may also not ideally represent mindfulness and mindlessness concepts. For example, although "rushed" and "concerned" were priming words for the non-mindfulness condition, an individual could respond mindfully while feeling rushed or concerned, since mindfulness practice is not contingent on calm or comfortable circumstances (Kabat-Zinn, 1990). Although other terms could arguably better represent mindfulness and non-mindfulness concepts, these priming words were chosen because they fit the vocabulary of participants and represent mindful and mindless states in a simple, straightforward fashion that suit the design of the priming exercise.

Additionally, the efficacy of priming mindfulness was measured by participants' appraisals of stressful events, rather than re-assessing mindfulness levels using a validated scale. Since participants had already completed the MAAS (Brown \& Ryan, 2003), it was not desirable to re-assess mindfulness levels, in order to prevent participant fatigue and effects related to demand characteristics. It is hence possible that priming mindfulness was effective, but that the priming had no impact on appraisals of situations.

Although both Study 1 and Study 2 were designed to reflect broad differences in appraisals and coping styles by presenting a variety of appraisals, coping methods, and common stressful situations, all participants were university students who might not be reflective of the general population. It is also notable that both studies used self-report measures, and participants' assessments of mindfulness, well being, appraisals, and coping use may not be accurate, as socially desirable responses and lack of selfawareness may have influenced results. 
Furthermore, nearly all reported effect sizes for both trait and state mindfulness were very small. While these effect sizes were comparable to those reported in other similar studies (e.g., Weinstein et al., 2009; Zeidan et al., 2010), the extent of the variance accounted for points to the limited impact of mindfulness priming and trait mindfulness. Although we believe that measures of mindfulness augment appraisal and coping models of stress, it is worth noting that relationships between appraisals, coping, and depression were strong before accounting for effects of mindfulness. Indeed, the effects of mindfulness, while unique and theoretically meaningful, represent a small piece of the psychosocial stress model.

Finally, even though the MAAS (Brown \& Ryan, 2003) has been thoroughly validated as a measure of trait mindfulness (Brown \& Ryan, 2007), it only taps into the attentional control component of mindfulness. Other facts of mindfulness (e.g., acceptance, self-compassion, etc.) may relate to appraisal, coping, or stressor responses differently, and this research is thus limited to the effects of the awareness dimension alone. It would be of obvious benefit to include the use of an additional (or alternative) index of trait mindfulness (e.g., Five Facet Mindfulness Questionnaire; Baer et al., 2006) to assess the relation between this variable and appraisal, coping and depression.

Despite its limits, the present research supplemented traditional appraisal and coping models of stress with new mindfulness theories to help explain the broad-reaching benefits of mindfulness. Several interesting findings, including the ways in which mindfulness and depression are mediated, and the moderating role of mindfulness in appraisal and coping models, were illuminated. 
The limits of mindfulness were also displayed through the lack of a priming effect. It would be useful to examine more thorough mindfulness priming inductions, including use of more visceral priming manipulations, although reducing the time required to gain a mindful perspective would undoubtedly increase the applications of mindfulness. 


\section{References}

Abramson, L. Y., Metalsky, G. I., \& Alloy, L. B. (1989). Hopelessness depression: a theory-based subtype of depression. Psychological Review, 96(2), 358-372.

Anderson, N.D., Lau, M.A., Segal, Z.V., \& Bishop, S. R. (2007). Mechanisms of mindfulness: attentional control. Clinical Psychology and Psychotherapy, 14, 449-463. doi: $10.1002 / \mathrm{cpp} .544$

Anisman, H., Merali, Z., \& Stead, J. D. (2008). Experiential and genetic contributions to depressive- and anxiety-like disorders: Clinical and experimental studies.

Neuroscience and Biobehavioral Reviews, 32, 1185-1206. doi:

10.1016/j.neubiorev.2008.03.001

Anisman, H., \& Zacharko, R. M. (1982). Depression: The predisposing influence of stress. Behavioural and Brain Science, 5, 89-137. doi:

$10.1017 / \mathrm{S} 0140525 \mathrm{X} 00010633$

Arch, J. J., \& Craske, M. G. (2006). Mechanisms of mindfulness: Emotion regulation following a focused breathing induction. Behaviour Research and Therapy, 44, 1849-1858. doi: 10.1016/j.brat.2005.12.007

Astin, J. (1997). Stress reduction through mindfulness meditation: Effects on psychological symptomatology, sense of control, and spiritual experiences. Psychotherapy and Psychosomatics, 66, 97-106.

Baer, R. A., Smith, G. T., Hopkins, J., Krietemeyer, J., \& Toney, L. (2006). Using selfreport assessment methods to explore facets of mindfulness. Assessment, 11, 191206. doi: $10.1177 / 1073191105283504$

Bargh, J. A., Chen, M., \& Burrows, L. (1996). Automaticity of social behaviour: Direct 
effects of trait construct and stereotype activation on action. Journal of Personality and Social Psychology, 71(2), 230-244.

Bargiel-Matusiewicz, K., Trzcieniecka-Green, A., \& Kielan, K. (2005). Cognitive appraisal and strategies of coping applied in an exam situation. Archives of Psychiatry and Psychotherapy, 7(4), 33-38.

Baron, R.M., \& Kenny, D.A. (1986). The moderator-mediator variable distinction in social psychological research: Conceptual, strategic, and statistical considerations. Journal of Personality and Social Psychology, 51, 1173-1182. doi: 10.1037/00223514.51.6.1173.

Beck, A. T., Rush, A., Shaw, B., \& Emery, G. (1979). Cognitive therapy of depression. New York, NY: Guilford Press.

Beck, A. T., Ward, C., Mendelson, M., Mock, J., \& Erbaugh, J. (1961). An inventory for measuring depression. Archives of General Psychiatry, 4, 561-569.

Bogels, S. M., \& Mansell, W. (2004). Attention processes in the maintenance and treatment of social phobia: Hypervigilance, avoidance and self-focused attention. Clinical Psychology Review, 24, 827-856. doi: 10.1016/j.cpr.2004.06.005

Brosshot, J. F., Gerin, W., \& Thayer, J. F. (2006). The perseverative cognition hypothesis: A review of worry, prolonged stress-related physiological activation, and health. Journal of Psychometric Research, 60, 113-124. doi: 10.1016/j.jpsychores.2005.06.074

Brosschot, J. F., Pieper, S., \& Thayer, J. F. (2005). Expanding stress theory: Prolonged activation and perseverative cognition. Psychoendocrinology, 30, 1043-1049. doi: 10.1016/j.psyneuen.2005.04.008 
Brown, K.W., \& Ryan, R. (2003). The benefits of being present: Mindfulness and its role in psychological well-being. Journal of Personality and Social Psychology, 84, 822-848. doi: 10.1037/0022-3514.84.4.822

Brown, K. W., Kasser, T., Ryan, R. M., Linley, P. A., \& Orzech, K. (2009). When what one has is enough: mindfulness, financial desire discrepancy, and subjective wellbeing. Journal of Research in Personality, 43, 727-736. doi:

10.1016/j.jrp.2009.07.002

Brown, K. W., Ryan, R. M., \& Creswell, J. D. (2007). Mindfulness: Theoretical foundations and evidence for its salutary effects. Psychological Inquiry, 18(4), 211-237.

Brown, K. W., Ryan, R. M., Creswell, J. D., \& Niemiec, C. P. (2008). Beyond me: mindful responses to social threat. In H. A. Wayment \& J. J. Bauer (Eds.), Transcending self-interest: Psychological explorations of the quiet ego (pp. 7584). Washington, DC: American Psychological Association.

Carmody, J., \& Baer, R. A. (2008). Relationships between mindfulness practice and levels of mindfulness, medical and psychological symptoms and well-being in a mindfulness-based stress reduction program. Journal of Behavioral Medicine, 31, 23-33. doi: 10.1007/s10865-007-9130-7

Carmody, J., \& Baer, R. A. (2009). How long does a mindfulness-based stress reduction program need to be? A review of class contact hours and effect sizes for psychological distress. Journal of Clinical Psychology, 65, 627-638. doi: $10.1002 /$ cdlp.2055 
Carmody, J., Baer, R. A., Lykins, E. L. B., \& Olendzki, N. (2009). An empirical study of the mechanisms of mindfulness in a mindfulness-based stress reduction program. Journal of Clinical Psychology, 65, 613-626. doi: 10.1002/jclp.20579

Carson, J. W., Carson, K. M., Gil, K. M., \& Baucom, D. H. (2007). Self-expansion as a mediator of relationship improvements in a mindfulness intervention. Journal of Marital and Family Therapy, 33(4), 517-528.

Carver, C. S. (2009). Threat sensitivity, incentive sensitivity, and the experience of relief. Journal of Personlity, 77, 125-138. doi: 10.1111/j.1467-6494.2008.00540.x

Carver, C. S., \& Scheier, M. F. (1994). Situational coping and coping dispositions in a stressful transaction. Journal of Personality and Social Psychology, 66(1), 184195.

Carver, C. S., Scheier, M. F., \& Weintraub, J. K. (1989). Assessing coping strategies: A theoretically based approach. Journal of Personality and Social Psychology, 56, 267-283. doi:10.1037/0022-3514.56.2.267

Clarke, D., \& Goosen, T. (2009). The mediating effects of coping strategies in the relationship between automatic negative thoughts and depression in a clinical sample of diabetes patients. Personality and Individual Differences, 46, 460-464. doi: 10.1016/j.paid.2008.11.014

Chiesa, A., \& Serretti, A. (2009). Mindfulness-based stress reduction for stress management in healthy people: A review and meta-analysis. The Journal of Alternative and Complementary Medicine, 15, 593-600. doi: 10.1089/acm.2008.0495 
Christopher, M. S., Charoensuk, S., Gilbert, B. D., Neary, T. J., \& Pearce, K. L. (2009). Mindfulness in thailand and the united states: A case of apples versus oranges? Journal of Clinical Psychology, 65, 590-612. doi: 10.1002/jclp.20580

Cohen, S., \& Williamson, G. M. (1991). Stress and infectious disease in humans. Psychological Bulletin, 109(1), 5-24.

Collins, S. E., Chawla, N., Hsu, S. H., Grow, J., Otto, J. M., \& Marlatt, G. A. (2009). Language-based measures of mindfulness: Initial validity and clinical utility. Psychology of Addictive Behaviors, 23, 743-749. doi: 10.1037/a0017579

Corcoran, K. M., \& Woody, S. R. (2009). Effects of suppression and appraisals on thought frequency and distress. Behaviour Research and Therapy, 47, 1024-1031. doi: $10.1016 / \mathrm{j} / \mathrm{brat} / 2009.07 .023$

Cordon, S. L., Brown, K. W., \& Gibson, P. R. (2009). The role of mindfulness-based stress reduction in perceived stress: Preliminary evidence for the moderating role of attachment style. Journal of Cognitive Psychotherapy: An International Quarterly, 23, 258-269. doi: 10.1891/0889-8391.23.3.258

Davis, H. A., Distefano, C., \& Schutz, P. A. (2008). Identifying patterns of appraising tests in first-year college students: Implications for anxiety and emotion regulation during test taking. Journal of Educational Psychology, 100, 942-960. doi: $10.1037 / \mathrm{a} 0013096$

Diener, E., Emmons, R., Larsen, R., \& Griffin, S. (1985). The satisfaction with life scale. Journal of Personality Assessment, 49, 71-75. doi: 10.1207/s15327752jpa4901_13. 
Ditto, B., Eclache, M., \& Goldman, N. (2006). Short-term autonomic and cardiovascular effects of mindfulness body scan meditation. Annals of Behavioral Medicine, 32, 227-234. doi: 10.1207/s15324796abm3203_9

Djikic, M., Langer, E. J., \& Stapleton, S. F. (2008). Reducing stereotyping through mindfulness: Effects on automatic stereotype-activated behaviours. Journal of Adult Development, 15, 106-111. doi: 10.1007/s10804-008-9040-0.

Eifert, G. H., \& Forsyth, J. P. (2005). Acceptance and commitment therapy for anxiety disorders: A practioner's treatment guide to using mindfulness, acceptance, and values-based behaviour change strategies. Oakland, CA: New Harbinger Publications.

Elkin, I., Shea, T., Watkins, J. T., Imber, S. D., Slotsky, S. M., Collins, J. F.,..,Parloff, M. B. (1989). National Institute of Mental Health treatment of depression collaborative research program. Archives of General Psychiatry, 46, 971-982.

Evans, D. R., Baer, R. A., \& Segerstrom, S. C. (2009). The effects of mindfulness and self-consciousness on persistence. Personality and Individual Differences, 47, 379-382. doi: 10.1016.j.paid.2009.03.026

Felton, B. J., Revenson, T. A., \& Hinrichsen, G. A. (1984). Stress and coping in the explanation of psychological adjustment among chronically ill adults. Social Science \& Medicine, 18(10), 889-898.

Folkman, S., \& Lazarus, R. S. (1988). Coping as a mediator of emotion. Journal of Personality and Social Psychology, 54(3), 466-475.

Folkman, S. Lazarus, R. S., Dunkel-Schetter, C., DeLongis, A., \& Gruen, R. J. (1986). Dynamics of a stressful encounter: Cognitive appraisal, coping, and encounter 
outcomes. Journal of Personality and Social Psychology, 50, 992-1003. doi: $10.1037 / 0022-3514.50 .5 .992$

Galosy, R. A., \& Gaebelein, C. J. (1977). Cardiovascular adaptation to environmental stress: Its role in the development of hypertension, responsible mechanisms, and hypotheses. Biobehavioral Reviews, 1, 165-175.

Greeson, J. M. (2009). Mindfulness research update: 2008. Complementary Health Practice Review, 14, 10-18. doi: 10.1177/1533210108329862

Gutman, D. A., \& Nemeroff, C. B. (2011). Stress and depression. In R. J. Contrada \& A. Baum (Eds.), The Handbook of Stress Science: Biology, Psychology, and Health (pp. 345-357). New York, NY: Springer Publishing Co.

Hagtvet, K., \& Zou, L. (2000). Conceptual and empirical components of an internal domain study: An illustration in terms of the Achievement Motives Scale. Scandinavian Journal of Educational Research, 44, 49-78. doi: $10.1080 / 713696664$

Hammen, C. (2005). Stress and depression. Annual Review of Clinical Psychology, 1, 293-319. doi: 10.1146/annurev.clinpsy.1.102803.143938

Hargus, E., Crane, C., Barnhofer, T., \& Williams, J. M. G. (2010). Effects of mindfulness on meta-awareness and specificity of describing prodromal symptoms in suicidal depression. Emotion, 20, 34-42. doi: 10.1037/a0016825

Herlitz, A., Nilsoon, L. G., \& Backman, L. (1997). Gender differences in episodic memory. Journal of Memory and Cognition, 25, 801-811. doi: 10.1037/08944105.13.4.590

Hofmann, S. G., Sawyer, A. T., Witt, A. A., \& Oh, D. (2010). The effect of mindfulness- 
based therapy on anxiety and depression: A meta-analytic review. Journal of Consulting and Clinical Psychology, 78, 169-183. doi: 10.1037/a0018555

Holahan, C. J., \& Moos, R. H. (1985). Life stress and health: Personality, coping, and family support in stress resistance. Journal of Personality and Social Psychology, 49(3), 739-747.

Howerton, A. \& Van Gundy, K. (2009). Sex differences in coping styles and implications for depressed mood. International Journal of Stress Management, 16, 333-350. doi: $10.1037 / \mathrm{a} 0016843$

Jha, A. P., Krompinger, J., \& Baime, M. J. (2007). Mindfulness training modifies subsystems of attention. Cognitive, Affective \& Behavioral Neuroscience, 72, 109-119. doi: 10.3758/CABN.7.2.109

Jimenez, S. S., Niles, B. L., \& Park, C. L. (2010). A mindfulness model of affect regulation and depressive symptoms: Positive emotions, mood regulation expectancies, and self-acceptance as regulatory mechanisms. Personality and Individual Differences, 49, 645-650. doi: 10.1016/j.paid.2010.05.041

Kabat-Zinn, J. (1990). Full catastrophe living: Using the wisdom of your body and mind to face stress, pain, and illness. New York, NY: Delacourt.

Kabat-Zinn, J. (1994). Wherever you go there you are: Mindfulness meditation in everyday life. New York, NY: Hyperion.

Kabat-Zinn, J., Lipworth, L., \& Burney, R. (1985). The clinical use of mindfulness meditation for the self-regulation of chronic pain. Journal of Behavioral Medicine, 8(2), 163-190. 
Kashdan, T. B., \& Kane, J. Q. (2011). Post-traumatic distress and the presence of posttraumatic growth and meaning in life: Experiential avoidance as a moderator. Personality and Individual Differences, 50, 84-89. doi:

$10.1016 /$ j.paid .2010 .08 .028

Keillor, J. M. (1999). On the locus of the bilateral lexicality priming effect (Doctoral dissertation). Retrieved from http:/uwspace.uwaterloo.ca/bitstream/10012/249/1/NQ30617

Kelly, O., Matheson, K., \& Anisman, H. (2003). The Appraisal of Ambiguous Situations Questionnaire. Unpublished manuscript, Department of Psychology, Carleton University, Ottawa, Canada.

Kelly, O., Matheson, K., Ravindran, A., Merali, Z., \& Anisman, H. (2007). Ruminative coping among patients with dysthymia before and after pharmacotherapy. Depression and Anxiety, 24, 233-243. doi: 10.1002/da.20236

Kenny, M. A., \& Williams, J. G. M. (2007). Treatment-resistant depressed patients show a good response to mindfulness-based cognitive therapy. Behaviour Research and Therapy, 45, 617-625. doi: 10.1016/j.brat.2006.04.008

Krackow, E., \& Rudolph, K. D. (2008). Life stress and the accuracy of cognitive appraisals in depressed youth. Journal of Clinical Child \& Adolescent Psychology, 37, 376-385. doi: 10.1080/15374410801955797

Kristeller, J. L., \& Hallett, B. (1999). Effects of a meditation-based intervention in the treatment of binge eating. Journal of Health Psychology, 4(3), 357-363.

Langer, E. (1989). Mindfulness. Cambridge, MA: Da Capo Press.

Lazarus, R. S., (1991). Emotion and adaptation. New York: Oxford University Press. In 
Pervin, L. A. (Ed.). Handbook of personality: Theory and Research (pp. 609637). New York: Guilford.

Lazarus, R. S., \& Folkman, S. (1984). Cognitive appraisals processes. In R. S. Lazarus \& S. Folkman (Eds.), Stress, Appraisal, and Coping (pp. 22-54). New York, NY: Springer.

Ledesma, D., \& Kumano, H. (2009). Mindfulness-based stress reduction and cancer: A meta-analysis. Psycho-Oncology, 18, 571-579. doi: 10.1002/pon.1400

MacKillop, J. \& Anderson, E. J. (2007). Further psychometric validation of the mindful attention awareness scale (MAAS). Journal of Psychopathology and Behavioral Assessment, 29, 289-293. doi: 10.1007/s10862-007-9045-1

Masaki, Y. \& Kunihiro, Y. (2009). The primal warrior: Outgroup threat priming enhances intergroup discrimination in men but not women. Journal of Experimental Social Psychology, 45, 271-274. doi: 10.1016/j.jesp.2008.08.018

Matheson K., \& Anisman H. (2003). Systems of coping associated with psychological distress: A profile perspective. Stress, 6, 223-234. doi:

$10.1080 / 10253890310001594487$

Matheson, K., \& Anisman, H. (2009). Anger and shame elicited by discrimination: Moderating role of coping on action endorsements and salivary cortisol. European Journal of Social Psychology, 39, 163-185. doi: 10.1002/ejsp.522

McEwen, B. S. (2003). Mood disorders and allostatic load. Society of Biological Psychiatry, 54, 200-207. doi: 10.1016/S0006-3223(03)00177-X

McHugh, L., Simpson, A., \& Reed, P. (2010). Mindfulness as a potential intervention for stimulus over-selectivity in older adults. Research in Developmental Disabilities, 
31, 178-184. doi: 10.1016/j.ridd.2009.08.009

Moore, S. D., \& Brody, L. R. (2009). Linguistic predictors of mindfulness in written selfdisclosure narratives. Journal of Language and Social Psychology, 28, 281-296. doi: $10.1177 / 0261927 \mathrm{X} 09335264$

Newth, S., \& DeLongis, A. (2004). Individual differences, mood, and coping with chronic pain in Rheumatoid Arthritis: A daily process analysis. Psychology \& Health, 19, 283-305. doi: 10.1080/0887044042000193451

Ng, W., \& Diener, E. (2009). Feeling bad? The "power" of positive thinking may not apply to everyone. Journal of Research in Personality, 43, 455-463. doi: 10.1016/j.jrp.2009.01.020

Nolen-Hoeksema, S., \& Morrow, J. (1993). Effects of rumination and distraction on naturally occurring depressed mood. Cognition and Emotion, 7, 561-570. doi: n/a.

Nolen-Hoeksema, S., Wisco, B., \& Lyubomirsky, S. (2008). Rethinking rumination. Perspectives on Psychological Science, 3, 400-424. doi: 10.1111/j.1745$6924.2008 .00088 . x$

Nowack, K. M. (1989). Coping style, cognitive hardiness, and health status. Journal of Behavioral Medicine, 12, 145-158. doi: 10.1007/BF00846548

O’Connor, K. M., Arnold, J. A., \& Maurizio, A. M. (2010). The prospect of negotiating: Stress, cognitive appraisal, and performance. Journal of Experimental Social Psychology, 46, 729-735. doi: 10.1016/j.jesp.2010.04.007

Ortner, Ortner, T.M. \& Sieverding, M. (2008). Where are the Gender Differences? Male Priming Boosts Spatial Skills in Women. Sex Roles, 59, 274-281. doi: 10.1007/s11199-008-9448-9 
Papageorgiou, C., \& Wells, A. (2000). Treatment of recurrent major depression with attention training. Cognitive and Behavioral Practice, 7, 407-413. doi: n/a.

Park, C. L., \& Adler, N. E. (2003). Coping style as a predictor of health and well-being across the first year of medical school. Health Psychology, 22, 627-631. doi: $10.1037 / 0278-6133.22 .6 .627$

Paykel, E. S. (1994). Life events, social support and depression. Acta Psychiatrica Scandinavica, 89, 50-58. doi: 10.1111/j.1600-0447.1991.tb05803.x

Paykel, E. S. (2003). Life events and affective disorders. Acta Psychiatrica Scandinavica, 108, 61-66. doi: 10.1034/j.1600-0447.108.s418.13.x

Paykel, E. S., \& Cooper, Z. (1992). Life events and social stress. In E. S. Paykel (Ed.), Handbook of Affective Disorders (pp. 149-170). New York, NY: Guilford.

Pearson, K. A., Watkins, E. R., Mullan, E. G., \& Moberly, N. J. (2010). Psychosocial correlates of depressive rumination. Behaviour Research and Therapy, 48, 784791. doi: $10.1016 /$ j.brat.2010.05.007

Pereira, D. B., Antoni, M. H., Danielson, A., Simon, T., Efantis-Potter, J., Carver, C. S.,...O'Sullivan, M. J. (2003). Life stress and cervical squamous intraepithelial lesions in women with human papillomavirus and human immunodeficiency virus. Psychosomatic Medicine, 65, 427-434. doi:

10.1097/01.PSY.0000041620.37866.89

Preacher, K. J., \& Hayes, A. F. (2004). SPSS and SAS procedures for estimating indirect effects in simple mediation models. Behavior Research Methods, Instruments, \& Computers, 36, 717-731. doi: 10.3758/BF03206553

Radel, R., Sarrazin, P., Legrain, P., \& Gobance, L. (2009). Subliminal priming of 
motivational orientation in educational settings: Effect on academic performance moderated by mindfulness. Journal of Research in Personality, 43, 695-698. doi: 10.1016/j.jrp.2009.02.011

Ray, S., Bates, M. E., \& Bly, B. M. (2004). Alcohol's dissociation of implicit and explicit memory processes: Implications of a parallel distributed processing model of semantic priming. Experimental and Clinical Psychopharmacology, 12, 118-125. doi: $10.1037 / 1064-1297.12 .2 .118$

Roberts, T.-A., \& Gettman, J. Y. (2004). Mere exposure: gender differences in the negative effects of priming a state of self-objectification. Sex Roles, 51, 17-27. doi: 10.1023/B:SERS.0000032306.20462.22

Roemer, L., Erisman, S. M., \& Orsillo, S. M. (2009). Mindfulness and acceptance-based treatments for anxiety disorders. In M. Antony \& M Stein (Eds.), Oxford Handbook of Anxiety and Related Disorders (pp. 476-487). Oxford, England: Oxford Library of Psychology.

Rozanski, A., Blumenthal, J. A., \& Kaplan, J. (1999). Impact of psychological factors on the pathogenesis of cardiovascular disease and implications for therapy. Circulation, 99, 2192-2216.

Sanders, W., \& Lam, D. (2010). Ruminative and mindful self-focused processing modes and their impact on problem solving in dysphoric individuals. Behaviour Research and Therapy, 48, 747-753. doi: 10.1016/j.brat.2010.04.007

Schutz, P. A., Benson, J., \& Decuir-Gunby, J. T. (2008). Approach/avoidance motives, test emotions, and emotional regulation related to testing. Anxiety, Stress, \& Coping, 2l, 263-281. doi: 10.1080/10615800701787672 
Segal, Z. V., Bieling, P., Young, T., MacQueen, G., Cooke, R., Martin, L., Bloch, R., \& Levitan, R. D. (2010). Antidepressant monotherapy vs sequential pharmacotherapy and mindfulness-based cognitive therapy, or placebo, for relapse prophylaxis in recurrent depression. Archives of General Psychiatry, $67(12), 256-1264$.

Segal, Z. V., Williams, J. M., \& Teasdale, J. D. (2002). Mindfulness-based cognitive therapy for depression: A new approach to preventing relapse. New York, NY: Guilford Press.

Shapiro, S. L., Brown, K. W., \& Biegel, G. M. (2007). Teaching self-care to caregivers: Effects of mindfulness-based stress reduction on the mental health of therapists in training. Training and Education in Professional Psychology, 1, 105-115. doi: $10.1037 / 1931-3918.1 .2 .105$

Shapiro, S. L., Carlson, L. E., Astin, J. A., \& Freedman, B. (2006). Mechanisms of Mindfulness. Journal of Clinical Psychology, 62, 373-386. doi: $10.1002 /$ jclp.20237

Smith, C. A. (1991). The self, appraisal and coping. In C. R. Snyder \& D. R. Forsyth (Eds), Handbook of Social and Clinical Psychology: The Health Perspective (pp. 116-137). Elmsford, NY: Pergamon Press.

Solomon, G. F., \& Amkraut, A. A. (1981). Psychoneuroendocrinological effects on the immune response. Annual Review of Microbiology, 35, 155-184. doi: 10.1146/annurev.mi.35.100181.001103 
Sorenson, M. K. (2009). Examining the role of mindfulness as a potential mediator of the relationship between gender role and disordered eating (Doctoral dissertation). Available from ProQuest Dissertations and Theses database.

Speca, M., Carlson, L. E., Goodey, E., \& Angen, M. (2000). A randomized, wait-list controlled clinical trial: The effect of a mindfulness meditation-based stress reduction program on mood and symptoms of stress in cancer outpatients. Psychosomatic Medicine, 62, 613-622. doi: n/a.

Stanton, A. L., Ganz, P. A., Rowland, J. H., Meyerowitz, B. E., Krupnick, J. L., \& Sears, S. R. (2005). Promoting adjustment after treatment for cancer. Cancer, 104, 26082613. doi: $10.1002 /$ cncr. 21246

Steer, R., Ball, R., Ranieri, W., \& Beck, A.T. (1999). Dimensions of the Beck Depression Inventory-II in clinically depressed outpatients. Journal of Clinical Psychology, 55, 117-128. doi: 10.1002/(SICI)1097-4679(199901)55:1

Sugiura, Y. (2004). Detached mindfulness and worry: A meta-cognitive analysis. Personality and Individual Differences, 37, 169-179. doi: $19.1016 /$ j.paid.2003.08.009

Suls, J., \& Fletcher, B. (1985). The relative efficacy of avoidant and non-avoidant coping strategies: A meta-analysis. Health Psychology, 4, 249-288. doi: 10.1037/02786133.4 .3 .249

Tabachnick, B., \& Fidell, L. (2007). Using multivariate statistics $\left(5^{\text {th }}\right.$ ed.). Boston, MA: Pearson.

Teasdale, J. D., Moore, R. G., Hayhurst, H., Pope, M., Williams, S., \& Segal, Z. V. (2002). Metacognitive awareness and prevention of relapse in depression: 
Empirical evidence. Journal of Consulting and Clinical Psychology, 70, 275-287. doi: $10.1037 / / 0022-006 X .70 .2 .275$

Teasdale, J. D., Segal, Z., \& Williams, J. M. G. (1995). How does cognitive therapy prevent depressive relapse and why should attentional control (mindfulness) training help? Behaviour Research and Therapy, 33, 25-39. doi: 10.1016/00057967(94)E0011-7

Teasdale, J. D., Segal, Z. V., Williams, J. M. G., Ridgeway, V. A., Soulsby, J. M., \& Lau, M. A. (2000). Prevention of relapse/recurrence in major depression by mindfulness-based cognitive therapy. Journal of Consulting and Clincal Psychology, 68, 615-623. doi: 10.1037//0022-006.68.4.615

Troy, A. S., Wilhelm, F. H., Shallcross, A. J., \& Mauss, I. B. (2010). Seeing the silver lining: Cognitive reappraisal ability moderates the relationship between stress and depressive symptoms. Emotion, 10, 1-13. doi: 10.1037/a0020262

van Dyke, S. (2007). Gender differences in lateralized semantic priming (Master's thesis). Wayne State University, Detroit, Michigan. UMI No. 1447091

Weinstein, N., Brown, K. W., \& Ryan, R. M. (2009). A multi-method examination of the effects of mindfulness on stress attribution, coping, and emotional well-being. Journal of Research in Personality, 43, 374-385. doi: 10.1016/j.jrp.2008.12.008

Wenk-Sormaz, H. (2005). Meditation can reduce habitual responding. Alternative Therapies in Health and Medicine, 11(2), 42-58. doi: n/a.

Wheeler, S. C., Morrison, K. R., DeMarree, K. G., \& Petty, R. E. (2008). Does selfconsciousness increase or decrease priming effects? It depends. Journal of Experimental Social Psychology, 44, 882-889. doi: 10.1016/j.jesp.2007.09.002 
Williams, J. M. G., Duggan, D. S., Crane, C. \& Fennell, M. J. V. (2006). Mindfulnessbased cognitive therapy for prevention of recurrence of suicidal behaviour. Journal of Clinical Psychology: in session, 1-10. doi: 10.1002/jclp.20223

Williams, K. (2006). Mindfulness-based stress reduction (MBSR) in a worksite wellness program. In R. A. Baer (Ed.), Mindfulness-based treatment approaches: Clinician's guide to evidence base and applications (pp. 361-376). San Diego, CA: Elsevier Academic Press.

Witkiewitz, K., \& Bowen, S. (2010). Depression, craving, and substance use following a randomized trial of mindfulness-based relapse prevention. Journal of Consulting and Clinical Psychology, 78, 362-374. doi: 10.1037/a0019172

Zeidan, F., Gordon, N.S., Merchant, J., \& Goolkasian, P. (2010). The effects of brief mindfulness meditation training on experimentally induced pain. The Journal of Pain, 11, 199-209. doi: 10.1089/acm.2009/0321 


\section{Appendix A: Study 1 Online/SONA Recruitment Notice}

\section{Electronic Sign-up System Information}

\section{Study Name: Self-Appraisals, Coping, and Well-Being}

Brief Abstract: This study examines how self-appraisals influence people's appraisals of different situations, and how these appraisals influence coping strategies and well-being.

Detailed Description: We are interested in exploring the relationship between personal characteristics (e.g., demographics, depressive symptoms, mindfulness), how individuals appraise a) themselves, and b) different types of situations, and the types of strategies individuals use for coping with stressful situations. We are further interested in examining how these variables are related to well-being. The session requires completion of a questionnaire package regarding personal characteristics, appraisals, the use of various types of coping strategies, and well-being. We will also ask you to write a short description of a stressful event you have recently experienced.

Duration: 1.5 hours

Credits: $1.5 \%$ increase 


\section{Appendix B: Informed Consent}

The purpose of an informed consent is to insure that you understand the purpose of the study and the nature of your involvement. The informed consent must provide sufficient information such that you have the opportunity to determine whether you wish to participate in the study.

\section{Present study: Self-Appraisals, Coping, and Well-Being}

Research personnel. The following people are involved in this research project, and may be contacted at any time if you have questions or concerns: Kelly-Lyn Christie (email:

klchrist@connect.carleton.ca, phone: 613-520-2600, ext. 6312), Valerie Repta (email: vrepta@connect.carleton.ca), Dr. Hymie Anisman (Faculty Sponsor, email:

hanisman@connect.carleton.ca), or Dr. Kimberly Matheson (email: kim matheson@carleton.ca). Should you have any ethical concerns about this research, please contact Dr. Monique Sénéchal, at : monique_senechal@carleton.ca (613-520-2600 ext.1155).

Purpose. The purpose of this study is to investigate the relationship between personal characteristics (e.g., demographics, depressive symptoms, mindfulness) and how individuals appraise themselves and different types of situations. We are interested in examining how these personal characteristics and appraisals influence the types of strategies people use when dealing with stressful situations, as well as how these variables predict well-being.

Task requirements. We are asking you to fill out a number of questionnaires regarding your background (e.g., demographics), personal characteristics (e.g., how you cope with things in your life), and how you feel about yourself (e.g., self-appraisals, well-being). We will also ask you to write a brief description of a stressful event you have experienced. The questionnaires will take about 90 minutes to complete. You will receive a $1.5 \%$ increase in your final grade of PSYC 1001, PSYC 1002, PSYC 2001 or PSYC 2002 for participating in this study. Testing will take place at Carleton University.

Potential risk/discomfort. There are no physical risks to participating in this study. Some individuals might feel uncomfortable when asked to recall stressful situations or to answer personal, sensitive questions about the coping strategies they use or feelings of depression they may have experienced. If you feel any discomfort or distress, you may choose not to answer specific questions, and you will not be penalized in any way if you do this. The debriefing form at the end of the study provides contact information for local support services that you may contact if you need or want help.

Anonymity/Confidentiality. The data collected in this experiment are strictly confidential. All data are coded such that your name is not associated with the responses you provide. Any identifying information associated with your code will be confined to a single page that will be separated from your questionnaire, and kept in a separate, secured file by the research investigators, who will keep this information confidential.

Right to withdraw. Your participation in this study is entirely voluntary. At any point during the study, you have the right to not complete certain questions, or to withdraw from the study without academic penalty.

Signatures

I have read the above form and understand the conditions of my participation. My participation in this study is voluntary, and I understand that if at any time I wish to leave the experiment, I 
may do so without having to give an explanation and with no penalty whatsoever. Furthermore, I am also aware that the data gathered in this study are confidential and anonymous with respect to my personal identity. My signature indicates that I agree to participate in this study.

Full Name (please print):

Participant Signature: Date:

Researcher Signature: Date: 


\section{Appendix C: Study 1 Questionnaires}

\section{Demographic Questionnaire}

Please fill out the following information about yourself and your background:

1. Age:

2. Gender (circle one): Male / Female

3. Marital Status (circle one):

Never Married / Married / Separated / Divorced / Widowed / Common-Law

(living together)

$\begin{array}{llllll}1 & 2 & 3 & 4 & 5 & 6\end{array}$

4. Ethnicity (select from a-h below):

a) Caucasian/European origin

b) African-Canadian/American

c) East Asian (Chinese, Japanese, Korean)

d) South Asian (Indian, Pakistani, Sri Lankan, etc.)

e) Middle Eastern

f) Native Canadian/American

g) Hispanic and South American Origin

h) Other or multi-ethnic origin

5. Are you currently a student? (Circle one)

YES NO 
a) If YES, what is your student status?

1. Full-time

2. Part-time

3. Special student

b) If YES, what is your major?

c) If YES, what is your current GPA?

6. What is the highest level of education you have completed? (please select one):

a) Elementary School

b) High School

c) College

d) University (undergraduate)

e) University (graduate)

7. Have you ever experienced depression or anxiety? (circle one)

YES NO

a) If YES, have you ever sought treatment (e.g., counselling) for these symptoms?

YES NO

b) Are you currently being treated for depression or anxiety? YES 
BDI

On this questionnaire are groups of statements. Please read the entire group of statements in each category. Then pick out ONE statement in that group which best describes the way you feel. Check off the number beside the statement you have chosen.

1. _ 0 - $=$ I do not feel sad

$1=$ I feel sad or blue

$2 \mathrm{a}=\mathrm{I}$ am blue or sad all of the time and I can't snap out of it

$2 b=I$ am so sad or unhappy that it is very painful

$3=$ I am so sad or unhappy that I can't stand it

2. $0=\mathrm{I}$ am not particularly pessimistic or discouraged about the future

$1=$ I feel discouraged about the future

$2 \mathrm{a}=\mathrm{I}$ feel I have nothing to look forward to

$2 b=$ I feel I won't every get over my troubles

$3=\mathrm{I}$ feel that the future is hopeless and things cannot improve

3. $0=$ I do not feel like a failure

$1=$ I feel I have failed more than the average person

$2 \mathrm{a}=\mathrm{I}$ feel I have accomplished very little that is worthwhile or that means anything

$2 b=$ As I look back on my life, all I can see is a lot of failures

$3=$ I feel I am a complete failure as a person

4. _ _ $0=$ I am not particularly dissatisfied

$\ldots$

$1 b=I$ don't enjoy things the way I used to

$2=$ I don't get satisfaction out of anything anymore 
$3=$ I am dissatisfied with everything

5. $\quad 0=$ I don't feel particularly guilty

_ $1=\mathrm{I}$ feel bad or unworthy a good part of the time

$2 \mathrm{a}=\mathrm{I}$ feel quite guilty

$2 b=I$ feel bad or unworthy practically of the time now

$3=\mathrm{I}$ feel as though I am very bad or worthless

6. ___ $0=$ I don't feel I am being punished

1 I I I have a feeling that something bad may happen to me

$2=\mathrm{I}$ feel I am being punished or will be punished

$3 \mathrm{a}=\mathrm{I}$ feel I deserve to be punished

$3 b=$ I want to be punished

7. $\_$_ $0=$ I don't feel disappointed in myself

$\ldots$

$\ldots$

$2=$ I am disgusted with myself

$3=$ I hate myself

8. _ 0 _ $\quad$ I do not feel I am any worse than anybody else

$1=\mathrm{I}$ am very critical of myself for my weaknesses or mistakes

$2 \mathrm{a}=$ I blame myself for everything that goes wrong

$2 \mathrm{~b}=\mathrm{I}$ feel I have many bad faults 
9. 0 _ 0 I don't have thoughts of harming myself

1 = I have thoughts of harming myself but I would not carry them out

$2 \mathrm{a}=\mathrm{I}$ feel I would be better off dead

$2 \mathrm{~b}=\mathrm{I}$ have definite plans about committing suicide

$2 c=$ I feel my family would be better off if I were dead

$3=$ I would kill myself if I could

10. $0=$ I don't cry any more than usual

$1=$ I cry more now than I used to

$2=$ I cry all the time now. I can't stop it.

$3=$ I used to be able to cry but now I can't cry at all even though I want to

11. $0=\mathrm{I}$ am no more irritated now than I ever am

1 - I get annoyed or irritated more easily than I used to

$2=$ I get irritated all the time

$3=$ I don't get irritated at all the things that used to irritate me.

12. $0=$ I have not lost interest in other people

$1=\mathrm{I}$ am less interested in other people than I used to be

2 _ 2 I have lost most of my interest in other people and I have little feeling for them

3 - I have lost all my interest in other people and don't care about them at all

13. $0=$ I make decisions about as well as ever

$1=I$ am less sure of myself now and try to put off making decisions

$2=$ I can't make decisions anymore without help 
3 = I can't make decisions at all anymore

14. $0=$ I don't feel I look any worse than I used to

1 = I am worried that I am looking old or unattractive

$2=\mathrm{I}$ feel that there are permanent changes in my appearance and they make me

look unattractive

3 = I feel that I am ugly or repulsive looking

15. 0 - I can work about as well as before

$1 \mathrm{a}=$ It takes extra effort to get started at doing something

$1 \mathrm{~b}=\mathrm{I}$ don't work as well as I used to

2 - I have to push myself very hard to do anything

$3=$ I can't do any work at all

16. $0=$ I can sleep as well as usual

$1=$ I wake up more tired in the morning than I used to

2 - I wake up 1-2 hours earlier than usual and find it hard to get back to sleep

$3=$ I wake up early every day and can't get more than 5 hours sleep

17. $0=$ I don't get any more tired than usual

$1=$ I get tired more easily than I used to

$2=$ I get tired from doing anything

$3=$ I get too tired to do anything

18. _ $0=$ My appetite is no worse than usual

$1=$ My appetite is not as good as it used to be

$2=$ My appetite is much worse now

$3=$ I have no appetite at all any more 
19. $0=$ I haven't lost much weight, if any, lately

1 I $=$ I have lost more than 5 pounds

2 = I have lost more than 10 pounds

$3=$ I have lost more than 15 pounds

20. _ $0=\mathrm{I}$ am no more concerned about my health than usual

$1=\mathrm{I}$ am concerned about aches and pains or upset stomach or constipation or other unpleasant feelings in my body

2 = I am so concerned with how I feel or what I feel that it's hard to think of much else

$3=\mathrm{I}$ am completely absorbed in what I feel

21.__ $0=\mathrm{I}$ have not noticed any recent change in my interest in sex

$1=\mathrm{I}$ am less interested in sex than I used to be

$2=\mathrm{I}$ am much less interested in sex now

$3=$ I have lost interest in sex completely 


\section{$\underline{\text { SCOPE }}$}

The purpose of this questionnaire is to find out how people deal with their problems or the stresses in their lives. The following are activities that you may have done. After each activity, please indicate the extent to which you have used this as a way of dealing with problems or stresses in recent weeks.

Ordinarily, in recent weeks, I have:

1. accepted that there is nothing I could do to change my situation.

2. blamed myself for my problems.

3. told others that I was really upset.

4. asked others for help or advice.

5. spent a lot of time thinking about my problems.

6. taken time for recreation or pleasure activities.

7. made plans to overcome my

concerns or problems.

8. avoided thinking about my problems.

9. told jokes about my situation.

10. thought a lot about who was responsible for

my problems (besides me).

11. worried about my problems a lot.

12. made humorous comments or stories about my situation.

13. wished the situation would just go away or be over with

14. thought a lot about how I brought my problems on myself.

15. decided to wait and see how things turned out. $\begin{array}{llll}\mathbf{0} & 1 & 2 & 3\end{array}$

4

Not at all Somewhat

Totally

$\begin{array}{lllll}0 & 1 & 2 & 3 & 4\end{array}$

$\begin{array}{lllll}0 & 1 & 2 & 3 & 4\end{array}$

$\begin{array}{lllll}0 & 1 & 2 & 3 & 4\end{array}$

$\begin{array}{lllll}0 & 1 & 2 & 3 & 4\end{array}$

$\begin{array}{lllll}0 & 1 & 2 & 3 & 4\end{array}$

$\begin{array}{lllll}0 & 1 & 2 & 3 & 4\end{array}$

$\begin{array}{lllll}0 & 1 & 2 & 3 & 4\end{array}$

$\begin{array}{lllll}0 & 1 & 2 & 3 & 4\end{array}$

$\begin{array}{lllll}0 & 1 & 2 & 3 & 4\end{array}$

$\begin{array}{lllll}0 & 1 & 2 & 3 & 4\end{array}$

$\begin{array}{lllll}0 & 1 & 2 & 3 & 4\end{array}$

$\begin{array}{lllll}0 & 1 & 2 & 3 & 4\end{array}$

$\begin{array}{lllll}0 & 1 & 2 & 3 & 4\end{array}$

$\begin{array}{lllll}0 & 1 & 2 & 3 & 4\end{array}$


16. tried to keep my mind off things

that were upsetting me.

0

$\begin{array}{llll}1 & 2 & 3 & 4\end{array}$

17. sought reassurance and emotional

support from others.

$\begin{array}{lllll}0 & 1 & 2 & 3 & 4\end{array}$

18. thought about how my problems were

caused by other people.

$\begin{array}{lllll}0 & 1 & 2 & 3 & 4\end{array}$

19. cried, even if someone else was around.

$\begin{array}{lllll}0 & 1 & 2 & 3 & 4\end{array}$

20. looked for how I could grow and learn

through my situation.

$\begin{array}{lllll}0 & 1 & 2 & 3 & 4\end{array}$

21. told myself that other people have

problems like mine.

$\begin{array}{lllll}0 & 1 & 2 & 3 & 4\end{array}$

22. done things to keep busy

or active (eg., exercised, went out). $\quad \begin{array}{lllll}0 & 1 & 2 & 3 & 4\end{array}$

$\begin{array}{lllllll}\text { 23. held in my feelings. } & 0 & 1 & 2 & 3 & 4\end{array}$

24. daydreamed about how things may turn out. $\quad \begin{array}{llllll}0 & 1 & 2 & 3 & 4\end{array}$

$\begin{array}{llllll}\text { 25. tried to act as if I wasn't feeling bad. } & 0 & 1 & 2 & 3 & 4\end{array}$

$\begin{array}{lllllll}\text { 26. taken steps to overcome the problem. } & 0 & 1 & 2 & 3 & 4\end{array}$

$\begin{array}{lllllll}\text { 27. turned to God or my faith. } & 0 & 1 & 2 & 3 & 4\end{array}$ 


\section{MAAS}

Instructions: Below is a collection of statements about your everyday experiences. Using the $1-6$ scale below, please indicate how frequently or infrequently you currently have each experience. Please answer according to what really reflects your experience, and not what you think your experience should be. Please treat each item separately from every other item.

$\begin{array}{cccccc}\text { Almost } & \begin{array}{c}\text { Very } \\ \text { Always }\end{array} & \begin{array}{c}\text { Somewhat } \\ \text { Frequently }\end{array} & \begin{array}{c}\text { Somewhat } \\ \text { Infrequently }\end{array} & \begin{array}{c}\text { Very } \\ \text { Infrequently }\end{array} & \begin{array}{c}\text { Almost } \\ \text { Never }\end{array} \\ 1 & 2 & 3 & 4 & 5 & 6\end{array}$

1. I could be experiencing some emotion and not be conscious of it until some time later.

$\begin{array}{llllll}1 & 2 & 3 & 4 & 5 & 6\end{array}$

2. I break or spill things because of carelessness, not paying attention, or thinking of something else.

$\begin{array}{llllll}1 & 2 & 3 & 4 & 5 & 6\end{array}$

3. I find it difficult to stay focused on what's happening in the present.

$\begin{array}{llllll}1 & 2 & 3 & 4 & 5 & 6\end{array}$

4. I tend to walk quickly to get where I'm going, without paying attention to what I experience along the way.

$\begin{array}{llllll}1 & 2 & 3 & 4 & 5 & 6\end{array}$

5. I tend not to notice feelings of physical tension or discomfort until they really grab my attention.

$\begin{array}{llllll}1 & 2 & 3 & 4 & 5 & 6\end{array}$

6. I forget a person's name almost as soon as I've been told it for the first time.

$\begin{array}{llllll}1 & 2 & 3 & 4 & 5 & 6\end{array}$

7. It seems I am "running on automatic", without much Awareness of what I'm doing.

$\begin{array}{llllll}1 & 2 & 3 & 4 & 5 & 6\end{array}$

8. I rush through activities without being really attentive to them.

$\begin{array}{llllll}1 & 2 & 3 & 4 & 5 & 6\end{array}$

9. I get so focused on the goal I want to achieve that I lose touch with what I'm doing right now to get there.

$\begin{array}{llllll}1 & 2 & 3 & 4 & 5 & 6\end{array}$

10. I do jobs or tasks automatically, without being aware of what I'm doing.

11. I find myself listening to something with one ear, doing something else at the same time. 
SWL

Instructions: Using the scale following each statement, please indicate the extent to which, on the whole, you agree or disagree with each one.

1. In most ways, my life is close to my ideal.

$\begin{array}{ccccccc}-3 & -2 & -1 & 0 & 1 & 2 & 3 \\ \text { Strongly } & \text { Moderately } & \text { Mildly } & \text { Neutral } & \text { Mildly } & \text { Moderately } & \text { Strongly } \\ \text { Disagree } & \text { Disagree } & \text { Disagree } & & \text { Agree } & \text { Agree } & \text { Agree }\end{array}$

2. If I could live my life over, I would change almost nothing.

$\begin{array}{ccccccc}-3 & -2 & -1 & 0 & 1 & 2 & 3 \\ \text { Strongly } & \text { Moderately } & \text { Mildly } & \text { Neutral } & \text { Mildly } & \text { Moderately } & \text { Strongly } \\ \text { Disagree } & \text { Disagree } & \text { Disagree } & & \text { Agree } & \text { Agree } & \text { Agree }\end{array}$

3. I am satisfied with my life.

$\begin{array}{ccccccc}-3 & -2 & -1 & 0 & 1 & 2 & 3 \\ \text { Strongly } & \text { Moderately } & \text { Mildly } & \text { Neutral } & \text { Mildly } & \text { Moderately } & \text { Strongly } \\ \text { Disagree } & \text { Disagree } & \text { Disagree } & & \text { Agree } & \text { Agree } & \text { Agree }\end{array}$

4. So far I have gotten the important things I want in life.

$\begin{array}{ccccccc}-3 & -2 & -1 & 0 & 1 & 2 & 3 \\ \text { Strongly } & \text { Moderately } & \text { Mildly } & \text { Neutral } & \text { Mildly } & \text { Moderately } & \text { Strongly } \\ \text { Disagree } & \text { Disagree } & \text { Disagree } & & \text { Agree } & \text { Agree } & \text { Agree }\end{array}$

5. The conditions of my life are excellent.

$\begin{array}{ccccccc}-3 & -2 & -1 & 0 & 1 & 2 & 3 \\ \text { Strongly } & \text { Moderately } & \text { Mildly } & \text { Neutral } & \text { Mildly } & \text { Moderately } & \text { Strongly } \\ \text { Disagree } & \text { Disagree } & \text { Disagree } & & \text { Agree } & \text { Agree } & \text { Agree }\end{array}$




\section{AASQ}

The following is a list of situations that you might encounter at one time or another. Please imagine yourself in each situation, and then indicate how threatening, as well as how distressing you would find each of these events. We will also be asking you to indicate your thoughts concerning each of these situations. Please note that there are no right answers for each question we are simply looking for your first reaction to each of these situations.

1) Your professor hands back last week's assignments to everyone but you, and then asks you to stay after class.

a. How threatening would this situation be for you?

1

2

3

4

5

Not at all

Extremely

b. How distressing would this situation be for you?

$\begin{array}{llll}1 & 2 & 3 & 4\end{array}$

5

Not at all

Extremely

c. How much control do you think you would have over the outcome of this event?

$\begin{array}{lllll}1 & 2 & 3 & 4 & 5\end{array}$

No control

Complete control

d. What would you think the professor is most likely to say?

Your assignment was excellent - I just wanted to put a name to a face.

Your assignment was great, but there was one question where you could've done

better.

Is this your assignment? You forgot to put your name at the top.

I'm a little worried that you might not understand the material.

Your assignment was completely unsatisfactory - you should consider dropping this

course. 
2) Imagine that you get home from class and there is a message from someone you're very close to (e.g., partner) who is away at another university that they really have to talk to you.

a. How threatening would this situation be to you?

$\begin{array}{lllll}1 & 2 & 3 & 4 & 5\end{array}$

Not at all

Extremely

b. How distressing would this situation be for you?

$\begin{array}{lllll}1 & 2 & 3 & 4 & 5\end{array}$

Not at all

Extremely

c. How much control do you think you would have over the outcome of this event?

$\begin{array}{lllll}1 & 2 & 3 & 4 & 5\end{array}$

No control

Complete control

$\mathrm{d}$. What would you think this person is most likely to say?

I really miss you - I just had to hear your voice.

I just got an A on my first mid-term.

I'm looking for an email address, do you have it?

I'm a little concerned about our relationship.

I've thought about it, and I don't think I need this relationship in my life.

3) CNN announces that an unknown number of planes have been hijacked simultaneously. You suddenly remember that your mother was flying to Minnesota for a business trip today.

a. How threatening would this situation be to you?

1

2

3

4

5

Not at all

Extremely 
b. How distressing would this situation be for you?

$\begin{array}{lllll}1 & 2 & 3 & 4 & 5\end{array}$

Not at all

Extremely

c. How much control do you think you would have over the outcome of this event?

$\begin{array}{lllll}1 & 2 & 3 & 4 & 5\end{array}$

No control

Complete control

d. What would you be most likely to think if you were in this situation?

The odds of my mom's plane being hijacked is incredibly small - I'm not worried about her at all.

I'm not worried yet, but I'd like to hear from her or at least get more information.

I'm a little bit apprehensive about this, but not so much that it disrupts my day

This is extremely worrisome - my mom very likely could be on one of those planes!

Oh my gosh! - I just know my mom is on one of those planes and is doomed.

4) You and your partner are at a bar, and he sees you talking to a male friend. The next day, he does not return your calls.

a. How threatening would this situation be for you?

1

2

3

4

5

Not at all

Extremely

b. How distressing would this situation be for you?
1
2
3
4
5

Not at all

Extremely

c. How much control do you think you would have over the outcome of this event?

1

2

3

4

5 
None at all

Complete control

d. What would you be most likely to think in this situation?

He's probably just out with his friends and hasn't had a chance to call me back yet.

I'm not worried yet, I'll wait a while longer to see if he calls.

He's probably a little mad/jealous, but I'm sure he'll call back soon.

I'm a little worried that he is not going to call.

I should have known that speaking to that guy would make him angry, I am worried that he's going to break up with me.

5) Most of your friends have left town to attend other universities.

a. How threatening would this situation be for you?

$\begin{array}{lllll}1 & 2 & 3 & 4 & 5\end{array}$

Not at all

Extremely

b. How distressing would this situation be for you?

$\begin{array}{lllll}1 & 2 & 3 & 4 & 5\end{array}$

Not at all

Extremely

c. How much control do you think you would have over the outcome of this event?

1

2

3

4

5

No control

Complete control

d. What would you think is most likely to happen to these friendships?

They will grow stronger.

They will get a little better.

They won't change at all.

They will get a little worse.

They will likely fade away. 
6) There is an outbreak of smallpox, and the government is only able to immunize a portion of the population. The criteria for immunization have not been disclosed.

a. How threatening would this situation be to you?

1

2

3

4

5

Not at all

Extremely

b. How distressing would this situation be for you?

1

2

3

4

5

Not at all

Extremely

c. How much control do you think you would have over the outcome of this event?

$\begin{array}{lllll}1 & 2 & 3 & 4 & 5\end{array}$

No control

Complete control

d. What would you be most likely to think of this possible outbreak of smallpox?

I'm sure that I'm safe - I will be immunized

Though I can't guarantee it, I'm fairly certain I'll be safe

It's hard to say either way what will happen

Knowing my luck, I probably won't meet the criteria - I might be in danger

I'm positive that I won't be picked - my life is in serious jeopardy

7) While doing a presentation, you notice a couple of students at the back of the class laughing.

a. How threatening would this situation be to you?

1

2

3

4

5

Not at all

Extremely

b. How distressing would this situation be for you?

1

2

3

4

Not at all

Extremely 
c. How much control do you think you would have over the outcome of this event?

$\begin{array}{lllll}1 & 2 & 3 & 4 & 5\end{array}$

No control

Complete control

d. What would you think that they would be most likely laughing about?

I must have said something funny - this presentation is going rather well.

Something that happened in the last person's presentation.

Something that happened last night and has nothing to do with my presentation.

My presentation in general - it's probably not that great.

I must look like a complete idiot up here, who has no idea what they are talking

about.

8) You have a friend visiting from out of town and you inform your partner that you won't be able to spend much time with him for a couple of days. Your partner expresses concern that your friends are taking up a lot of your time, and that he hasn't been able to see you much lately.

a. How threatening would this situation be for you?

$\begin{array}{lllll}1 & 2 & 3 & 4\end{array}$

Not at all

Extremely

b. How distressing would this situation be for you?

$\begin{array}{lllll}1 & 2 & 3 & 4 & 5\end{array}$

Not at all

Extremely

c. How much control do you think you would have over the outcome of this event?

1

2

3

4

5

Not at all

Complete control 
d. What would you be most likely to think in this situation?

He really cares about me and just wants to spend as much time as possible together. He's just feeling left out.

It's too bad that we can't spend much time together lately, but I'm sure he'll understand.

I'm worried that if I don't devote more time to him, this may negatively affect our relationship.

I'm concerned that if this keeps up, he may consider breaking up with me.

9) You are at health services for what you think is something minor. After the initial exam you glimpse of the nurse who just examined you speaking with your physician. They both appear to be concerned.

a. How threatening would this situation be to you?
1
2
3
4
5

Not at all

Extremely

b. How distressing would this situation be for you?
1
2
3
4
5

Not at all

Extremely

c. How much control do you think you would have over the outcome of this event?
1
2
3
4
5

No control

Complete control

d. What would you be most likely to think that is happening?

They are discussing a matter unrelated to my problem

They might be talking about me, but I'm sure it's nothing

Hmm....they look pretty serious. I wonder what that's about?

That doesn't look good - maybe the nurse suspects something?

This is definitely bad news - I've got something really serious wrong with me. 
10) You overhear a discussion about a party that your friends went to last week; however you are only hearing about it now.

a. How threatening would this situation be to you?

$\begin{array}{lllll}1 & 2 & 3 & 4 & 5\end{array}$

Not at all

Extremely

b. How distressing would this situation be for you?

$\begin{array}{lllll}1 & 2 & 3 & 4 & 5\end{array}$

Not at all

Extremely

c. How much control do you think you would have over the outcome of this event?

1

$2 \quad 3$

4

5

No control

Complete control

d. What would you think is the most likely reason that you didn't get invited along?

It was my own fault - I was at the library all night and they couldn't reach me.

My friends are forgetful, but it doesn't mean anything.

I must've mentioned a few days earlier that I didn't feel like going, so they didn't

ask.

This has happened a few times now - I must have done something wrong.

I'm certain that I've fallen out of favour with my friends.

11) You have asked someone out on a date and they said "yes"; but, the next time you see them they seem distracted, in a bad mood, and essentially ignore you.

a. How threatening would this situation be to you?

$\begin{array}{lllll}1 & 2 & 3 & 4 & 5\end{array}$

Not at all

Extremely

b. How distressing would this situation be for you?

$\begin{array}{lllll}1 & 2 & 3 & 4 & 5\end{array}$

Not at all

Extremely 
c. How much control do you think you would have over the outcome of this event?

4

5

No control

Complete control

d. What would think is the most likely reason that they are acting this way?

No big deal - they are just in a bad mood, and it has nothing to do with me.

They are in a bad mood unrelated to me, but maybe I aggravated things but appearing suddenly.

It's hard to say... it could be about me, but maybe not.

The person is now unsure about me and is feeling awkward.

They didn't really want to say "yes" to the date in first place and are trying to let me

know.

12) You are flipping around on the television when you notice that a severe weather warning has been issued for your area with reports of a tornado having touched down just west of your town.

a. How threatening would this situation be to you?

$\begin{array}{lllll}1 & 2 & 3 & 4 & 5\end{array}$

Not at all

Extremely

b. How distressing would this situation be for you?

1

2

3

4

5

Not at all

Extremely

c. How much control do you think you would have over the outcome of this event?

1

2

3

4

5

No control

Complete control 
d. What would you be most likely to think of the threat of a potential tornado?

Excellent - I'll get to watch a great storm

It's probably nothing, but I'll keep an eye out

Hmm....while I'm concerned, it still doesn't call for action

I don't have a good feeling about this at all - I'm pretty sure I'm in danger.

This is horrible - this could pose a real threat to my life!

13) You're going to meet your partner's parents for the first time. Your partner tells you that he doesn't particularly like the outfit you are wearing to meet them, and suggests that you change.

a. How threatening would this situation be for you?

1

2

3

4

5

Not at all

Extremely

b. How distressing would this situation be for you?

1

2

3

4

5

Not at all

Extremely

c. How much control do you think you would have over the outcome of this event?

$\begin{array}{lllll}1 & 2 & 3 & 4 & 5\end{array}$

Not at all Complete control

d. What would you most likely think in this situation?

He must really be concerned about his parents' opinions.

He's just nervous about the meeting and wants me to make a good first impression. I appreciate his input but I'll just wear whatever makes me feel most comfortable. I must not look very good in this outfit.

He is embarrassed to introduce me to his parents. 
14) The supervisor at your part-time job calls and asks you to come in to discuss your most recent evaluation.

a. How threatening would this situation be to you?

1

2

3

4

5

Not at all

Extremely

b. How distressing would this situation be for you?

1

2

3

4

5

Not at all

Extremely

c. How much control do you think you would have over the outcome of this event?

1

2

3

4

5

No control

Complete control

d. What would you think they are most likely to say?

Excellent job! - We would like to give you a raise

You are doing well - keep it up.

So far so good, but there is room for improvement

There are some serious problems here.

Things just aren't working out - we have to let you go.

15) Your first-year seminar instructor has asked a group of fellow students to participate in a student/teacher liaison committee but has not mentioned it to you.

a. How threatening would this situation be to you?

1

2

3

4

5

Not at all

Extremely

b. How distressing would this situation be for you?
1
2
3
4
5

Not at all

Extremely 
c. How much control do you think you would have over the outcome of this event?

1

No control
2

3
4

Complete control

d. What would you think is the most likely reason that it wasn't mentioned to you?

The instructor wanted to give the opportunity to students who really needed it.

I was most likely considered, but in the end went with someone else for whatever

reason

The students were just picked at random

I'm not completely sure, but sometimes I think the instructor believes my ideas are

weird

The instructor thinks that I'm not that intelligent, so he didn't bother asking me

16) You receive an unexpected message on your machine from student health services asking you to call the office after having gone in for routine check up/tests the week before.

a. How threatening would this situation be to you?

1

Not at all

b. How distressing would this situation be for you?

1

2

3

4

Not at all
3

c. How much control do you think you would have over the outcome of this event?

1 2

3

4 5

No control

Complete control 
d. What would you think is the most likely reason that they have asked you to call the office?

They just wanted to let me know that my test results came back normal.

My tests came back normal, but I need to schedule more tests for Spring.

They probably just need to confirm my health number for their records.

Something of concern probably showed up in my test results - this could be bad.

There is obviously something seriously wrong - why would they bother calling?

17) You go to take money out of your account, but your grant/scholarship/student loan check has not been processed by the bank / deposited by the university. Everyone else has his or hers.

a. How threatening would this situation be to you?

$\begin{array}{lllll}1 & 2 & 3 & 4 & 5\end{array}$

Not at all

Extremely

b. How distressing would this situation be for you?
1
2
3
4 5

Not at all

Extremely

c. How much control do you think you would have over the outcome of this event?

1

2

3

4

5

No control

Complete control

d. What would you be most likely to think if this happened?

No big deal - It must just be delayed due to an administrative error. I'm confident

it's on the way.

I should probably keep an eye on it, but I'm pretty sure everything is okay.

Something is obviously wrong and I'm quite worried.

Something has definitely gone wrong with my loan/scholarship - I'm going to be 
broke for the year!

18) You are having a disagreement with your partner over some relationship issues and after stating your views on the situation, he gets frustrated and stomps out of the house.

a. How threatening would this situation be for you?
1
2
3
4
5

Not at all

Extremely

b. How distressing would this situation be for you?

$\begin{array}{lllll}1 & 2 & 3 & 4 & 5\end{array}$

Not at all Extremely

c. How much control do you think you would have over the outcome of this event?

$\begin{array}{lllll}1 & 2 & 3 & 4\end{array}$

Not at all Complete control

d. What would you be most likely to think in this situation?

His anger over this argument was kind of excessive.

Sometimes our arguments get out of hand but I'm sure things will be fine.

I'm not sure what to think...

He's really mad at me, I'm worried about how things will be between us when he gets back.

I shouldn't have made him so angry, I'm sure he won't be back for a while.

19) There has been a recent wave of "sniper" killings in town over the past few months. There aren't any firm leads and the victims seem to be chosen at random.

a. How threatening would this situation be to you?
1
2
3
4
5

Not at all

Extremely 
b. How distressing would this situation be for you?

$\begin{array}{llll}1 & 2 & 3 & 4\end{array}$ 5

Not at all

Extremely

c. How much control do you think you would have over the outcome of this event?

1

2

3

4

5

No control

Complete control

d. What would you be most likely to think about these sniper shootings?

With all the extra police around the city, crime will probably go down.

The chance of this impacting my life is pretty low. I'm not that worried.

This situation isn't critical yet, but it could get worse

This is pretty scary - I'm worried for both myself and my family

It's only a matter of time before this hit really close to home - I'm terrified.

20) You get an anonymous spiteful letter left on your locker door / left on your desk.

a. How threatening would this situation be to you?

$\begin{array}{llllll}1 & 2 & 3 & 4 & 5\end{array}$

Not at all

Extremely

b. How distressing would this situation be for you?

$\begin{array}{lllll}1 & 2 & 3 & 4 & 5\end{array}$

Not at all

Extremely

c. How much control do you think you would have over the outcome of this event?

$\begin{array}{lllll}1 & 2 & 3 & 4 & 5\end{array}$

No control Complete control 
d. What would you be most likely to think if you were left this note?

My friends are such jokers - this is hilarious!

It's probably my friends playing a joke, but it's a pretty bad one.

I'm not really sure either way.

Does one of my "friends" really hate me?

This is devastating - I knew my friends have been irritated with me lately but I didn't

think it was this bad

21) One of your friends calls you to tell you that they saw your boyfriend/girlfriend out with another person on the weekend.

a. How threatening would this situation be to you?

$\begin{array}{lllll}1 & 2 & 3 & 4 & 5\end{array}$

Not at all

Extremely

b. How distressing would this situation be for you?

$\begin{array}{llllll}1 & 2 & 3 & 4 & 5\end{array}$

$\begin{array}{ll}\text { Not at all Extremely } & \end{array}$

c. How much control do you think you would have over the outcome of this event?

$\begin{array}{llllll}1 & 2 & 3 & 4 & 5\end{array}$

No control Complete control

d. What would be most likely to be your first thought?

$\mathrm{He} /$ she goes out with friends all the time - I trust them completely

It's probably nothing - he/she probably had some friends in town.

It's strange that they didn't mention it, but maybe they just forgot.

This is not a good sign...I think he/she is losing interest in me.

I just knew that they were cheating on me. This relationship is over. 
22) You see a report on the news that there is plausible evidence that a "dirty bomb" has recently been smuggled into the country and may be used shortly.

a. How threatening would this situation be to you?

1

2

3

4

5

Not at all

Extremely

b. How distressing would this situation be for you?

$\begin{array}{llllll}1 & 2 & 3 & 4 & 5\end{array}$

Not at all

Extremely

c. How much control do you think you would have over the outcome of this event?

$\begin{array}{llllll}1 & 2 & 3 & 4 & 5\end{array}$

No control

Complete control

d. What would you be most likely to think about the threat of this "dirty bomb"?

This is probably just another rumor - I'm going to ignore it.

It might be true, but I'm sure that I'm safe.

This may be something to take seriously, but I need more information first.

This really concerns me - I think I may be in danger

It is just a matter of time before we are hit with a devastating terrorist attack - I'm

definitely in serious danger.

23) You were really drunk at a party last Friday night, the events are hazy but you know you've stepped on a few toes/made a fool of yourself and you have to face the class/ friends on Monday.

a. How threatening would this situation be to you?

$\begin{array}{llllll}1 & 2 & 3 & 4 & 5\end{array}$

Not at all

Extremely

b. How distressing would this situation be for you?

$\begin{array}{lllll}1 & 2 & 3 & 4\end{array}$

Not at all Extremely 
c. How much control do you think you would have over the outcome of this event?

$\begin{array}{lllll}1 & 2 & 3 & 4 & 5\end{array}$

No control

Complete control

d. What would you be most likely to think that would happen?

My friends are going to think I'm a party animal and fun to hang out with.

I'm probably going to get made fun of but everyone will probably understand.

It's hard to say - some people might have been mildly offended, but maybe I'm

exaggerating

I'm pretty sure I've damaged a few friendships - things will definitely be awkward

for a while.

I'm going to be thought of as an idiot and I've definitely ruined a lot of friendships.

24) You are out to dinner at a restaurant with your partner, and he tells you he thinks you need to cut down on the amount of food you are eating.

a. How threatening would this situation be for you?

$\begin{array}{llllll}1 & 2 & 3 & 4 & 5\end{array}$

Not at all Extremely

b. How distressing would this situation be for you?

$\begin{array}{llllll}1 & 2 & 3 & 4 & 5\end{array}$

Not at all Extremely

c. How much control do you think you would have over the outcome of this event?

$\begin{array}{llllll}1 & 2 & 3 & 4 & 5\end{array}$

Not at all Complete control 
d. What would you most likely think is the reason for his comment?

He is just looking out for my health, he really cares about me.

He probably just thinks that restaurant portions are too big these days, he didn't mean it as anything personal.

I'm not sure what to think...

He may be a little concerned that I will gain weight.

He thinks I am getting fat.

25) You are applying some sunscreen when you notice a small mass on your neck. Your physician performs a small biopsy and says it's probably nothing, but that he can't be sure until the test results come back in a week.

a. How threatening would this situation be to you?

1

Not at all

b. How distressing would this situation be for you?

1

2

3

3
4 5

Not at all

4 Extremely

c. How much control do you think you would have over the outcome of this event?
1
2
3
4
5

No control

Complete control

d. What would be most likely to be your first thought?

It's definitely nothing to be concerned about

I'm a little concerned, but it's probably nothing

I'm not sure what to make of this

I'm pretty worried about this - I don't have a good feeling about it.

It's definitely something life-threatening- why else would they bother with a biopsy? 
26) A couple of weeks after you have decided to invest a significant portion of your student loan in stocks, the market begins to waiver.

a. How threatening would this situation be to you?

1

Not at all

b. How distressing would this situation be for you?

1

2

Not at all
2

3
4

4
Extremely

c. How much control do you think you would have over the outcome of this event?
1
2
3
4
5

No control

Complete control

d. What would you be most likely to think about this situation?

It is a pretty safe bet - In the long term things will work out

It is getting a bit risky, but I think I know what I'm doing

I'm going to wait and see but it could go either way.

Uh oh...I'm pretty worried that I could lose it all

What have I done? - this is going to ruin me for the year!

27) Someone you are very close to (e.g., partner) leaves to drive home and is supposed to call your when they get in. It's been a couple of hours and you haven't heard anything. There is no answer at their place.

a. How threatening would this situation be to you?

$$
1
$$

2

3

4

5

Not at all

Extremely

b. How distressing would this situation be for you?
1
2
3
4
5

Not at all

Extremely 
c. How much control do you think you would have over the outcome of this event?

1

No control
2

3

4

5

Complete control

d. What would you think is the most likely reason they haven't called?

I'm positive they just forgot to call and went to friend's house on the way home

I'm a little surprised I haven't heard from them, but everything should be okay

I don't know what to think...

This is not a good sign - something might have happened

I'm certain that something terrible has happened - I'm positive I would have heard

from them by now.

28) You phone your department to see if your request to switch your major has gone through, but the person at the desk tells you that the matter cannot be discussed on the phone and that a letter has been mailed to you in this regard.

a. How threatening would this situation be to you?

1

2

3

4

5

Not at all

Extremely

b. How distressing would this situation be for you?

1

2

3

4

5

Not at all

Extremely

c. How much control do you think you would have over the outcome of this event?

1

2

3

4

5

No control

Complete control 
d. What would you be most likely to think that has happened with your application?

This must be standard procedure for the department - everything is fine

I wish they could just tell me, but I'm pretty sure it's fine

That is odd - why can't they just tell me? Hmm...

That doesn't sound very good - it could be bad news

That does it - my transfer didn't go through. It's just a matter of time before I get my

rejection letter.

29) You have heard reports that a group of youths has been beating and robbing individuals around shopping malls and bus stations. On the way to the bus-stop you notice that a group of kids is beginning to congregate in the adjacent parking lot.

a. How threatening would this situation be to you?

$\begin{array}{llllll}1 & 2 & 3 & 4 & 5\end{array}$

Not at all

Extremely

b. How distressing would this situation be for you?

$\begin{array}{lllll}1 & 2 & 3 & 4 & 5\end{array}$

Not at all

Extremely

c. How much control do you think you would have over the outcome of this event?

$\begin{array}{llllll}1 & 2 & 3 & 4 & 5\end{array}$

No control Complete control

d. What would be most likely to think of this situation?

It's just a bunch of kids - I'm sure they are just hanging out and having a good time and aren't going to harm anyone.

I wonder if I recognize any of those. They seem to be ready to engage in some sort of activity.

What a big group of kids....I wonder what they are up to.

This is a bit scary - I hope this isn't the group I heard about it.

I'm terrified - That is the group of kids who have been stealing people's money - If I

go over there I'm sure to be attacked! 


\section{Appendix D: Debriefing}

\section{What are we trying to learn in this research?}

This research examines the relationship between personal factors, appraisals, depressive symptoms and well-being. The questionnaires you completed assessed subjective well-being, depressive symptoms and mindfulness. We also asked you to provide information on the coping strategies you typically use, and how you tend to appraise yourself and different situations. We are interested in learning if positive self-appraisals and mindfulness are associated with the use of more effective coping strategies and general well-being. We are also interested in determining if reading and reflecting upon concepts related to mindfulness encourages people to view situations in a more positive way. To assess this, we asked you to think of a recent stressful event in your life, and to write about this situation using words related to either mindfulness, non-mindfulness, or to describe this event in your own words. We used these different sets of instructions in order to see if these words influenced how people evaluated different hypothetical situations in later questionnaires.

\section{Why is this important to scientists or the general public?}

Previous research has shown a relationship between people's appraisals of different situations, and how they cope with those situations. Less is known, however, about the specific factors that lead people to appraise events in different ways. Understanding individual difference variables (e.g., mindfulness) and self-appraisals (e.g., self-esteem, mastery) that might be associated with more positive appraisals of events is important, since these appraisals may predict enhanced coping abilities. If mindfulness and positive self-appraisals are related to effective coping and well-being, it might be helpful to focus on promoting the development of these skills in order to reduce stress and improve well-being.

\section{What are our hypotheses and predictions?}

We predict that individuals' self-appraisals (the way people evaluate themselves) will predict how they approach different situations, and will also predict how well they are able to cope with stressful situations. We also predict that mindfulness (e.g., the ability to live "in the moment", and to observe situations in an objective, non self-judgmental way) will be associated with more positive selfappraisals, coping and well-being.

\section{Is there anything I can do if I found this experiment to be emotionally upsetting?}

Yes. If you feel any distress or anxiety after participating in this study, please feel free to contact the Carleton University Health and Counseling Services at: 613-520-6674, or the Distress Centre of Ottawa and Region at 613-238-3311 (http://www.dcottawa.on.ca).

\section{What if I have questions later?}

If you have any remaining concerns, questions, or comments about the experiment, please feel free to contact Kelly-Lyn Christie (Principal Investigator), at: klchrist@connect.carleton.ca (613-520-2600, ext.6312), Valerie Repta, at: vrepta@connect.carleton.ca (613-520-2600, ext. 7513), Dr. Hymie Anisman (Faculty Sponsor), at: hanisman@connect.carleton.ca, or Dr. Kimberly Matheson, at: kim matheson@carleton.ca. Should you have any ethical concerns about this research, please contact Dr. Monique Sénéchal at: Monique_senechal@carleton.ca (613-520-2600 ext 1155). 
For other concerns, please contact Dr. Janet Mantler (Chair, Department of Psychology, 613-5202600, ext. 2648, psychchair@carleton.ca).

Thank you for participating in this research! 


\section{Appendix E: Study 2 Written Priming Exercise}

\section{Mindfulness condition}

INSTRUCTIONS: Please take a few moments to think of a recent stressful event you have experienced in your life, and write a brief description of this event in the space provided below. When describing this event, please include any thoughts you remember having during this event, how you felt about the event, and how you resolved the situation (if the situation was resolved). You may write about any recent stressful event you wish, and there are no right or wrong statements. In your description, please include the following five words:

\section{Aware, Noticed, Accepted, Observed, Attention}


Non-Mindfulness condition

INSTRUCTIONS: Please take a few moments to think of a recent stressful event you have experienced in your life, and write a brief description of this event in the space provided below. When describing this event, please include any thoughts you remember having during this event, how you felt about the event, and how you resolved the situation (if the situation was resolved). You may write about any recent stressful event you wish, and there are no right or wrong statements. In your description, please include the following five words:

Distracted, Concerned, Rushed, Unaware, Overwhelmed 


\section{Control condition}

INSTRUCTIONS: Please take a few moments to think of a recent stressful event you have experienced in your life, and write a brief description of this event in the space provided below. When describing this event, please include any thoughts you remember having during this event, how you felt about the event, and how you resolved the situation (if the situation was resolved). You may write about any recent stressful event you wish, in your own words. There are no right or wrong statements. 